UNIVERSIDADE DE SÃO PAULO

ESCOLA DE ENFERMAGEM

NATÁLIA ALENCAR DE PINHO

FATORES ASSOCIADOS À DOENÇA RENAL CRÔNICA EM PACIENTES INTERNADOS

EM UM HOSPITAL UNIVERSITÁRIO NA CIDADE DE SÃO PAULO

SÃO PAULO

2013 


\section{FATORES ASSOCIADOS À DOENÇA RENAL CRÔNICA EM PACIENTES INTERNADOS EM UM HOSPITAL UNIVERSITÁRIO NA CIDADE DE SÃO PAULO}

Dissertação apresentada ao Programa de Pós-Graduação de Enfermagem na Saúde do Adulto da Escola de Enfermagem da Universidade de São Paulo para obtenção do título de Mestre em Ciências

Orientadora:

Prof. ${ }^{a}$ Dr. ${ }^{a}$ Angela Maria Geraldo Pierin

\section{SÃO PAULO}


AUTORIZO A REPRODUÇÃO E DIVULGAÇÃO TOTAL OU PARCIAL DESTE TRABALHO, POR QUALQUER MEIO CONVENCIONAL OU ELETRÔNICO, PARA FINS DE ESTUDO E PESQUISA, DESDE QUE CITADA A FONTE.

Assinatura:

Data:

Pinho, Natália Alencar

Fatores associados à doença renal crônica em pacientes internados em um hospital universitário na cidade de São Paulo / Natália Alencar de Pinho. -- São Paulo, 2013. $160 \mathrm{p}$.

Dissertação (Mestrado) - Escola de Enfermagem da Universidade de São Paulo.

Oriet.: Prof ${ }^{a}$. Dr ${ }^{a}$. Angela Maria Geraldo Pierin

1. Doença crônica 2. Insuficiência renal crônica Prevenção e controle 3. Hipertensão I. Título. 
Nome: Natália Alencar de Pinho

Título: Fatores associados à doença renal crônica em pacientes internados em um hospital universitário na cidade de São Paulo.

Dissertação apresentada ao Programa de Pós-Graduação de Enfermagem na Saúde do Adulto da Escola de Enfermagem da Universidade de São Paulo para obtenção do título de Mestre em Ciências.

Aprovado em:

Banca Examinadora

Prof. Dr. Instituição:

Julgamento: Assinatura:

Prof. Dr. Instituição:

Julgamento: Assinatura:

Prof. Dr. Instituição:

Julgamento: Assinatura: 


\section{DEDICATÓRIA}

À minha família, que caminhou ao meu lado nesta jornada. Meu amor e minha vitória são hoje e sempre para vocês. 


\section{AGRADECIMENTOS}

A Deus, pelo milagre de cada dia.

À Prof. a Angela Pierin, pela dedicação nestes anos em que tive o privilégio de trabalhar com a Senhora. Por acreditar neste estudo, pela brilhante orientação e por ensinar mais do que eu esperaria aprender.

À minha mãe, Maria Izabel, e minha irmã, Juliana, pela fé que sempre depositaram em mim e pela solidariedade nos momentos difíceis.

Ao meu esposo, Bastien, pelo amor, companheirismo e apoio incondicionais.

À Enf. ${ }^{a}$ Sandra Fuzii e aos colegas do serviço de hemodiálise do HU-USP, pela valiosa ajuda e principalmente pela amizade.

À Suzane Pontes e Cássia Campos, pela colaboração na coleta e tabulação dos dados.

À Julia Fukushima pela competente assessoria estatística.

À Marisa Perez e Jorge Lima, pela revisão final desta dissertação.

Aos colegas do grupo de pesquisa "A problemática do controle na Hipertensão Arterial", pelas sugestões e troca de experiências.

A todos que colaboraram direta e indiretamente com este estudo.

Aos pacientes, que mesmo sem conhecimento, forneceram as preciosas informações utilizadas neste estudo. Meu mais profundo respeito. 
"Há um tempo em que é preciso abandonar as roupas usadas, que já têm a forma do nosso corpo, e esquecer os nossos caminhos, que nos levam sempre aos mesmos lugares. É o tempo da travessia: e, se não ousarmos fazê-la, teremos ficado, para sempre, à margem de nós mesmos."

(Fernando Pessoa) 
Pinho NA. Fatores associados à doença renal crônica em pacientes internados em um hospital universitário na cidade de São Paulo. [dissertação]. São Paulo: Escola de Enfermagem. Universidade de São Paulo; 2013.

\section{RESUMO}

Introdução: a doença renal crônica constitui importante problema de saúde pública mundial. Contudo, pouco se sabe sobre suas características em nosso meio. Objetivo: identificar os fatores associados à doença renal crônica em pacientes internados em um hospital universitário. Método: foram selecionados, aleatoriamente, 386 pacientes que constituíram dois grupos: com e sem doença renal crônica. A doença renal crônica foi definida pela presença de diagnóstico médico ou antecedente pessoal. Os dados foram obtidos do prontuário do paciente. Foram comparados os grupos com e sem doença renal crônica e os hipertensos com e sem doença renal crônica, mediante as variáveis de estudo. Estimou-se a taxa de filtração glomerular (eTFG) dos pacientes sem doença renal a partir das equações Modification of Diet in Renal Disease abreviada (MDRD4) e Chronic Kidney Disease Epidemiology Collaboration (CKD-EPI). Verificou-se a associação da eTFG $<90 \mathrm{~mL} / \mathrm{min} / 1,73 \mathrm{~m}^{2}$, pela MDRD4, com dados biossociais e comorbidades. O nível de significância foi de $p<0,05$. Resultados: a amostra foi $50,5 \%$ homens, $64,4 \%$ brancos, 50,7\% com companheiro e idade de $58,2 \pm 18,6$ anos. Os pacientes com doença renal crônica se distinguiram daqueles sem a doença $(p<0,05)$ em relação a: viverem com companheiro (59,8\% vs $47,3 \%)$; idade mais elevada $(65,8 \pm 15,6$ vs $55,3 \pm 18,9$ anos); menor frequência de fumantes $(11,1 \%$ vs $29,7 \%)$; terem antecedente pessoal de hipertensão arterial (75,2\% vs $46,3 \%)$, diabetes $(49,5 \%$ vs $22,4 \%)$, dislipidemia $(23,8 \%$ vs $14,9 \%)$, infarto agudo do miocárdio (14,3\% vs $6,0 \%)$ e insuficiência cardíaca congestiva ( $18,1 \%$ vs $4,3 \%)$; evolução a óbito (12,4\% vs $1,4 \%)$; e maior tempo de internação (11 (8-18) vs 9 (6-12) dias); além dos exames laboratoriais, exceto glicemia e perfil lipídico. A análise de regressão logística indicou associação independente da 
doença renal crônica com as seguintes variáveis (OR, odds ratio; IC, intervalo de confiança de 95\%): idade (OR 1,019, IC 1,003-1,036); hipertensão arterial (OR 2,032, IC 1,128-3,660), diabetes (OR 2,097, IC 1,232-3,570) e insuficiência cardíaca congestiva (OR 2,665, IC 1,173-6,056). Os hipertensos com e sem doença renal crônica foram distintos $(p<0,05)$ em relação a: possuíam companheiro $(64,3 \%$ vs $50,7 \%)$; uso de maior número de medicamentos $(4,0(2,0-5,0)$ vs 2,0 $(0,5-4,0))$, não fumantes $(9,9 \%$ vs $25 \%)$; terem antecedentes pessoais para diabetes $(53,5 \%$ vs $36,4 \%)$ e insuficiência cardíaca congestiva $(19,8 \%$ vs $7,0 \%)$; uso de medicamentos antihipertensivos $(79,1 \%$ vs $66,4 \%)$; tratamento com insulina (24,4\% vs $7,0 \%$ ); além dos exames laboratoriais, exceto glicemia, perfil lipídico e ácido úrico. Houve boa concordância da classificação da eTFG de pacientes sem doença renal crônica pelas equações MDRD4 e CKDEPI (kappa 0,854). De acordo com a equação MDRD4, 54,4\% tinham eTFG $\geq 90 \mathrm{~mL} / \mathrm{min} / 1,73 \mathrm{~m}^{2} ; \quad 37,7 \%$, eTFG $\quad 60-89$ $\mathrm{mL} / \mathrm{min} / 1,73 \mathrm{~m}^{2}$; e $7,8 \%$, eTFG $<60 \mathrm{~mL} / \mathrm{min} / 1,73 \mathrm{~m}^{2}$. Pacientes com eTFG $<90 \mathrm{~mL} / \mathrm{min} / 1,73 \mathrm{~m}^{2}$ se destacaram $(p<0,05)$ por apresentar maior frequência de hipertensão arterial $(63,3 \%$ vs $32,0 \%)$, diabetes $(29,7 \%$ vs $16,3 \%)$ e dislipidemia $(24,2 \%$ vs $7,2 \%)$ em relação a pacientes com eTFG $\geq 90 \mathrm{~mL} / \mathrm{min} / 1,73 \mathrm{~m}^{2}$. Conclusão: a doença renal crônica esteve associada a fatores de risco cardiovascular, em sua maioria, modificáveis.

PALAVRAS-CHAVE: Doença Crônica, Falência Renal Crônica (prevenção \& controle), Hipertensão, Taxa de Filtração Glomerular. 
Pinho NA. Factors associated with chronic kidney disease among hospitalized patients in a university hospital in the city of São Paulo [dissertation - Master Degree]. São Paulo: Nursing School. University of São Paulo; 2013.

\section{ABSTRACT}

Introduction: chronic kidney disease is an important public health problem worldwide. Nevertheless, little is known about its features in our setting. Objective: identify factors associated with chronic kidney disease among hospitalized patients in a university hospital. Method: 386 patients were randomly selected and divided in two groups: with and without chronic kidney disease. Chronic kidney disease was defined by the presence of medical diagnosis or personal history. Data was acquired from medical records. Patients with and without chronic kidney disease, as well as hypertensive patients with and without chronic kidney disease, were compared with regard to the variables under study. Glomerular filtration rate (eGFR) of patients without chronic kidney disease was estimated using abbreviated Modification of Diet in Renal Disease (MDRD4) and Chronic Kidney Disease Epidemiology Collaboration (CKD-EPI) equations. The association between eTFG $<90 / \mathrm{mL} / \mathrm{min} / 1,73 \mathrm{~m}^{2}$ and biosocial data and comorbidities was assessed. Significance level was $p<0,05$. Results: the study sample was $50,5 \%$ male, $64,4 \%$ white, $50,7 \%$ living with partner, and $58,2 \pm 18,6$ years-old. Patients with chronic kidney disease differed $(p<0,05)$ from patients without, regarding to: living with partner $(59,8 \%$ vs $47,3 \%)$; older age $(65,8 \pm 15,6$ vs $55,3 \pm 18,9$ years-old); no smokers ( $11,1 \%$ vs $29,7 \%$ ); personal history of hypertension $(75,2 \%$ vs $46,3 \%)$, diabetes $(49,5 \%$ vs $22,4 \%)$, dyslipidemia (23,8\% vs $14,9 \%)$, acute myocardial infarction $(14,3 \%$ vs $6,0 \%)$ and congestive heart failure $(18,1 \%$ vs $4,3 \%)$; occurrence of death $(12,4 \%$ vs $1,4 \%)$; and length of hospitalization (11 (8-18) vs 9 (6-12) days), as well as laboratory tests, excepted blood glucose level and lipidemic profile. Logistic regression indicated independent association of chronic kidney disease for the following variables (OR, 
odds ratio; $\mathrm{Cl}$, confidence interval at 95\%): age (OR 1,019, $\mathrm{Cl} 1,003-$ 1,036); hypertension (OR 2,032, Cl 1,128-3,660), diabetes (OR 2,097, $\mathrm{Cl} 1,232-3,570$ ) and congestive heart failure (OR 2,665, $\mathrm{Cl}$ 1,173-6,056). Hypertensive patients with and without chronic kidney disease were different $(p<0,05)$ regarding to: living with partner (64,3\% vs $50,7 \%)$; greater number of continuous-use medication ( 4,0 $(2,0-5,0)$ vs $2,0(0,5-4,0))$; no smokers $(9,9 \%$ vs $25 \%)$; personal history of diabetes $(53,5 \%$ vs $36,4 \%)$ and congestive heart failure (19,8\% vs $7,0 \%)$; use of antihypertensive drugs $(79,1 \%$ vs $66,4 \%)$; insulin therapy $(24,4 \%$ vs $7,0 \%)$; as well as laboratory tests, excepted blood glucose level, lipidemic profile and uric acid. Relevant agreement was shown between eGRF classification by MDRD4 and CKD-EPI equations for patients without kidney disease (kappa 0,854). According to MDRD4 equation, 54,4\% had eGRF $\geq 90$ $\mathrm{mL} / \mathrm{min} / 1,73 \mathrm{~m}^{2} ; 37,7 \%$, eGFR $60-89 \mathrm{~mL} / \mathrm{min} / 1,73 \mathrm{~m}^{2} ;$ and $7,8 \%$, eGFR $<60 \mathrm{~mL} / \mathrm{min} / 1,73 \mathrm{~m}^{2}$. Patients with eGFR $<90 \mathrm{~mL} / \mathrm{min} / 1,73 \mathrm{~m}^{2}$ stood out $(p<0,05)$ from those with eGFR $\geq 90 \mathrm{~mL} / \mathrm{min} / 1,73 \mathrm{~m}^{2}$ as presenting higher frequencies of hypertension $(63,3 \%$ vs $32,0 \%)$, diabetes $(29,7 \%$ vs $16,3 \%)$ and dyslipidemia $(24,2 \%$ vs $7,2 \%)$. Conclusion: chronic kidney disease showed association with cardiovascular risk factors, most of which modifiable.

KEYWORDS: Chronic Disease; Kidney Failure, Chronic (prevention \& control); Hypertension; Glomerular Filtration Rate. 


\section{LISTA DE FIGURAS}

Figura 1 - Distribuição interquartílica dos valores de creatinina sérica nos primeiros dez dias de internação dos indivíduos com e sem doença renal crônica. São Paulo, 2013.

Figura 2 - Comparação dos valores de pressão arterial dos pacientes internados em uma clínica médica, com e sem doença renal crônica, que apresentaram medidas registradas do primeiro ao décimo dia de internação. São Paulo, 2013.

Figura 3 - Variação da pressão arterial dos pacientes com doença renal crônica internados em uma clínica médica que apresentaram medidas registradas do primeiro ao décimo dia de internação. São Paulo, 2013.

Figura 4 - Variação da pressão arterial dos pacientes sem doença renal crônica internados em uma clínica médica que apresentaram medidas registradas do primeiro ao décimo dia de internação. São Paulo, 2013.

Figura 5 - Comparação dos valores de pressão arterial dos hipertensos com e sem doença renal crônica que apresentaram medidas registradas do primeiro ao décimo dia de internação. São Paulo, 2013.

Figura 6 - Variação da pressão arterial dos pacientes com doença renal crônica internados em uma clínica médica que apresentaram medidas registradas do primeiro ao décimo dia de internação. São Paulo, 2013.

Figura 7 - Variação da pressão arterial dos pacientes sem doença renal crônica internados em uma clínica médica que apresentaram medidas registradas do primeiro ao décimo dia de internação. São Paulo, 2013.

Figura 8 - Controle da hipertensão arterial de hipertensos internados em uma clínica médica, com e sem doença renal crônica. São Paulo, 2013. .... 88

Figura 9 - Regressão linear dos valores de taxa de filtração glomerular estimada dos pacientes internados em uma clínica médica sem doença renal crônica segundo emprego das equações Modification of Diet in Renal Disease abreviada e Chronic Kidney Disease Epidemiology Collaboration. São Paulo, 2013. 


\section{LISTA DE TABELAS}

Tabela 1 - Características biossociais dos pacientes internados em uma clínica médica, com e sem doença renal crônica. São Paulo, 2013.

Tabela 2 - Hábitos de vida, acompanhamento em serviço de saúde e uso contínuo de medicamentos dos pacientes internados em uma clínica médica, com e sem doença renal crônica. São Paulo, 2013.

Tabela 3 - Principais antecedentes de saúde, pessoais e familiares, dos pacientes internados em uma clínica médica, com e sem doença renal crônica. São Paulo, 2013.

Tabela 4 - Principais medicamentos de uso contínuo dos pacientes internados em uma clínica médica, com e sem doença renal crônica. São Paulo, 2013.

Tabela 5 - Principais diagnósticos médicos dos pacientes internados em uma clínica médica, com e sem doença renal crônica. São Paulo, 2013... 64

Tabela 6 - Exames laboratoriais dos pacientes internados em uma clínica médica, com e sem doença renal crônica. São Paulo, 2013.

Tabela 7 - Valores de creatinina sérica nos primeiros dez dias de internação dos pacientes internados em uma clínica médica, com e sem doença renal crônica. São Paulo, 2013.

Tabela 8 - Valores de pressão arterial nos primeiros dez dias de internação dos pacientes internados em uma clínica médica, com e sem doença renal crônica. São Paulo, 2013.

Tabela 9 - Valores de pressão arterial dos pacientes internados em uma clínica médica, com e sem doença renal crônica, que apresentaram medidas registradas do primeiro ao décimo dia de internação. São Paulo, 2013.

Tabela 10 - Principais diagnósticos de enfermagem dos pacientes com e sem doença renal crônica na admissão e alta em clínica médica. São Paulo, 2013.

Tabela 11 - Desfechos da hospitalização dos pacientes internados em uma clínica médica, com e sem doença renal crônica. São Paulo, 2013... 74

Tabela 12 - Preditores de doença renal crônica em pacientes internados em uma clínica médica segundo análise multivariada. São Paulo, 2013. 75

Tabela 13 - Características biossociais dos hipertensos internados em uma clínica médica, com e sem doença renal crônica. São Paulo, 2013... 76

Tabela 14 - Hábitos de vida, acompanhamento em serviço de saúde e uso contínuo de medicamentos dos hipertensos internados em uma clínica médica, com e sem doença renal crônica. São Paulo, 2013... 77

Tabela 15 - Principais antecedentes de saúde, pessoais e familiares, dos hipertensos internados em uma clínica médica, com e sem doença renal crônica. São Paulo, 2013.

Tabela 16 - Principais medicamentos de uso contínuo dos hipertensos internados em uma clínica médica, com e sem doença renal crônica. São Paulo, 2013.

Tabela 17 - Número e classe de medicamentos anti-hipertensivos de uso contínuo dos hipertensos internados em uma clínica médica, com e sem doença renal crônica. São Paulo, 2013. 
Tabela 18 - Principais diagnósticos médicos dos hipertensos internados em uma clínica médica, com e sem doença renal crônica. São Paulo, 2013.

Tabela 19 - Exames laboratoriais dos hipertensos internados em uma clínica médica, com e sem doença renal crônica. São Paulo, 2013.

Tabela 20 - Valores de pressão arterial nos primeiros dez dias de hospitalização dos hipertensos internados em uma clínica médica, com e sem doença renal crônica. São Paulo, 2013.

Tabela 21 - Valores de pressão arterial dos hipertensos internados em uma clínica médica, com e sem doença renal crônica, que apresentaram medidas registradas do primeiro ao décimo dia de internação. São Paulo, 2013.

Tabela 22 - Desfechos da hospitalização dos hipertensos internados em uma clínica médica com e sem doença renal crônica. São Paulo, 2013 .... 89

Tabela 23 - Classificação da taxa de filtração glomerular estimada dos pacientes internados em uma clínica médica sem doença renal crônica segundo emprego das equações Modification of Diet in Renal Disease abreviada e Chronic Kidney Disease Epidemiology Collaboration.. São Paulo, 2013.

Tabela 24 - Reclassificação da taxa de filtração glomerular estimada dos pacientes internados em uma clínica médica sem doença renal crônica segundo emprego das equações Modification of Diet in Renal Disease abreviada e Chronic Kidney Disease Epidemiology Collaboration. São Paulo, 2013.

Tabela 25 - Características biossociais dos pacientes internados em uma clínica médica sem doença renal crônica segundo taxa de filtração glomerular estimada pela equação Modification of Diet in Renal Disease abreviada. São Paulo, 2013

Tabela 26 - Principais antecedentes pessoais dos pacientes internados em clínica médica sem doença renal crônica segundo taxa de filtração glomerular estimada pela equação Modification of Diet in Renal Disease abreviada. São Paulo, 2013

Tabela 27 - Valores de creatinina sérica nos primeiros dez dias de hospitalização dos pacientes internados em uma clínica médica sem doença renal crônica segundo taxa de filtração glomerular estimada pela equação Modification of Diet in Renal Disease abreviada. São Paulo, 2013.

Tabela 28 - Desfechos da hospitalização dos pacientes internados em uma clínica médica sem doença renal crônica segundo taxa de filtração glomerular estimada pela equação Modification of Diet in Renal Disease abreviada. São Paulo, 2013. 


\section{SUMÁRIO}

1 INTRODUÇÃO

1.1 DEFINIÇÃO E EPIDEMIOLOGIA DA DOENÇA RENAL CRÔNICA ............. 16

1.2 AVALIAÇÃO DA TAXA DE FILTRAÇÃO GLOMERULAR …......................... 33

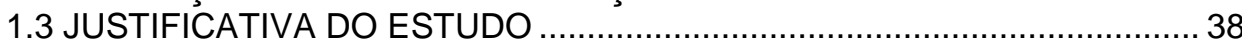

2 OBJETIVOS

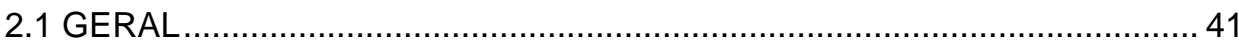

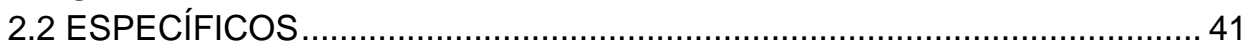

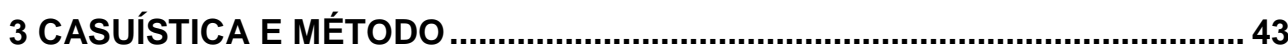

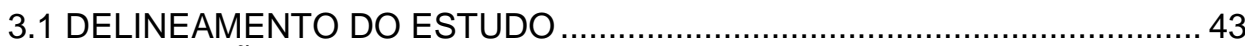

3.2 POPULAÇÃO E LOCAL DO ESTUDO

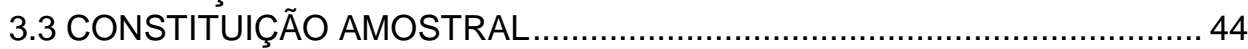

3.3.1 Definição de doença renal crônica ................................................... 45

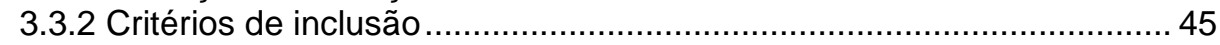

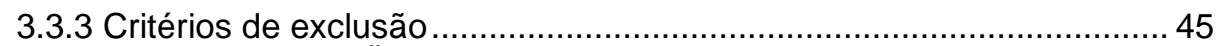

3.4 OPERACIONALIZAÇÃO DA COLETA DE DADOS …............................. 48

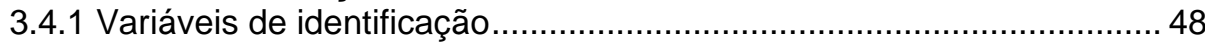

3.4.2 Variáveis antropométricas e de pressão arterial................................. 49

3.4.3 Variáveis de diagnóstico ............................................................... 50

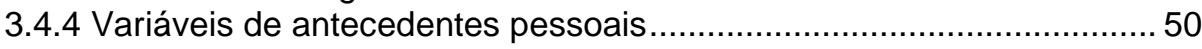

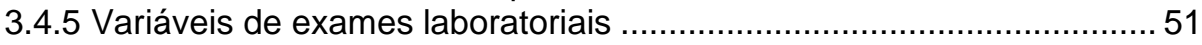

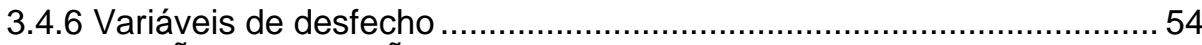

3.5 AVALIAÇÃO DA FUNÇÃO RENAL ..................................................54

3.5.1 Equação Modification of Diet in Renal Disease abreviada (MDRD4) ... 55

3.5.2 Equação Chronic Kidney Disease Epidemiology Collaboration............. 55

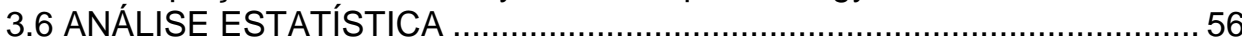

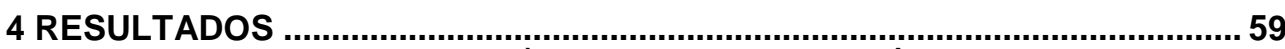

4.1 FATORES ASSOCIADOS À DOENÇA RENAL CRÔNICA ........................ 59

4.2 FATORES ASSOCIADOS À HIPERTENSÃO ARTERIAL NA DOENÇA

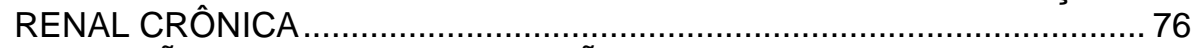

4.3 AVALIAÇÃO DA TAXA DE FILTRAÇÃO GLOMERULAR EM PACIENTES SEM DOENÇA RENAL CRÔNICA ….................................... 90

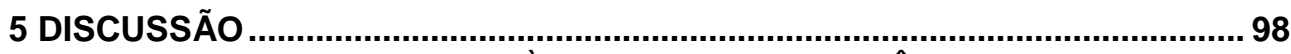

5.1 FATORES ASSOCIADOS À DOENÇA RENAL CRÔNICA ........................98

5.2 FATORES ASSOCIADOS À HIPERTENSÃO ARTERIAL NA DOENÇA RENAL CRÔNICA ......................................................................... 118

5.3 AVALIAÇÃO DA TAXA DE FILTRAÇÃO GLOMERULAR EM PACIENTES SEM DOENÇA RENAL CRÔNICA ........................................ 125

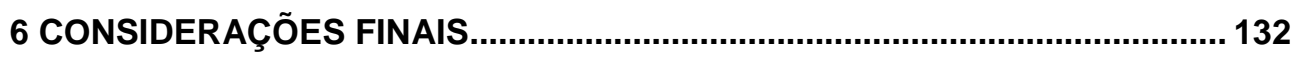

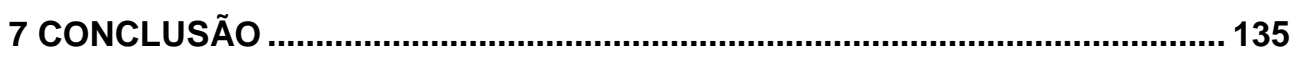

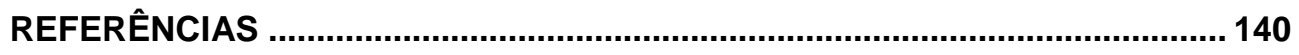

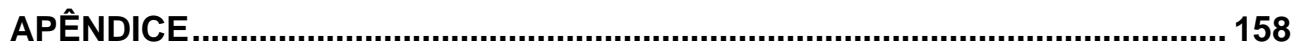




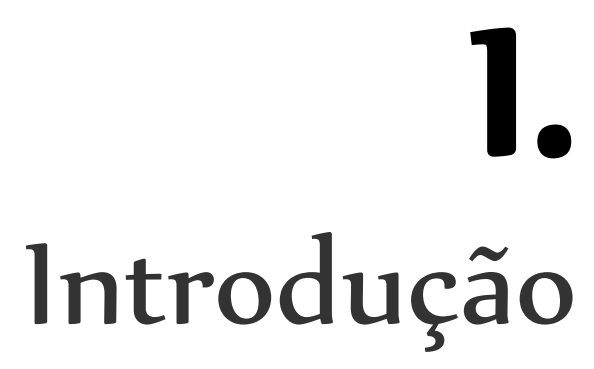




\section{INTRODUÇÃO}

A doença renal crônica assumiu, nos últimos anos, o status de problema de saúde pública devido à elevação de sua prevalência entre a população mundial e ao seu impacto na morbimortalidade dos indivíduos acometidos. Resultado, sobretudo, da crescente epidemia dos fatores de risco cardiovascular, como a hipertensão arterial e o diabetes melito, a doença renal crônica implica em hospitalizações frequentes e em elevado custo socioeconômico ${ }^{12} 34$.

\subsection{DEFINIÇÃO E EPIDEMIOLOGIA DA DOENÇA RENAL CRÔNIÇA}

A doença renal crônica é caracterizada pelo acometimento persistente e progressivo do parênquima renal e da taxa de filtração glomerular. Trata-se de uma síndrome heterogênea, na qual etiologia, mecanismo patológico, velocidade de progressão e severidade variam entre os indivíduos doentes. Em geral, se observa a perda paulatina e insidiosa das funções regulatórias, excretórias e endócrinas do rim, com o comprometimento da homeostase do indivíduo no estágio mais avançado da doença ${ }^{3}{ }^{4} 5$. Os critérios determinados pela instituição americana National Kidney Foundation $(\mathrm{NKF})^{6}$ para a definição da doença renal crônica, referendados pela Sociedade Brasileira de Nefrologia ${ }^{3}$, são: lesão presente por período igual ou superior a três meses, definida por anormalidades estruturais ou funcionais do rim, com ou sem diminuição da filtração glomerular, evidenciada por anormalidades histopatológicas ou de marcadores de lesão renal, incluindo alterações sanguíneas ou urinárias, ou ainda de exames de imagem; e taxa de filtração glomerular menor que $60 \mathrm{~mL} / \mathrm{min} / 1,73 \mathrm{~m}^{2}$ por período igual ou superior a três meses com ou sem lesão renal. 
Natália Alencar de Pinho

Tendo em vista o largo espectro de apresentação da doença renal crônica, seu sistema de classificação é ainda objeto de discussão. Entre as questões debatidas, se encontram o papel da albuminúria no risco de progressão da doença renal crônica e na mortalidade cardiovascular, o uso exclusivo de dados laboratoriais no diagnóstico da doença, a sobreutilização dos recursos em saúde com o diagnóstico precoce e a possibilidade de estratificação dos pontos de corte para a doença segundo a idade ${ }^{7}$.

O mais recente fórum da National Kidney Foundation - Kidney Disease Outcomes Quality Initiative (KDOQI) ${ }^{7}$ promoveu em 2009 uma revisão da classificação da doença renal crônica proposta pela mesma comissão em 2002. Baseadas em uma metanálise dos riscos relativos de desfechos de morbidade renal e mortalidade por todas as causas e cardiovascular, as seguintes recomendações foram adotadas: 1) manutenção da classificação da doença renal crônica segundo prognóstico; 2) subdivisão do estágio 3 de taxa de filtração glomerular; 3) adição de três estágios de albuminúria em todos as categorias de taxa de filtração glomerular; e 4) ênfase do diagnóstico clínico da doença renal crônica. Os critérios propostos pela Kidney Disease - Improving Global Outcomes (KDIGO) ${ }^{8}$ para a classificação da doença renal crônica são apresentados nos quadros 1 e 2.

Quadro 1 - Classificação da doença renal crônica segundo taxa de filtração glomerular proposta pela KDIGO. São Paulo, 2013.

\begin{tabular}{|lll|}
\hline Categoria & $\begin{array}{c}\text { TFG } \\
(\mathbf{m L} / \mathbf{m i n} / \mathbf{1 , 7 3} \mathbf{~ m 2})\end{array}$ & \multicolumn{1}{c|}{ Denominação da função renal } \\
\hline G1 & $>90$ & Normal ou aumentada* \\
G2 & $60-89$ & Redução leve ** \\
G3a & $45-59$ & Redução leve à moderada \\
G3b & $44-30$ & Redução moderada à severa \\
G4 & $29-15$ & Redução severa \\
G5 & $<15$ & Falência renal ou doença renal crônica terminal \\
\hline
\end{tabular}

Fonte: Kidney Disease - Improving Global Outcomes, 2013

Abreviação: TFG, taxa de filtração glomerular.

${ }^{*} \mathrm{Na}$ ausência de evidência de lesão renal, as categorias G1 e G2 não satisfazem os critérios para diagnóstico da doença renal crônica.

** Relativo aos parâmetros para adultos jovens. 
Natália Alencar de Pinho

Quadro 2 - Classificação da doença renal crônica segundo albuminúria proposta pela KDIGO. São Paulo, 2013.

\begin{tabular}{|c|c|c|c|c|}
\hline \multirow{2}{*}{ Categoria } & \multirow{2}{*}{$\begin{array}{l}\text { EUA } \\
\text { (mg/24horas) }\end{array}$} & \multicolumn{2}{|c|}{$\mathrm{RAC}$} & \multirow{2}{*}{$\begin{array}{l}\text { Denominação da } \\
\text { função renal }\end{array}$} \\
\hline & & $(\mathrm{mg} / \mathrm{mmol})$ & $(\mathrm{mg} / \mathrm{g})$ & \\
\hline $\mathrm{A} 1$ & $<30$ & $<3$ & $<30$ & $\begin{array}{l}\text { Normal ou levemente } \\
\text { reduzida }\end{array}$ \\
\hline $\mathrm{A} 2$ & $30-300$ & $3-30$ & $30-300$ & Redução moderada* \\
\hline A3 & $>300$ & $>30$ & $>300$ & Redução severa** \\
\hline
\end{tabular}

Com a evolução conceitual da doença renal crônica, que passou de "enfermidade letal e pouco frequente" para "condição comum e de gravidade variável", esforços têm sido feitos a fim de se estruturar a atenção em saúde pública, inclusive na detecção da doença $^{9}$. Observa-se, contudo, variação importante da prevalência da doença renal crônica obtida pelos estudos epidemiológicos. É imperativo considerar os referenciais utilizados para a verificação da prevalência e as diversas populações estudadas. Os dados são heterogêneos e dificultam sua comparação.

Zhang e Rothenbacher ${ }^{10}$ conduziram uma revisão sistemática a fim de sumarizar a prevalência da doença renal crônica identificada por estudos populacionais. Foram incluídos 26 estudos de origem norte-americana, europeia, asiática e australiana. A prevalência de doença renal crônica, definida pela estimativa da taxa de filtração glomerular $<60 \mathrm{~mL} / \mathrm{min} / 1,73 \mathrm{~m} 2$ pelas equações Modification of Diet in Renal Disease abreviada (MDRD4) e CockroftGault ajustada para uma superfície corporal de 1,73 m2 (CockroftGault/BSA), variou de $1,5 \%$ a $43,3 \%$ nas diferentes coortes. A mediana da prevalência para adultos com idade igual ou superior a 30 anos foi de $7,2 \%$.

Revisão sistemática mais recente, realizada por McCullough et $a l^{11}$, evidenciou grande diferença entre as prevalências 
Natália Alencar de Pinho

apresentadas pelos estudos de base populacional: 0,6 a 42,6\%. Quarenta três estudos e duas revisões sistemáticas foram incluídos. Preocupando-se com o rigor do critério de tempo superior a três meses para definição de doença renal crônica, os autores denominaram seu objeto de estudo como disfunção renal, caracterizada pela taxa de filtração glomerular menor que 60 $\mathrm{mL} / \mathrm{min} / 1,73 \mathrm{~m}^{2}$ estimada pelas equações MDRD4 ou Cockroft-Gault, depuração de creatinina menor que $60 \mathrm{~mL} / \mathrm{min}$, e hipercreatinemia. Uma avaliação qualitativa dos estudos revisados também foi realizada neste trabalho, mediante análise do critério de cronicidade da doença renal, da constituição amostral e da calibração dos ensaios de creatinina. Os estudos considerados de alta qualidade, que visaram a identificar a disfunção renal pela estimativa da taxa de filtração glomerular, apresentaram prevalência da ordem de 1,7 a $8,1 \%$.

Considerando a presença persistente de albuminúria juntamente à redução da taxa de filtração glomerular estimada pela equação MDRD4, Coresh et $a l^{12}$ encontraram prevalência de doença renal crônica (estágios 1 a 4) de 13,1\% no período de 1999-2004 para uma amostra representativa de adultos norte-americanos nãoinstitucionalizados.. Evidenciaram, também, o acréscimo da prevalência desta doença em relação à análise de um período anterior (1988-1994) que era de 10\%, atribuída possivelmente ao envelhecimento da população ${ }^{13}$.

Estudo populacional conduzido na Romênia identificou a prevalência de decréscimo na taxa de filtração glomerular de 6,69\% e 7,32\%, utilizando como referência a estimativa de filtração glomerular pelas equações MDRD4 e Chronic Kidney Disease Epidemiology Collaboration (CKD-EPI), respectivamente ${ }^{14}$. $\mathrm{Na}$ China, estudo transversal de base populacional identificou prevalência ajustada de doença renal crônica de 10,8\%, mediante critério de taxa de filtração glomerular estimada pela equação 
Natália Alencar de Pinho

MDRD4 e a presença de albuminúria ${ }^{15}$.(2) No México, o Kidney Early Evaluation Program (KEEP) obteve a prevalência de doença renal crônica de 22 e 33\% para a Cidade do México e para o Estado de Jalisco, respectivamente, utilizando como critério a estimativa da taxa de filtração glomerular pela equação MDRD4 e pela presença de albuminúria ${ }^{16}$.

No Brasil, as prevalências para doença renal crônica em estudos de base populacional variaram de 0,48 a 46,9\%. Yokota et $a l^{17}$, em estudo sobre vigilância de fatores de risco e proteção para agravos não transmissíveis em um município de pequeno porte no Espírito Santo - Brasil, identificaram prevalência de disfunção renal de 46,9\%, mediante uso da equação Cockroft-Gault. Os resultados mostraram que 33\% apresentavam redução leve da função, 11,4\%, redução moderada e 1,4\%, falência renal. Passos et al ${ }^{18}$ descreveram prevalência de disfunção renal de $0,48 \%$ para indivíduos de 18 a 59 anos e 5,09\% para maiores de 60 anos, considerando os valores de creatinina sérica superiores a 1,1 $\mathrm{mg} / \mathrm{dL}$, para mulheres, e 1,3 mg/dL, para homens, em Bambuí (MG), Brasil. A prevalência de creatinina sérica superior a 1,3 mg/dL, para ambos os sexos, identificada por Lessa et $a l^{19}$ em segmento da população soteropolitana (BA), Brasil, foi de 3,1\% nos adultos em geral. Para uma amostra não representativa da população, Bastos et $a f^{20}$ verificaram a prevalência de doença renal crônica conforme sua gravidade (estágios 3 a 5, segundo estimativa da taxa de filtração glomerular pela equação MDRD4), a partir de registros de indivíduos não-hospitalizados submetidos a exames em laboratório privado de Juiz de Fora (MG), Brasil, obtendo os seguintes valores: 11,6\% para o estágio 3; 0,5\% para o estágio 4; e 0,3\% para o estágio 5 .

O relatório anual do United States Renal Data System ${ }^{21}$, de 2012, indicou que 594.374 pessoas apresentavam falência renal nos Estados Unidos em 2010, perfazendo a prevalência de 1.763 pacientes por milhão de população (pmp). A incidência de doença 
Natália Alencar de Pinho

renal crônica terminal no mesmo ano foi de 348 pmp. Ambos indicadores apresentaram variação da ordem de $\pm 2 \%$ em relação a 2009.

Dados brasileiros de 2011, disponibilizados pelo censo da Sociedade Brasileira de Nefrologia $^{22}$, resultaram na estimativa de 91.314 indivíduos em tratamento dialítico naquele ano, o correspondente à prevalência de 475 pmp. A incidência de pacientes em diálise, nesta mesma avaliação, foi de 149 pmp. Enquanto a prevalência de diálise crônica no Brasil, em 2011, manteve-se estável em relação ao ano anterior, o número de pacientes novos superou em cerca de 10.000 aquele de 2010. Os casos incidentes detectados pelo subsistema de Autorização de Procedimentos de Alta Complexidade (APAC) entre os anos de 2000 e 2006 revelaram média anual de 119,8 casos por milhão de habitantes/ano. Este coeficiente de incidência foi superior para homens em relação às mulheres (138,9 vs 101,2 casos por milhão de habitantes/ano, respectivamente) e aumentou segundo a faixa etária (78,3 na faixa de 20 a 44 anos; 328,5 na faixa de 45 a 64 anos; 585,9 na faixa de 65 a 74 anos; e 604,7, para 75 anos ou mais). As regiões Sul e Sudeste apresentaram coeficientes de incidência mais elevados (143,6 e 141,1 casos por milhão de habitantes/ano, respectivamente) do que as demais regiões (108,7 para CentroOeste, 92,3 para Nordeste e 66,3 para Norte) $)^{23}$.

Observa-se, no Brasil, número de pacientes em terapia renal substitutiva inferior ao de países desenvolvidos. Uma explicação para tal discrepância pode ser a baixa participação dos centros de diálise no censo, atualmente em torno de $50 \%$, fato que exige uma estimativa dos dados por parte de entidades. Pacientes tratados por transplantes também não são contabilizados pelo censo brasileiro. A hipótese mais alarmante, porém, repousa sobre o precário acesso aos serviços de saúde: acredita-se que 50 a $70 \%$ dos brasileiros que têm doença renal crônica terminal morrem sem usufruir de qualquer 
Natália Alencar de Pinho

modalidade de tratamento 24

Os principais fatores de risco aos quais se tem atribuído a crescente prevalência da doença renal crônica no mundo são: aumento da expectativa de vida, diabetes melito e hipertensão arterial $^{24}$. Estes fatores de risco estão intimamente associados ao desenvolvimento socioeconômico de uma determinada população: por um lado há diminuição das causas de morte infecciosas e externas pela melhora da condição de vida e do acesso aos serviços de saúde; por outro, vê-se a adoção de estilos de vida sedentários e a piora dos hábitos nutricionais ${ }^{1}$.

O processo de envelhecimento reproduz alterações anátomofisiológicas nos rins. As alterações estruturais incluem a diminuição da massa e da área total dos rins, esclerose dos glomérulos (sobretudo daqueles situados no córtex renal) e mudanças no sistema arteriolar eferente e aferente, com formação de shunts na região medular renal. Observa-se igualmente a fibrose tubulointersticial e a diminuição do túbulo proximal. Do ponto de vista funcional, estudos mostraram que a taxa de filtração glomerular diminui com a idade, à velocidade aproximada de $1 / \mathrm{mL} / \mathrm{min} / 1,73 \mathrm{~m}^{2} /$ ano a partir dos 40 anos de idade. $O$ fluxo sanguíneo renal é reduzido, enquanto a resistência vascular renal e a fração de filtração aumentam (notadamente nos glomérulos justamedulares, provavelmente devido a uma resposta adaptativa para a preservação da função renal). A função tubular também é prejudicada, resultando em poliúria noturna ${ }^{25}$. Entretanto, o fato de tais alterações serem ligadas à senescência ou a processos patológicos na terceira idade não está completamente elucidado.

Estudo de Linderman et $a^{26}$, cuja amostra incluiu 446 indivíduos saudáveis, identificou diminuição média da taxa de filtração glomerular de $0,75 / \mathrm{mL} / \mathrm{min} / 1,73 \mathrm{~m}^{2} /$ ano durante 0 seguimento de 24 anos. Cerca de um terço dos participantes não apresentaram redução absoluta da taxa de filtração glomerular e 
Natália Alencar de Pinho

somente uma pequena porcentagem evoluiu com diminuição significante desta $(p<0,05)$. Mais recentemente, Jiang et $a^{27}$ identificaram diferença significativa $(p<0,05)$ da redução média da taxa de filtração glomerular estimada pela equação CKD-EPI em um período de cinco anos entre indivíduos com idade de 60 a 74 anos ($11,2 \% \pm 13,8 \%)$ e com idade igual ou superior a 75 anos $(-12,1 \% \pm$ $12,1 \%)$ comparados àqueles com idade de 45 a 59 anos $(-5,5 \% \pm$ $11,6 \%)$ e com idade inferior a 44 anos $(-3,9 \% \pm 12,6 \%)$. Contudo, $43 \%$ da amostra apresentou aumento ou manutenção da taxa de filtração glomerular ao longo do estudo, sugerindo que o processo de perda de função renal possa não ser inelutável.

O decréscimo da função renal poderia suscetibilizar os idosos ao desenvolvimento da doença renal crônica, sobretudo se considerada a alta prevalência de comorbidades neste grupo ${ }^{3}$. Segundo o censo da Sociedade Brasileira de Nefrologia, 31,5\% da população em diálise no Brasil tem idade superior a 65 anos $^{22}$.

Whiting et $a^{28}$ estimaram, mediante uso de dados dos 80 países mais populosos do mundo, a prevalência global de diabetes melito para os anos de 2011 e 2030: 8,3\% e 9,9\%, respectivamente. A prevalência de diabetes ajustada para a idade no Brasil supera aquela mundial, sendo de 9,7\% (em 2011) e de 12,3\% (em 2030), crescimento que supera a expectativa de aumento da população brasileira no mesmo período. Acredita-se que o número de indivíduos com esta doença no mundo dobrará nos próximos 20 anos.

O estresse oxidativo produzido pela hiperglicemia, assim como a proteinúria, a hiperperfusão e a hiperfiltração renal, participam da patogênese da doença renal crônica. Fatores comumente associados ao diabetes, como a obesidade e as doenças cardiovasculares, contribuem igualmente para o desenvolvimento de lesões renais ${ }^{29}$. Estudo mexicano identificou um odds ratio para presença de doença renal crônica em diabéticos de 
Natália Alencar de Pinho

1,97 (IC95\% 1,34 - 2,90; p = 0,006), mediante regressão logística incluindo hipertensão arterial, doença isquêmica do coração e acidente vascular encefálico ${ }^{30}$. Tal associação não foi, contudo, encontrada em estudo de Passos et al ${ }^{18}$ em Bambuí (MG), Brasil, embora a prevalência de diabetes entre os doentes renais cônicos tenha se mostrado superior à da amostra geral $(22,4 \%$ vs $14,5 \%$, respectivamente).

A doença renal crônica terminal em pacientes com diabetes melito tipo 2, presumidamente associada à glomeruloesclerose diabética, assumiu nas últimas décadas grande importância em países de estilo de vida ocidental. Sua incidência aumentou dramaticamente entre as décadas de 1980 e 1990, passando de 23,4 pmp (em 1984) para 66 pmp (em 1994), no Japão, e de 29,2 pmp para 107 pmp, nos Estados Unidos, neste mesmo período ${ }^{31}$. Embora dados dos Estados Unidos tenham mostrado redução de $3,9 \%$ por ano na incidência de doença renal crônica terminal ajustada à idade, de 1996 a 2006, o diabetes figura como primeira causa de falência renal neste país (44\% dos novos casos tratados) ${ }^{32}$, a exemplo de México, Malásia, Taiwan, Nova Zelândia, Japão, Israel, e outros países. ${ }^{33} \mathrm{O}$ diabetes melito figura como 0 segundo diagnóstico de base para pacientes em terapia renal substitutiva dialítica no Brasil, com frequência de $28 \%$ em $2011^{22}$.

Enquanto o diabetes melito corresponde à principal causa isolada para doença renal crônica terminal em diversos países, a hipertensão arterial é a etiologia mais frequente no Brasil, tendo sido identificada em $35,1 \%$ dos pacientes em diálise ${ }^{22}$. Considerando que a grande relevância do diabetes melito em países desenvolvidos tem sido atribuída à diminuição da mortalidade pela hipertensão arterial e outras causas cardiovasculares ${ }^{31}$, pode-se inferir que o controle dos distúrbios pressóricos na população brasileira esteja aquém do desejável.

A hipertensão arterial é um importante problema de saúde 
Natália Alencar de Pinho

pública, devido à sua alta prevalência e às suas complicações cardiovasculares. Ela é caracterizada em adultos pela persistência de níveis de pressão arterial iguais ou superiores a $140 \mathrm{mmHg}$, para sistólica, e a $90 \mathrm{mmHg}$, para diastólica, identificada pela medida casual em consultório. A hipertensão arterial tem origem multifatorial e está frequentemente associada a alterações metabólicas e a lesões de órgãos-alvo (coração, encéfalo, rins e vasos sanguíneos) ${ }^{34}$.

As prevalências de hipertensão arterial, identificadas por WolfMaier et $a^{\beta 5}$ para os Estados Unidos e para seis países da Europa ocidental, foram de 28 e 44\%, respectivamente. Estudos brasileiros de base populacional apontaram valores de prevalência que variam entre $19,2 \%$ a $44,4 \%{ }^{36}$. Metanálise de estudos transversais e de coorte, que avaliaram a prevalência de hipertensão arterial entre os anos de 1980 e 2010 no Brasil, identificou frequência de 28,7\% para o ano de $2000^{37}$. Na cidade de São Paulo (SP), Brasil, a prevalência referida de hipertensão arterial foi de $23 \%$. Porém, ao se considerar a referência dos valores da última medida de pressão arterial igual ou superior a 140/90 mm Hg, esta prevalência se elevou para $32 \%{ }^{38}$.

A elevação da pressão arterial determina o incremento do risco cardiovascular contínuo e independente ${ }^{34}$. Os níveis pressóricos elevados foram identificados como o principal fator de risco para carga global de doenças no mundo em 2010. A proporção de disability-adjusted life years (DALY - tempo vivido com incapacidade e tempo perdido por mortalidade prematura ${ }^{39}$ ) atribuída à pressão arterial foi de $7,0 \%$ para todas as causas e $53 \%$ para doença isquêmica do coração $^{40}$. Diante disso, o controle da hipertensão arterial tem como objetivo a redução da morbimortalidade pelas doenças cardiovasculares ${ }^{34}$, as quais constituem a primeira causa de óbito e a segunda causa de hospitalização no Brasil ${ }^{41}$.

A hipertensão arterial também pode determinar o surgimento 
Natália Alencar de Pinho

da doença renal crônica e representar um catalisador para sua progressão até o estágio terminal ${ }^{24}$. A correlação dos níveis de pressão arterial com a deterioração da função renal tem sido demonstrada por diversos trabalhos. Estudo de base populacional em Maryland, Estados Unidos, identificou uma razão de incidência (hazard ratio) de falência renal tratada e morte com doença renal crônica de 3,2 (IC95\% 1,0 - 10,4), 5,7 (IC95\% 1,7 - 18,9) e 8,8 (2,6 - 30,3) para os estágios um, dois, e três de hipertensão arterial, respectivamente, durante período de 20 anos e tendo como referência os níveis ótimos de pressão arterial ${ }^{42}$. Entre hipertensos, Perry $\mathrm{Jr}$ et $a /^{43}$ avaliaram os níveis tensionais pré- tratamento e sua associação com falência renal em segmento de 15 anos, obtendo um hazard ratio de 2,8, para a faixa de pressão arterial sistólica entre 165 e $180 \mathrm{mmHg}$, e de 7,6, para pressão arterial sistólica superior a $180 \mathrm{mmHg}$. Os autores identificaram, igualmente, diminuição do risco para falência renal com a redução da pressão arterial sistólica após instituição de tratamento anti-hipertensivo, o qual chegou a $60 \%$, com reduções superiores a $20 \mathrm{mmHg}$.

No que concerne à progressão da doença renal crônica, o Reduction of Endpoints in Non-insulin-dependent Diabetes Mellitus With the Angiotensin II Antagonist Losartan Study (RENAAL) identificou risco adicional de 6,7\% ( $p=0,007)$ para doença renal crônica terminal ou morte a cada $10 \%$ de acréscimo na pressão arterial sistólica de hipertensos nefropatas e diabéticos ${ }^{44}$. Bloomfield et $\left.a\right|^{45}$, por sua vez, obtiveram um odds ratio de 5,1 (IC95\% 1,42 18,35) para progressão da doença renal crônica em indivíduos previamente classificados no estágio três de doença renal crônica, utilizando como critério de progressão da doença renal crônica a redução da taxa de filtração glomerular estimada por equação baseada na cistatina $\mathrm{C}$.

Embora a hipertensão arterial seja um fator de risco modificável, pela adoção de medidas medicamentosas e não 
Natália Alencar de Pinho

medicamentosas, seu controle ainda está aquém do desejável ${ }^{34}$. Estudos de base populacional conduzidos no Brasil apontam frequências de controle que oscilam entre 31,4 e 57,6\% ${ }^{38} 4647$.

Outros grupos de risco para o desenvolvimento da doença renal crônica são indivíduos que apresentam: familiares portadores de doença renal crônica; uso de medicamentos nefrotóxicos, sobretudo quando há comprometimento renal previamente estabelecido; litíase e obstrução renal; infecções; e doenças autoimunes $^{3} 5$. Evidências recentes têm sugerido que a síndrome metabólica também se constitui um importante fator de risco para doença renal crônica.

A síndrome metabólica é definida pela coexistência de pelo menos três das seguintes anomalias: obesidade abdominal; pressão arterial aumentada; tolerância à glicose ou diabetes melito; e dislipidemia, caracterizada pelo aumento dos níveis de triglicérides ou diminuição dos níveis de high-density lipoproteins (HDL) ${ }^{48} 49$. Dados do NHANES III mostraram associação entre síndrome metabólica e doença renal crônica, mediante análise transversal, com odds ratios de 2,6 (IC95\% 1,68 - 4,03) e 1,89 (IC95\% 1,34 $2,67)$. para presença de taxa de filtração glomerular estimada inferior a $60 \mathrm{~mL} / \mathrm{min} / 1,73 \mathrm{~m}^{2}$ e microalbuminúria, respectivamente, na vigência de síndrome metabólica ${ }^{50}$. Estudo longitudinal norteamericano, com dados provenientes do Atherosclerosis Risk in Communities (ARIC), identificou um odds ratio para desenvolvimento de taxa de filtração glomerular estimada inferior a $60 \mathrm{~mL} / \mathrm{min} / 1,73 \mathrm{~m}^{2}$ de 1,43 (IC95\% 1,18 - 1,73) em pacientes com síndrome metabólica, após ajuste para fatores demográficos e de estilo de vida, índice de massa corporal e doença coronariana. A associação encontrada neste estudo se manteve significante, mesmo após a exclusão de diabetes e hipertensão arterial incidentes nos nove anos de seguimento ${ }^{51}$. Ryu et $a^{p^{2}}$ verificaram que a síndrome metabólica, ao longo do tempo, predisse o desenvolvimento de doença renal 
Natália Alencar de Pinho

crônica como variável tempo-dependente, com um hazard ratio de 1,75 (IC95\% 1,28-2,39) em estudo com homens sul-coreanos.

A prevalência dos fatores clássicos de risco cardiovascular entre os doentes renais crônicos tem se mostrado mais elevada do que entre a população em geral. Dados do estudo NHANES III revelaram que $19 \%$ dos indivíduos com creatinina sérica elevada (> $1,6 \mathrm{mg} / \mathrm{dL}$, nos homens, $>1,4 \mathrm{mg} / \mathrm{dL}$, nas mulheres) tinham diabetes e $70 \%$ deles tinham hipertensão arterial. Em contrapartida, a prevalência de diabetes e hipertensão arterial em toda a amostra deste estudo foi de $4,8 \%$ e $22,8 \%$, respectivamente. Da mesma forma, as alterações lipidêmicas foram mais frequentes entre os indivíduos com doença renal crônica: a vigência de colesterol total superior a $240 \mathrm{mg} / \mathrm{dL}$ foi de 90\%, para doença renal crônica com síndrome nefrótica (DRCSN), contra $20 \%$ da população em geral. O HDL inferior a $35 \mathrm{mg} / \mathrm{dL}$ esteve presente em $50 \%$ dos indivíduos com DRCSN, contra $15 \%$ da população em geral ${ }^{53}$.

Embora fatores associados ao desenvolvimento de doenças cardiovasculares sejam altamente prevalentes na doença renal crônica e contribuam para a morbidade destes indivíduos, a doença renal crônica tem sido reconhecida como fator de risco cardiovascular independente. Tanto a redução da filtração glomerular como a albuminúria são consideradas marcadores poderosos do comprometimento progressivo das funções cardiovasculares. Os processos deletérios associados à doença renal crônica, como uremia, aumento do estresse oxidativo, alterações na cascata de coagulação e hipervolemia, são fatores que contribuem para a gênese da aterosclerose e implicam no aumento do risco cardiovascular de forma independente dos fatores de risco clássicos ${ }^{54} 55$.

Estudo chinês, com 4.421 diabéticos, identificou uma taxa de incidência de eventos cardiovasculares (definidas como hospitalizações por doenças isquêmicas coronarianas, insuficiência 
Natália Alencar de Pinho

cardíaca ou acidente vascular encefálico) de 2,1\% (IC 95\% 2,2 $3,3 \%$, para indivíduos com taxa de filtração glomerular estimada igual ou superior a $90 \mathrm{~mL} / \mathrm{min} / 1,73 \mathrm{~m}^{2}$, contra 25,3\% (IC 95\% 15,0 $35,7 \%$, para indivíduos com taxa estimada entre 29 e 15 $\mathrm{mL} / \mathrm{min} / 1,73 \mathrm{~m}^{2}$. Embora o hazard ratio ajustado para variáveis demográficas, laboratoriais e de comorbidade só tenha sido significante para a faixa compatível com o estágio 4 de doença renal crônica, foi observado aumento significativo $(p<0,001)$ do risco de incidência de eventos cardiovasculares segundo decréscimo da taxa de filtração glomerular estimada ${ }^{56}$.

A análise agrupada de dados de quatro estudos longitudinais norte-americanos, cujo período de seguimento mínimo foi de dez anos, identificou um hazard ratio ajustado de 1,19 (IC95\% 1,07 1,32) para a ocorrência de eventos cardiovasculares fatais e nãofatais e mortalidade por todas as causas em indivíduos com taxa de filtração glomerular estimada entre 60 e $15 \mathrm{~mL} / \mathrm{min} / 1,73 \mathrm{~m}^{2}{ }^{57}$.

Em 1998, a National Kidney Foundation Task Force on Cardiovascular Disease publicou um relatório enfatizando o alto risco de doenças cardiovasculares na vigência de doença renal crônica. Este relatório informou que a mortalidade por doenças cardiovasculares é de 10 a 30 vezes maior nos pacientes em diálise que na população em geral $^{58}$.

A associação de marcadores de doença renal crônica com mortalidade cardiovascular foi identificada em revisão sistemática, com metanálise que incluiu mais de 100.000 indivíduos provenientes de estudos de base populacional em diversos países. Ao considerar, como referência, a taxa de filtração glomerular estimada entre 90 e $104 \mathrm{~mL} / \mathrm{min} / 1,73 \mathrm{~m}^{2}$, esta associação foi observada a partir de valores inferiores a $60 \mathrm{~mL} / \mathrm{min} / 1,73 \mathrm{~m}^{2}$, com hazard ratio ajustado de 1,52 (IC95\% 1,18 - 1,97) para a faixa de 60 a $45 \mathrm{~mL} / \mathrm{min} / 1,73 \mathrm{~m}^{2}$, 2,40 (IC95\% 1,80 - 2,21) para a faixa de 30 a $44 \mathrm{~mL} / \mathrm{min} / 1,73 \mathrm{~m} 2$, e 13,51 (IC95\% 4,89 - 37,35) para a faixa compreendida entre 15 e 29 
Natália Alencar de Pinho

$\mathrm{mL} / \mathrm{min} / 1,73 \mathrm{~m}^{2}$. No que concerne à relação albumina/creatinina urinária, a associação com mortalidade cardiovascular se mostrou linear, com hazard ratio ajustado de 1,63 (IC95\% 1,20 - 2,19), para valores entre 10 e $29 \mathrm{mg} / \mathrm{g}$, chegando a 4,77 (IC95\% 3,16 - 7,22), para valores superiores a $300 \mathrm{mg} / \mathrm{g}$, na vigência de taxa de filtração glomerular estimada normal. Embora menos pronunciada do que para as causas cardiovasculares, também houve associação dos marcadores de doença renal crônica com mortalidade por todas as causas $^{59}$.

Revisão sistemática de Tonelli et $a^{60}$ verificou variação do risco relativo de 0,94 a 5,00 em 41 coortes seguidas por pelo menos um ano em 37 estudos que avaliaram a relação de doença renal crônica com mortalidade por todas as causas. O risco relativo ajustado para idade, sexo, pressão arterial, hipertensão arterial e diabetes melito obtido mediante metanálise de 14 destes estudos, foi de 2,73 (IC 95\%, 1,64 - 4,54), para estimativas de taxa de filtração glomerular inferiores a $60 \mathrm{~mL} / \mathrm{min} / 1,73 \mathrm{~m}^{2}$. Na análise da associação de função renal e mortalidade segundo sexo, conduzida por Nitsch et $a^{61}$, se observou que a curva da relação de risco de morte em relação à taxa de filtração glomerular estimada foi mais acentuada para mulheres que para homens, se tornando significante em taxas de filtração glomerular mais elevadas para mulheres (52 vs 44 $\mathrm{mL} / \mathrm{min} / 1,73 \mathrm{~m}^{2}$, respectivamente). Todavia, o risco de morte foi $60 \%$ superior para homens em todas as faixas de taxa de filtração glomerular (IC95\%, 1,52 - 1,69).

Dados norte-americanos de 2010, provenientes do United States Renal Data System, revelam taxas de morbimortalidade mais elevadas para doentes renais crônicos comparados à população geral. A taxa de hospitalização de doentes renais crônicos nos estágio 4 a 5 foi cerca de $50 \%$ maior que aquela dos indivíduos sem doença renal crônica, correspondendo a 416 admissões por paciente-ano para pacientes com idade superior a 65 anos 
Natália Alencar de Pinho

assistidos pela seguradora Medicare. A frequência de readmissão hospitalar também foi mais elevada para doentes renais crônicos, sendo de $24 \%$ contra $18 \%$ para a população geral. As taxas de mortalidade por todas as causas, ajustada para idade, sexo, etnia, comorbidades e hospitalizações anteriores, foram de 60, 69 e 115 mortes por paciente-ano para os estágios 1-2, estágio 3 e estágios 4-5 de doença renal crônica, respectivamente ${ }^{62}$.

Nos Estados Unidos, aproximadamente metade das mortes de pacientes em terapia renal substitutiva é atribuída às causas cardiovasculares. ${ }^{63}$ Estudo de Almeida et $a^{64}$, com pacientes em hemodiálise na cidade de Salvador (BA), Brasil, descreveu frequência de mortalidade cardiovascular de 41,7\%, sendo 86,7\% por eventos cardíacos e 13,3\% por acidente vascular encefálico.

As doenças cardiovasculares foram a causa de hospitalização mais frequente para pacientes em hemodiálise na Alemanha, na Itália e na Espanha - 37,4\%, 29,3\% e 30,4\%, respectivamente segundo dados do Dialysis Outcomes Practice Patterns Study (DOPPS) $^{65}$. Na China, esta também foi a primeira causa de hospitalização para pacientes em hemodiálise e em diálise peritoneal, com frequências de $47,6 \%$ e 39,8\%, respectivamente ${ }^{66}$. Entretanto, estudo sobre a hospitalização de pacientes em hemodiálise em São José do Rio Preto (SP), Brasil, identificou como seu principal motivo a confecção ou a complicação de fístulas arteriovenosas; a causa cardiovascular mais frequentemente encontrada foi a hipertensão arterial: 3\% para homens e 7,1\% para mulheres, associada ou não a outras comorbidades ${ }^{67}$.

As infecções aparecem como importante causa de morbimortalidade de pacientes com doença crônica terminal e são consideradas a segunda causa de morte para esta população; a ocorrência de morte por quadros infecciosos agudos é maior entre os pacientes em diálise comparados à população em geral ${ }^{68}$. Em 2008, a infecção foi identificada como causa do óbito de $26 \%$ dos 
Natália Alencar de Pinho

pacientes em diálise no Brasil $^{69}$. Sua representatividade, entretanto, pode variar segundo o centro de terapia renal substitutiva estudado; para Barbosa et $a l^{70}$, as infecções corresponderam a $66 \%$ das causas de mortalidade em clínica de diálise em São Paulo, Brasil.

Nota-se que os dados sobre morbimortalidade em doentes renais crônicos são ainda muito restritos à população em diálise. De fato, a falência renal tratada com diálise ou transplante é o desfecho da doença renal crônica com maior visibilidade. Entretanto, as doenças cardiovasculares estão frequentemente associadas à doença renal crônica, o que é de grande relevância quando se assume que os doentes renais crônicos são mais propensos a morrer de doença cardiovascular que a evoluir para a falência renal $^{58}$.

O modelo conceitual proposto pela NKF-KDOQI em 2002 e revisado pela KDIGO, em 2005, representa o continuum de desenvolvimento, progressão e complicações da doença renal crônica. Ele tem sido utilizado pelo Center of Diseases Control and Prevention dos Estados Unidos para desenvolvimento de vigilância e estratégias em saúde pública ${ }^{71}$.

No Brasil, o Plano de Reorganização da Atenção à Hipertensão Arterial e ao Diabetes Mellitus (HIPERDIA) é a principal abordagem para prevenção das complicações das doenças crônicas não transmissíveis do Sistema Único de Saúde (SUS) ${ }^{72}{ }^{73}$. Considerando-se que a hipertensão arterial e o diabetes melito correspondem a cerca de $60 \%$ das causas de falência renal tratada por diálise no Brasil, esperar-se-ia a identificação e o monitoramento da doença renal crônica nesta população. Entretanto, o percentual de indivíduos cadastrados no HIPERDIA corresponde a menos da metade da estimativa da população-alvo ${ }^{74}$. Desta forma, pouco se sabe sobre a prevalência, a morbidade e a mortalidade da doença renal crônica no Brasil. 
Natália Alencar de Pinho

\subsection{AVALIAÇÃO DA TAXA DE FILTRAÇÃO GLOMERULAR}

A taxa de filtração glomerular pode ser aferida utilizando-se marcadores de origem endógena ou exógena ${ }^{75}$. No primeiro caso, avalia-se a capacidade de filtração dos rins através da depuração de creatinina. O chamado clearance de creatinina considera a taxa de filtração glomerular igual ao produto da concentração urinária de creatinina com o volume urinário em 24 horas dividido pela concentração plasmática de creatinina. Para a obtenção das variáveis da fórmula, realiza-se a dosagem da creatinina em uma amostra de sangue e em uma de urina coletada em 24 horas. Contudo, muitos fatores contribuem para que o clearance de creatinina não constitua uma medida fidedigna da taxa de filtração glomerular. A excreção de creatinina pelos rins é resultado, além da filtração glomerular, da secreção variável e imprevisível desta substância pelos túbulos renais, a qual está associada a características individuais como idade, gênero, etnia, massa muscular e dieta. Relata-se, ainda, dificuldade por parte do paciente na realização da coleta de urina de 24 horas, seja pela alteração nos hábitos cotidianos no que concerne à ingestão hídrica ou de medicamentos que alteram a secreção tubular de creatinina na ocasião da coleta, seja pela incompreensão das orientações para a coleta minutada ${ }^{76}$.

Os marcadores exógenos utilizados para aferição da taxa de filtração glomerular incluem a inulina, o l-iotalamato, o 51 Cr-EDTA, o 99 Tc-DTPA e o ioexol. A depuração destas substâncias determina a mensuração da taxa de filtração glomerular mais acurada do que aquela da creatinina, pois estas não são secretadas ou reabsorvidas pelos túbulos renais. Entretanto, os marcadores exógenos são menos disponíveis nas instituições de saúde e implicam em maior custo da avaliação ${ }^{75}$.

A medida da creatinina sérica tem sido largamente utilizada na identificação da doença renal crônica, uma vez que constitui um 
Natália Alencar de Pinho

teste relativamente barato e comum na prática clínica ${ }^{78}$. No entanto, é importante considerar que o valor da creatinina no sangue sofre influência da massa muscular e ingestão proteica, apresentando grande variação entre os indivíduos ${ }^{76}$. Os métodos de ensaios clínicos também influenciam os valores de creatinina sérica. ${ }^{79}$ Além disso, os valores de creatinemia constituem um instrumento tardio e pouco dinâmico para a avaliação da função renal: a elevação da creatinina sérica acima dos valores referendados $(0,5$ a 1,3 mg/dL ) corresponde à perda de mais de $50 \%$ da função glomerular ${ }^{2}$.

A estimativa da taxa de filtração glomerular, a partir de equações que utilizam o valor de creatinina sérica, pode ser útil como ferramenta de triagem para doença renal crônica ${ }^{12}$. O emprego conjunto de variáveis antropométricas e demográficas, as quais influenciam substancialmente a produção de creatinina, permite maior aproximação dos valores reais de filtração glomerular sem o aumento do custo da avaliação. As equações mais utilizadas são a de Cockroft-Gault e a Modification of Diet in Renal Disease (MDRD).

A equação Cockroft-Gault foi desenvolvida na década de 1970 e baseou-se na análise de 249 ensaios pareados de clearance de creatinina, sendo a amostra constituída exclusivamente por homens. A observação pelos pesquisadores da regressão linear derivada da relação entre as variáveis creatinina sérica, idade e peso motivou-os a traduzi-la em uma equação. Um fator de correção para o gênero também foi proposto pelos autores ${ }^{80}$. Seu uso para avaliação da função renal em adultos é recomendado pelas diretrizes do KDOQI. As diretrizes da Sociedade Brasileira de Nefrologia chamam a atenção para a necessidade de ajuste da equação Cockroft-Gault para uma superfície corporal de 1,73 m² ${ }^{81}$.

A equação MDRD foi desenvolvida por Levey et $a^{82}$ a partir de um estudo tranversal com 1.628 doentes renais crônicos incluídos no estudo Modification of Diet in Renal Disease, o qual deu origem à equação MDRD com seis variáveis (MDRD6), a saber, 
Natália Alencar de Pinho

creatinina sérica, idade, sexo, raça, ureia sérica e albumina sérica. Em 2000, após nova análise das variáveis desta mesma população, Levey et $a^{\beta 3}$ publicaram versões abreviadas da equação MDRD, com cinco e quatro variáveis (MDRD5 e MDRD4), as quais utilizam idade, sexo, raça, creatinina sérica e, na fórmula MDRD5, também a ureia sérica para o cálculo da filtração glomerular. Uma nova abordagem destes dados resultou em uma re-expressão das equações MDRD4 e MDRD6, agora com o objetivo de adequá-la à padronização dos ensaios para a determinação da creatinina sérica, conforme o método de diluição isotópica e espectrometria de massa $(\text { IDMS })^{84}$.

Segundo a conferência promovida pela KDIGO em 2004, as equações de estimativa da filtração glomerular devem apresentar as seguintes características: terem sido desenvolvidas em grande coorte, com inclusão de vários grupos raciais e étnicos, para comparações internacionais; possuírem adequada precisão e baixo viés, em comparação a um padrão-ouro de mensuração de taxa de filtração glomerular; e serem práticas para uso clínico, considerando seu custo, variáveis requeridas pela fórmula, generalização, calibração e confiabilidade ${ }^{75}$.

A equação MDRD abreviada (MDRD4) é considerada útil na prática clínica pelas diretrizes do $\mathrm{KDQOI}^{79}$, justamente por obedecer à maior parte destes critérios: a equação foi desenvolvida mediante mensuração da taxa de filtração glomerular pelo clearance de Iiotalamato; larga amostra foi utilizada na elaboração da fórmula; houve inclusão de participantes de etnias branca e negra; e a validação foi realizada separadamente, a partir de um grande grupo de indivíduos, como parte de seu desenvolvimento. Para seu uso, as diretrizes da Sociedade Brasileira de Nefrologia ${ }^{81}$ recomendam a calibração do ensaio da creatinina segundo o método IDMS e o ajuste da equação MDRD para o referido método, com o objetivo de aumentar a precisão da estimativa e a comparabilidade dos 
Natália Alencar de Pinho

resultados.

A equação Cockroft-Gault seria de emprego mais difícil em laboratórios clínicos, pois tem como variável o peso do paciente e, no caso de ajuste para a superfície corporal de 1,73 $\mathrm{m}^{2}$, requer ainda a altura. Além disso, sua calibração de creatinina sérica é incerta. Tanto a equação Cockroft-Gault quanto a MDRD são imprecisas em taxas de filtração glomerular mais altas, o que pode levar a erro de classificação em determinadas populações como em indivíduos sem problema renal, crianças e gestantes. Indica-se a medida da depuração da creatinina em 24 horas ao uso das fórmulas de estimativa de filtração glomerular nas seguintes condições: pacientes com grosseira anormalidade da massa muscular, como nos casos de amputação, paralisias, doenças musculares; baixo índice de massa corporal (abaixo de $18,5 \mathrm{~kg} / \mathrm{m}^{2}$ ); alta ou baixa ingestão de creatinina ou creatina; rápidas alterações da função renal; e gravidez ${ }^{75}$

Recentemente, uma nova fórmula para a estimativa da taxa de filtração glomerular foi desenvolvida: a Chronic Kidney Disease Epidemiology Collaboration (CKD-EPI). A justificativa dos pesquisadores para a elaboração desta nova equação baseou-se nas limitações de acurácia da fórmula MDRD em indivíduos com função renal preservada, uma vez que esta é imprecisa e subestima as taxas de filtração glomerular maiores. Foram incluídos 8.254 participantes, para o desenvolvimento da equação, e 3.896, para sua validação, todos provenientes de trabalhos nos quais o clearance de marcadores de filtração exógenos foi acessado. As variáveis da nova equação incluem a creatinina sérica, o gênero, a raça e a idade, assim como na MDRD4. Na amostra de validação, a CKD-EPI mostrou melhor desempenho em relação à MDRD4, especialmente na vigência de taxas de filtração glomerular mais elevadas, sendo a acurácia dentro de $30 \%$ do valor de taxa de filtração glomerular mensurada de $84,1 \%$ para a CKD-EPI contra $80,6 \%$ da MDRD4. 
Natália Alencar de Pinho

Realizou-se ainda a verificação da prevalência da doença renal crônica em amostra representativa da população norte-americana, a partir dos dados compreendidos entre 1999 e 2006 do National Health and Nutrition Examination Survey (NHANES). A prevalência obtida mediante uso da fórmula CKD-EPI foi inferior àquela resultante do uso da MDRD4: $11,5 \%$ e $13,1 \%$, respectivamente ${ }^{85}$.

Muitos estudos foram conduzidos com o objetivo de comparar as equações de estimativa da filtração glomerular entre si e em relação aos métodos de referência de avaliação da função renal.

Estudo de Lin et $a^{\beta 6}$, que comparou diversas equações de estimativa da taxa de filtração glomerular em indivíduos sem doença renal crônica, entre elas MDRD6, MDRD4 e Cockroft-Gault, verificou que as fórmulas MDRD apresentaram melhor predição da taxa de filtração glomerular quando o clearance do I-iotalamato foi utilizado como método de referência em relação ao clearance de Tc-DTPA (acurácia dentro de $30 \%$ de $78 \%$ e $49 \%$, respectivamente, para a fórmula MDRD4). A fórmula Cockroft-Gault, por sua vez, apresentou melhor acurácia com o Tc-DTPA como método de referência, 73\%, quando comparado ao método de I-iotalamato, 45\%.

Utilizando o ioexol como método de referência para comparação das equações de estimativa da taxa de filtração glomerular em indivíduos com doença renal crônica e valores de creatinina sérica inferiores a $1,5 \mathrm{mg} / \mathrm{dL}$, Bostom et $a^{\beta 7}$ identificaram melhor precisão das fórmulas MDRD6 e MDRD4 em comparação à Cockroft-Gault $(0,31,0,29$ e 0,17, respectivamente). A acurácia dentro de $30 \%$ foi mais elevada para a fórmula Cockroft-Gault, entretanto, esta se apresentou aquém dos valores considerados ideais para uso na prática clínica (50\% para Cockroft-Gault, 24\% para MDRD6 e 28\% para MDRD4).

$\mathrm{Na}$ comparação da estimativa da taxa de filtração glomerular pelas equações Cockroft-Gault, MDRD4 e CKD-EPI com o padrãoouro i-iotalamato, a tendência geral de viés foi significativamente 
Natália Alencar de Pinho

inferior para a MDRD4 (0,8 (MDRD4) vs 9,9 (Cockroft-Gault) vs 4,5 (CKD-EPI), $p \leq 0,01)$. Já a acurácia dentro de $30 \%$ para a CKD-EPI foi superior ( $p<0,01)$ em relação a Cockroft-Gault $(84,5 \%$ vs 74,2$)$, porém não diferiu daquela apresentada pela MDRD4 $(81,2 \%){ }^{88}$

Estudo comparativo das equações MDRD4, rastreável pelo método IDMS, e CKD-EPI em relação ao clearance de 51Cr-EDTA, conduzido no sul do Brasil com adultos sem doença renal crônica, identificou coeficientes de correlação fracos entre as taxas de filtração glomerular mensuradas e estimadas: $r=0,26$ e $r=0,37$ para as equações MDRD e CKD-EPI, respectivamente $(p<0,05)$. A equação CKD-EPI demonstrou melhor desempenho do que a MDRD, com menor viés (10 vs 18, respectivamente) e maior acurácia dentro de $30 \%$ (85\% vs $69 \%$, respectivamente $)^{89}$.

A utilização das equações de estimativa da taxa de filtração glomerular baseadas na creatinina sérica apresenta limitações. As equações foram desenvolvidas para o balanço de creatinina estável e, consequentemente, as estimativas não são acuradas em pacientes com rápidas mudanças na filtração glomerular. Além disso, por terem como referência indivíduos de massa muscular relativamente típica para uma dada idade, sexo e raça, as equações superestimam a taxa de filtração glomerular em pessoas com maior perda muscular, como naquelas amputadas, paralíticas ou caquéticas $^{75}$. Uma alternativa ao uso da creatinina sérica em equações seria a cistatina $C$ sérica; contudo, sua aferição ainda é pouco disponível na prática clínica no Brasil $^{77}$ 90. Como outros resultados laboratoriais, incluindo a simples mensuração da creatinina, a estimativa da taxa de filtração glomerular deve ser interpretada dentro de maior contexto clínico ${ }^{7}$.

\subsection{JUSTIFICATIVA DO ESTUDO}

Durante minha atuação como enfermeira em hemodiálise, me 
Natália Alencar de Pinho

confrontei com 0 fato de que muitos dos pacientes eram encaminhados à terapia renal substitutiva sem qualquer conhecimento prévio de sua doença renal. Além disso, a carga de doenças cardiovasculares era de grande relevância na resposta destes indivíduos ao processo de saúde e tratamento, com qualidade de vida comprometida e número importante de complicações intradialíticas. Tais observações suscitaram interrogações sobre os fatores relacionados à doença renal crônica nos seus diferentes estágios e que contribuiriam para a morbimortalidade destes indivíduos em nosso meio.

A enfermagem tem papel preponderante nos diversos níveis de prevenção das doenças crônicas. Este grupo profissional constitui o maior contingente de força de trabalho em saúde, além de ser amplamente distribuído nos serviços de promoção à saúde, prevenção de doenças, tratamento de afecções crônicas e agudas, reabilitação e cuidados paliativos ${ }^{91}$. O conhecimento dos fatores relacionados à doença renal crônica poderia representar grande contribuição para o cuidado de indivíduos e comunidades em todos os níveis da assistência. No contexto hospitalar, a identificação dos fatores relacionados à doença renal crônica poderia concorrer para a melhor referência e contrarreferência destes indivíduos, favorecendo a continuidade de cuidado após a alta.

Os temas abordados nesta introdução põem em evidência a magnitude da doença renal crônica e as lacunas de conhecimento sobre suas características nos diversos estágios da doença. Frente a esta problemática, se propôs com o presente estudo identificar os fatores associados à doença renal crônica em indivíduos que passaram por processo de hospitalização em um hospital universitário. Sugere-se, ainda, a investigação do perfil da taxa de filtração glomerular de pacientes sem doença renal crônica e sua relação com dados biossociais e de morbidade. 


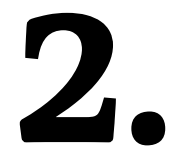

Objetivos 


\section{OBJETIVOS}

\subsection{GERAL}

Identificar os fatores associados à doença renal crônica em pacientes admitidos na enfermaria de uma clínica médica de um hospital universitário.

\subsection{ESPECÍFICOS}

1. Comparar os pacientes com e sem doença renal crônica segundo dados biossociais, clínicos e diagnósticos de enfermagem durante a hospitalização.

2. Comparar os pacientes hipertensos com e sem doença renal crônica segundo dados biossociais e de tratamento para hipertensão arterial.

3. Estimar a taxa de filtração glomerular a partir das equações Modification of Diet in Renal Disease versão simplificada (MDRD4) e Chronic Kidney Disease Epidemiology Collaboration (CKD-EPI) de pacientes sem doença renal crônica. 


\section{3. \\ Casuística e Método}




\section{CASUÍSTICA E MÉTODO}

\subsection{DELINEAMENTO DO ESTUDO}

Trata-se de um estudo transversal, retrospectivo, descritivo e de abordagem quantitativa.

O projeto foi aprovado pelo comitê de ética em pesquisa do Hospital Universitário da Universidade de São Paulo sob o número de 1103/11.

\subsection{POPULAÇÃO E LOCAL DO ESTUDO}

A população de referência para o estudo correspondeu aos indivíduos adultos que foram admitidos na enfermaria de clínica médica do hospital no período de $1^{\circ}$ de janeiro a 31 de dezembro de 2009. A clínica médica é geral e recebe principalmente os pacientes oriundos do pronto socorro ou transferidos de outras unidades do hospital, como as terapias Intensiva e semi Intensiva.

O hospital universitário, onde foram coletados os dados, se situa na zona oeste de São Paulo. Está instalado em uma área de $36.000 \mathrm{~m}^{2}$ e conta com 258 leitos, sendo 41 deles destinados à enfermaria de clínica médica. Este hospital iniciou suas atividades em 1968, com a missão de desempenhar atividades na área de ensino e pesquisa, na área da saúde, e prestar assistência hospitalar de média complexidade às populações do Distrito de Saúde do Butantã e da comunidade universitária, esta última constituída por seus docentes, discentes e servidores ${ }^{92}$. A área geográfica correspondente ao Distrito de Saúde do Butantã, com 428.217 habitantes em 2010 , é a $10^{\underline{a}}$ em população em relação às demais 31 subprefeituras ${ }^{93}$. 
Natália Alencar de Pinho

Em 2009, foram realizadas 11.321 admissões hospitalares, a taxa de ocupação foi de $78,0 \%$, o tempo médio de permanência foi de 5,7 dias e a taxa de mortalidade, 2,8\% (conforme informações publicadas no website do hospital em acesso em 16 de outubro de 2010).

Segundo o registro de internações ocorridas, 1.422 pacientes estiveram internados na enfermaria de clínica médica em 2009. A amostra para este estudo foi calculada considerando-se a estimativa da prevalência de doença renal de $13 \%$, variação de $5 \%, 5 \%$ de erro tipo I e $80 \%$ de poder do teste. Sob estes parâmetros, o tamanho da amostra ficou em 387 indivíduos.

\subsection{CONSTITUIÇÃO AMOSTRAL}

A lista de pacientes hospitalizados em enfermaria de clínica médica no período de $1^{\circ}$. de janeiro a 31 de dezembro de 2009 foi obtida por meio de relatório em formato Excel emitido pelo Serviço de Arquivo e Estatística Médica do hospital no qual foi realizado o estudo. O sorteio dos indivíduos foi realizado mediante ferramenta de aleatorização disponível neste mesmo programa.

A constituição amostral compreendeu duas fases. $\mathrm{Na}$ primeira, 400 indivíduos foram selecionados, de forma aleatória, a partir da lista de pacientes hospitalizados na clínica médica em 2009, e 206 foram considerados elegíveis. Para reposição das exclusões, foi selecionado o próximo indivíduo elegível da lista de pacientes para cada respectiva exclusão. Dados de 426 indivíduos foram verificados, sendo que 194 deles foram incluídos na amostra. Durante o processo de coleta de dados, 18 prontuários não foram encontrados. 


\subsubsection{Definição de doença renal crônica}

A doença renal crônica foi definida pela presença de diagnóstico médico ou antecedente pessoal registrado em prontuário no período de internação estudado.

\subsubsection{Critérios de inclusão}

- Ser adulto com idade igual ou superior a 18 anos

- Ter sido hospitalizado em enfermaria de clínica médica

- Apresentar pelo menos dois valores de creatinina sérica aferidos no período de hospitalização avaliado

\subsubsection{Critérios de exclusão}

- Gestantes

- Tempo de internação em enfermaria de clínica médica inferior a 24 horas

- Pacientes sem diagnóstico médico de doença renal crônica que evoluíram com insuficiência renal aguda segundo diagnóstico médico

- Pacientes sem diagnóstico médico de doença renal crônica que apresentaram variação da creatinina sérica igual ou superior a $0,3 \mathrm{mg} / \mathrm{dL}$ ou igual ou superior a $50 \%$ durante a internação

O critério de exclusão acima descrito, inspirado no critério de creatinina sérica para classificação da lesão renal aguda proposto pelo Acute Kidney Injury Network $(\mathrm{AKIN})^{94}$, foi adotado porque a utilização da creatinina sérica como variável de exposição (doença renal crônica) e de desfecho (lesão renal aguda) limita a habilidade em diferenciar o caráter agudo ou crônico da lesão ${ }^{95}$, sobretudo em 
Natália Alencar de Pinho

pacientes hospitalizados, nos quais se desconhece o valor de creatinina sérica de base. Além disso, a distinção entre lesão renal aguda e doença renal crônica pode ser artificial, na medida em que a associação entre as duas tem sido identificada por diversos estudos e os critérios para definição de doença renal crônica "agudizada" não estejam claramente estabelecidos ${ }^{96} 9798$. Considerando-se que tais argumentos possam dificultar o diagnóstico de doença renal crônica em indivíduos com lesão renal aguda no contexto hospitalar, se optou pela exclusão de pacientes sem diagnóstico médico de doença renal crônica nos quais alterações agudas da função renal foram identificadas, a fim de diminuir a possível interferência na associação com as variáveis do estudo.

Frente à elevada frequência de pacientes com doença renal crônica que apresentaram variação de creatinina sérica durante a hospitalização (Fluxograma 1), optou-se pela avaliação da taxa de filtração glomerular exclusivamente em pacientes sem doença renal crônica. As equações para estimativa da filtração glomerular foram desenvolvidas para utilização em pacientes com balanço de creatinina estável e, consequentemente, seus resultados podem ser menos acurados em pacientes com rápidas mudanças na filtração glomerular, como naqueles com lesão renal aguda ${ }^{99}$.

Para a determinação da variação de creatinina sérica, foi realizado o seguinte procedimento: 1) determinou-se o valor de creatinina sérica de referência, a partir da média dos menores valores obtidos durante a hospitalização e que não apresentassem diferença igual ou superior a $0,3 \mathrm{mg} / \mathrm{dL}$ ou a $50 \%$ entre si; 2) identificou-se o maior valor de creatinina sérica obtido durante a hospitalização; e 3) subtraiu-se o valor de creatinina sérica de referência do maior valor obtido durante a hospitalização. Após discussão com nefrologistas, decidiu-se adotar tal procedimento, pois o valor de creatinina sérica de base dos indivíduos não era conhecido e pequenas oscilações poderiam ser comuns. Tal 
procedimento dispensava utilização de métodos estatísticos avançados, fato que colaborou na sua utilização durante a coleta de dados.

Fluxograma 1 - Constituição amostral.

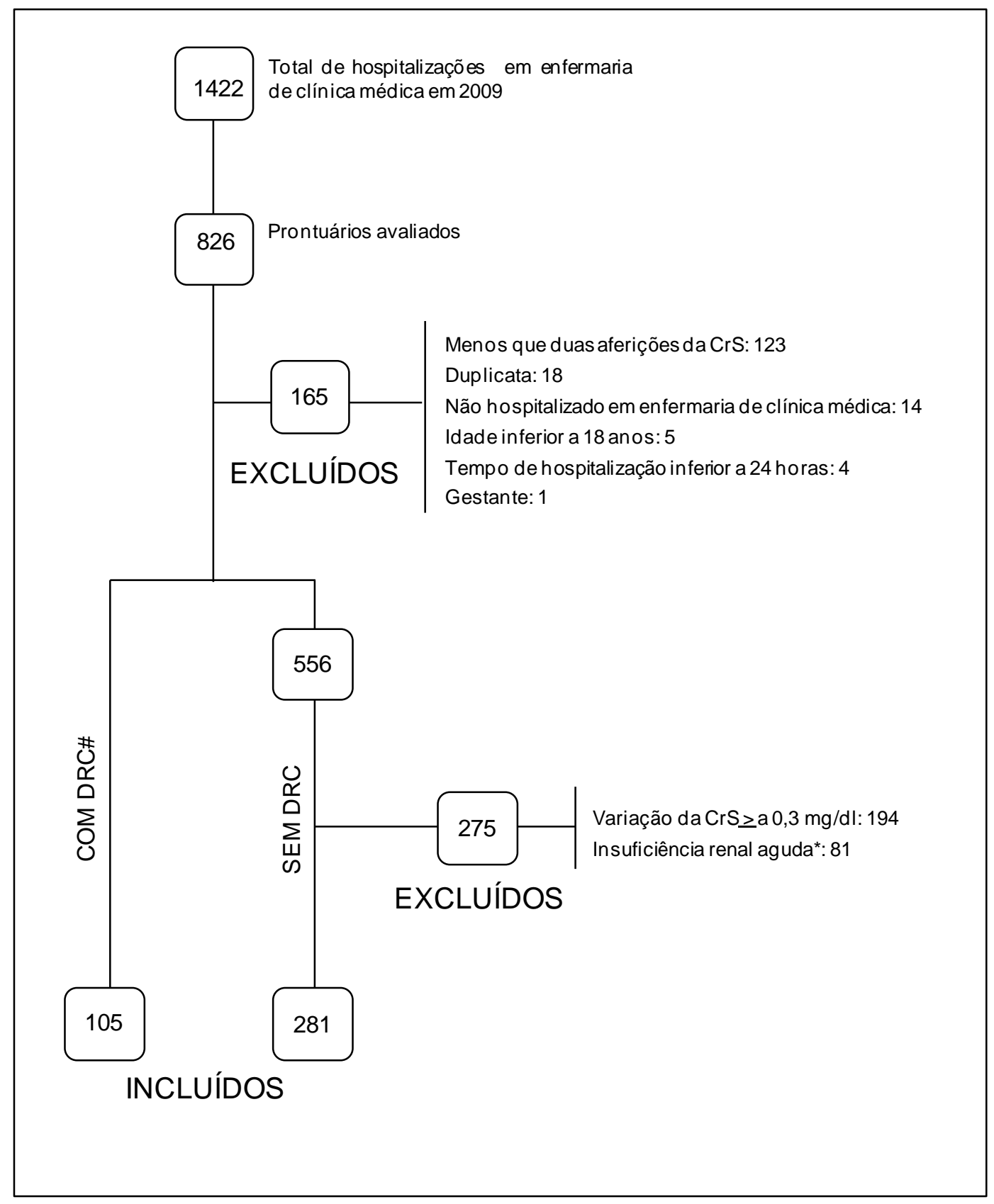

Siglas: DRC, doença renal crônica; CrS, creatinina sérica.

\# Onze pacientes apresentaram creatinina estável durante a hospitalização; 47, variação da creatinina sérica igual ou superior a $0,3 \mathrm{mg} / \mathrm{dL}$ ou a $50 \% ; 20$, insuficiência renal crônica agudizada; e 27 , insuficiência renal crônica terminal tratada por diálise.

* Segundo diagnóstico médico. 
Natália Alencar de Pinho

Após a primeira etapa de exclusão, foram identificados 105 indivíduos com doença renal crônica, perfazendo a prevalência de 15,9\%. Destes, 10,5\% apresentaram creatinina sérica estável segundo os critérios de seleção, 44,8\% variação de creatinina igual ou superior a $0,3 \mathrm{mg} / \mathrm{dL}$ ou a $50 \%, 19 \%$ diagnóstico e insuficiência renal crônica agudizada e $25,7 \%$ doença renal crônica terminal dialítica.

Entre os indivíduos sem doença renal crônica, 34,9\% apresentaram variação de creatinina igual ou superior a $0,3 \mathrm{mg} / \mathrm{dL}$ ou a $50 \%$ e $14,6 \%$ diagnóstico de insuficiência renal aguda, os quais foram excluídos da amostra. Desta forma, 281 indivíduos sem doença renal crônica atenderam os critérios de inclusão para este grupo.

\subsection{OPERACIONALIZAÇÃO DA COLETA DE DADOS}

Para cada paciente incluso no estudo, foram coletadas 31 variáveis, mediante uso de instrumento desenvolvido para este fim (Apêndice 1). Os dados foram obtidos a partir do prontuário médico em papel e do registro informatizado de exames laboratoriais (Sistema de Apoio Diagnóstico e Terapêutico).

\subsubsection{Variáveis de identificação}

Desejou-se, com estas variáveis, descrever a amostra do ponto de vista biossocial. As variáveis foram coletadas conforme os itens descritos a seguir.

- Idade - em anos completos, no momento da admissão hospitalar. Variável calculada a partir da data de nascimento de cada indivíduo. 
- Sexo - variável binária definida como "masculino" ou "feminino".

- Etnia - conjunto morfológico que designa cor da pele e constituição física, definida como "branca", "negra", "amarela", "parda" e "mulata".

- Estado civil - situação em relação ao matrimônio ou sociedade conjugal, definida por "com companheiro" para indivíduos casados e amasiados; e por "sem companheiro" para indivíduos solteiros, separados, divorciados e viúvos.

- Ocupação - situação empregatícia na ocasião de internação hospitalar, definida por "trabalhador ativo", para indivíduos cujo registro indicou exercício de atividade remunerada, e "dona de casa", "desempregado", "estudante" e "aposentado", conforme registro em prontuário.

- Profissão - atividade econômica desempenhada anteriormente ou na época da internação hospitalar.

\subsubsection{Variáveis antropométricas e de pressão arterial}

A partir das variáveis antropométricas e de pressão arterial, se buscou identificar o índice de massa corporal e as alterações da pressão arterial durante a hospitalização.

- Peso - definido em quilogramas, aferido durante a internação; foi considerado o primeiro valor registrado.

- Altura - definida em metros, aferida durante a internação; foi considerado o primeiro valor registrado.

- Pressão arterial: definida em milímetros de mercúrio, aferida durante a internação. Foi considerado o primeiro registro em prontuário da manhã de cada dia, os demais valores sendo descartados. Valores de pressão arterial sistólica inferiores a $130 \mathrm{mmHg}$ e de diastólica inferiores a 
$80 \mathrm{mmHg}$ foram considerados como controle da hipertensão arterial em pacientes com doença renal crônica. Valores inferiores a 140 e 90 mmHg para pressão arterial sistólica e diastólica, respectivamente, foram adotados como critério de controle para os sem doença renal crônica ${ }^{34}$.

O índice de massa corporal foi calculado como peso/altura ${ }^{2}$, sendo o peso definido em quilogramas e a altura em metros ${ }^{100}$.

\subsubsection{Variáveis de diagnóstico}

As variáveis da categoria de diagnóstico visaram à identificação das doenças que motivaram ou contribuiram para a hospitalização, as demandas de cuidados de enfermagem e a presença de doença renal crônica ou aguda.

- Diagnósticos médicos - registrados na última evolução médica da internação.

- Diagnósticos de enfermagem - registrados em evolução de enfermagem referente à admissão e à alta hospitalar segundo taxonomia da North American Nursing Diagnosis Association (NANDA).

\subsubsection{Variáveis de antecedentes pessoais}

Estas variáveis tiveram como objetivo complementar as características clínicas dos pacientes e oferecer dados sobre comorbidades e hábitos associados ao desenvolvimento da doença renal crônica e de doenças cardiovasculares.

- Tabagismo - história prévia ou atual de consumo regular de tabaco, registrada em histórico de enfermagem, 
anamnese médica ou diagnóstico médico.

- Etilismo - segundo diagnóstico médico registrado em última evolução médica da internação.

- Antecedentes pessoais - história prévia ou atual de doenças, registrada em histórico de enfermagem, anamenese médica ou diagnóstico médico.

- Antecedentes familiares - história prévia ou atual de doença renal crônica, hipertensão arterial ou diabetes melito na família, registrada em histórico de enfermagem, anamenese médica ou diagnóstico médico.

- Acompanhamento em saúde - seguimento regular em instituições referidas pelo paciente para a prevenção ou o tratamento em saúde, registrado em histórico de enfermagem ou anamenese médica.

- Medicamentos de uso contínuo - medicamentos utilizados regularmente com ou sem indicação médica, registrados em histórico de enfermagem ou anamenese médica.

\subsubsection{Variáveis de exames laboratoriais}

Estas variáveis foram avaliadas para complementação das características clínicas do paciente. A creatinina sérica foi utilizada para a seleção da amostra e para a estimativa da taxa de filtração glomerular em indivíduos sem doença renal crônica. A metodologia do exame e os valores de referência adotados foram aqueles descritos no Sistema de Apoio Diagnóstico e Terapêutico.

- Ureia sérica - metodologia "urease automatizado", valores de referência entre 10 a $50 \mathrm{mg} / \mathrm{dL}$. A medida avaliada corresponde ao primeiro valor obtido durante a internação.

- Potássio sérico - metodologia "ISE", valores de referência entre 3,5 e 5,0 mEq/l. A medida avaliada corresponde ao primeiro valor obtido durante a internação. 
- Fósforo sérico - metodologia "fosfomolibdato automatizado", valores de referência entre 2,5 e 4,8 $\mathrm{mg} / \mathrm{dL}$. A medida avaliada corresponde ao primeiro valor obtido durante a internação.

- Ácido úrico - metodologia "uricase automatizado", valores de referência entre 3,5 e $7,2 \mathrm{mg} / \mathrm{dL}$, para homens, e entre 2,6 e 6,0 mg/dL, para mulheres. A medida avaliada corresponde ao primeiro valor obtido durante a internação.

- Albumina sérica - metodologia "VBC automatizado", valores de referência entre 3,0 e $5,0 \mathrm{~g} / \mathrm{dL}$. A medida avaliada corresponde ao primeiro valor obtido durante a internação.

- Hemoglobina - metodologia "automatizada", valores de referência entre 14,0 e 17,4 g/dL, para homens, e entre 12,3 e 15,3 g/dL, para mulheres. A medida avaliada corresponde ao primeiro valor obtido durante a internação.

- Hematócrito - metodologia "automatizada", valores de referência entre 41,5 e 50,4\%, para homens, e entre 36 e $45 \%$ para mulheres. A medida avaliada corresponde ao primeiro valor obtido durante a internação.

- Colesterol total (soro) - metodologia "colesterol oxidase automatizado", valores de referência:

- Desejável: inferiores a $200 \mathrm{mg} / \mathrm{dL}$

- Limítrofe: entre 200 e 239 mg/dL

- Aumentado: iguais ou superiores a $240 \mathrm{mg} / \mathrm{dL}$

A medida avaliada corresponde ao primeiro valor obtido durante a internação.

- High-density lipoprotein (HDL) - metodologia "direto automatizado", valores de referência:

- Superiores a $40 \mathrm{mg} / \mathrm{dL}$ para pacientes não-diabéticos

- Superiores a $45 \mathrm{mg} / \mathrm{dL}$ para pacientes diabéticos.

A medida avaliada corresponde ao primeiro valor obtido 
Natália Alencar de Pinho

durante a internação.

- Low-desity lipoprotein (LDL) - metodologia "cálculo de Friedewald", valores de referência:

- Inferiores a $100 \mathrm{mg} / \mathrm{dL}$ para pacientes de alto risco

- Inferiores a $130 \mathrm{mg} / \mathrm{dL}$ para pacientes de médio risco

o Inferiores a $160 \mathrm{mg} / \mathrm{dL}$ para pacientes de baixo risco

A medida avaliada corresponde ao primeiro valor obtido durante a internação.

- Triglicérides - metodologia "glicerol peroxidase automatizado", valores de referência inferiores a 150 $\mathrm{mg} / \mathrm{dL}$. A medida avaliada corresponde ao primeiro valor obtido durante a internação.

- Glicemia - metodologia "hexoquinase automatizado", valores de referência entre 70 e $99 \mathrm{mg} / \mathrm{dL}$, para pacientes em jejum, e entre 70 e $140 \mathrm{mg} / \mathrm{dL}$, para medida aleatória. A medida avaliada corresponde ao primeiro valor obtido durante a internação.

- Proteinúria: metodologia "vermelho pirogalol automatizado"; valores de referência para amostra isolada inferiores a $15 \mathrm{mg} / \mathrm{dL}$.

- Creatinina sérica - metodologia "picrato alcalino automatizado", valores de referência entre 0,4 e 1,3 $\mathrm{mg} / \mathrm{dL}$. Foi considerado o primeiro valor disponível para cada dia de internação.

O ensaio para aferição da creatinina sérica foi realizado pelo sistema CREA ADVIA® 1650 (Siemens Healthcare Diagnostics Inc.), rastreável de acordo com o método de cromatografia líquida de alta pressão, utilizando materiais de referência do National Institute of Standards and Technology (NIST). A estimativa da taxa de filtração glomerular pela equação MDRD4 é apresentada juntamente aos valores de creatinina sérica na emissão dos resultados pelo Sistema de Apoio Diagnóstico e Terapêutico do hospital no qual foi realizado 
Natália Alencar de Pinho

o presente estudo.

\subsubsection{Variáveis de desfecho}

As variáveis de desfecho visaram identificar características da internação no que concerne à sua duração, à submissão ao tratamento dialítico, à mortalidade intra-hospitalar e ao seguimento pós-alta.

- Tempo de internação - tempo total de internação desde a admissão hospitalar até seu desfecho.

- Unidades de internação - no caso de permanência em outra unidade de internação dentro do hospital no qual foi realizado o estudo, além da enfermaria de clínica médica.

- Diálise - realização de terapia renal substitutiva durante a hospitalização, definida pela modalidade peritoneal ou hemodialítica.

- Desfecho - último evento do seguimento clínico do paciente na internação, admitindo-se como possibilidades: a transferência para outro serviço hospitalar, a alta hospitalar, o óbito e a perda do seguimento.

- Encaminhamento/seguimento - relato médico de encaminhamento para serviço de saúde de nível primário após alta hospitalar obtido em resumo de alta.

\subsection{AVALIAÇÃO DA FUNÇÃO RENAL}

A avaliação da função renal foi realizada para indivíduos sem diagnóstico médico de doença renal crônica, mediante uso das equações MDRD4 e CKD-EPI. O fator de correção para afrodescendentes foi empregado para indivíduos negros e pardos. $\mathrm{O}$ valor de creatinina sérica utilizado no cálculo foi o resultado da mediana do conjunto de valores obtidos durante a internação para 
cada indivíduo. A classificação da função renal foi realizada da seguinte forma:

- Taxa de filtração glomerular estimada igual ou superior a $90 \mathrm{~mL} / \mathrm{min} / 1,73 \mathrm{~m}^{2}$

- Taxa de filtração glomerular estimada compreendida entre 89 e $60 \mathrm{~mL} / \mathrm{min} / 1,73 \mathrm{~m}^{2}$

- Taxa de filtração glomerular estimada inferior a 60 $\mathrm{mL} / \mathrm{min} / 1,73 \mathrm{~m}^{2}$

\subsubsection{Equação Modification of Diet in Renal Disease abreviada (MDRD4)}

Taxa de filtração glomerular MDRD4 (não-rastreável pelo método IDMS $)=186 \times(\text { creatinina sérica })^{-1,154} \times(\text { idade })^{-0,203} \times 0,742$ [se mulher] $x$ 1,212 [se afrodescendente], sendo a idade discriminada em anos e a creatina sérica em $\mathrm{mg} / \mathrm{dL} .^{83}$

A fórmula MDRD4 é ajustada para a superfície corporal de $1,73 \mathrm{~m}^{2}$.

\subsubsection{Equação Chronic Kidney Disease Epidemiology Collaboration}

Taxa de filtração glomerular CKD-EPI = $141 \times$ min (creatinina

sérica/ $k, 1)^{\infty} \times \max (\text { creatinina sérica/ } k, 1)^{-1,209} \times 0,993^{\text {(idade) }} \times 1,018$ [se mulher] $x$ 1,159 [se afrodescendente], sendo a idade discriminada em anos e a creatina sérica em $\mathrm{mg} / \mathrm{dL}$, min para valores de creatinina sérica iguais ou inferiores a $0,9 \mathrm{mg} / \mathrm{dL}$ em homens ou $0,7 \mathrm{mg} / \mathrm{dL}$ em mulheres, max para valores de creatinina sérica superiores a $0,9 \mathrm{mg} / \mathrm{dL}$ em homens ou $0,7 \mathrm{mg} / \mathrm{dL}$ em mulheres, $\infty$ igual a $-0,411$ para homens ou $-0,329$ para mulheres. ${ }^{8585}$

A fórmula CKD-EPI é ajustada para a superfície corporal de $1,73 \mathrm{~m}^{2}$. 
Natália Alencar de Pinho

\subsection{ANÁLISE ESTATÍSTICA}

A análise estatística foi realizada com a ajuda de um assessor estatístico, segundo descrito por Rosner ${ }^{101}$.

As variáveis classificatórias foram descritivamente apresentadas em tabelas de contingência contendo frequências absolutas (n) e relativas (\%). A associação entre elas e o grupo (doença renal crônica ou taxa de filtração glomerular estimada pela equação MDRD4) foi avaliada com o teste qui-quadrado ou o teste da razão de verossimilhança ou o teste exato de Fisher.

Utilizou-se o teste de Kolmogorov-Smirnov para avaliar a distribuição normal das variáveis quantitativas. As variáveis quantitativas foram apresentadas descritivamente em tabelas contendo média e desvio padrão, para as variáveis com distribuição normal, e teste t-Student, para comparação das médias; caso contrário, utilizou-se mediana, intervalo interquartílico (1ํ. e 3 ํ․ quartis) e teste de Mann-Whitney para comparar as distribuições.

As variáveis que apresentaram significância estatística na análise univariada (descrita anteriormente), e relatadas pela literatura como potencial fator de risco para doença renal crônica, foram utilizadas no ajuste do modelo de regressão logística múltipla.

As pressões arteriais de pacientes que apresentaram valores registrados do primeiro ao décimo dia de internação foram avaliadas com análise de variâncias para medidas repetidas.

A análise de correlação entre as taxas de filtração glomerular, estimadas pelas equações MDRD4 e CKD-EPI como variável contínua, foi realizada mediante emprego do coeficiente de correlação de postos de Spearman e da regressão linear. O coeficiente Kappa foi utilizado para descrever e testar o grau de concordância na classificação da taxa de filtração glomerular estimada pelas duas equações. 
Natália Alencar de Pinho

Os valores de $\mathrm{p}<0,05$ foram considerados estatisticamente significantes. 


\section{4. Resultados}




\section{RESULTADOS}

Os resultados são apresentados na forma de tabelas e figuras comentadas, segundo os objetivos do estudo.

Na primeira parte, são apresentados os resultados referentes às características dos indivíduos com e sem doença renal crônica, bem como as análises de regressão logística das variáveis que apresentaram significância estatística. $\mathrm{Na}$ segunda parte, são apresentados os resultados referentes aos pacientes hipertensos; e, na terceira, os relacionados à avaliação da função renal pela estimativa da taxa de filtração glomerular dos indivíduos sem doença renal crônica.

\subsection{FATORES ASSOCIADOS À DOENÇA RENAL CRÔNICA}

Tabela 1 - Características biossociais dos pacientes internados em uma clínica médica, com e sem doença renal crônica. São Paulo, 2013.

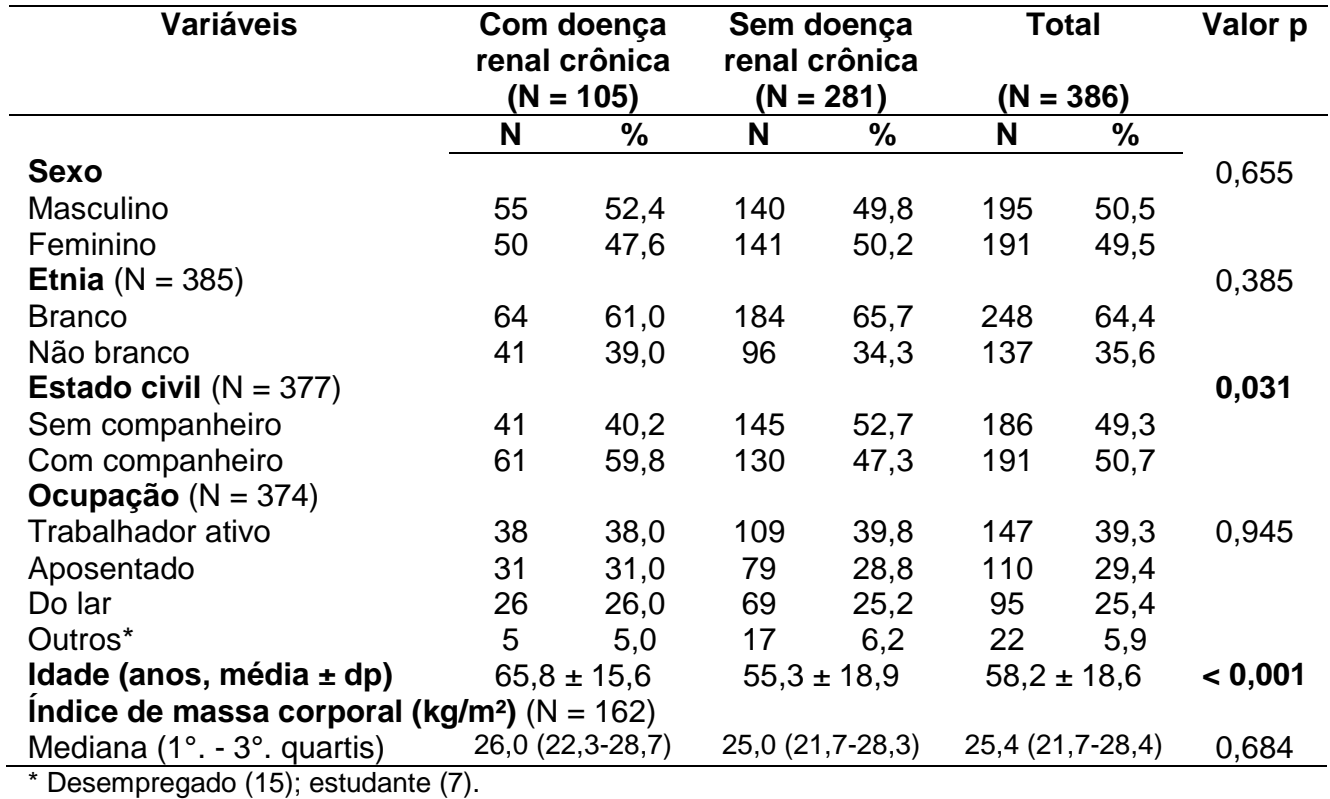


Dos 386 pacientes que compuseram a amostra, 105 (27,2\%) apresentaram doença renal crônica de acordo com os critérios adotados no presente estudo.

Os dados da Tabela 1 mostram que os pacientes com e sem doença renal crônica foram semelhantes em relação a: proporção de indivíduos do sexo masculino (50,5\%), maioria de etnia branca $(64,4 \%)$, ocupação com predomínio dos trabalhadores ativos $(39,3 \%)$ e índice de massa corporal compatível com sobrepeso $(25,4$ $\left.(21,7-28,4) \mathrm{kg} / \mathrm{m}^{2}\right)$. Foram estatisticamente significantes $(p<0,05)$ as diferenças entre os grupos para as variáveis: idade e estado civil. Os que possuíam doença renal crônica eram mais velhos (65,8 \pm 15,6 anos vs $55,3 \pm 18,9$ anos) e possuíam companheiro (59,8\% vs $47,3 \%)$.

Tabela 2 - Hábitos de vida, acompanhamento em serviço de saúde e uso contínuo de medicamentos dos pacientes internados em uma clínica médica, com e sem doença renal crônica. São Paulo, 2013.

\begin{tabular}{|c|c|c|c|c|c|c|c|}
\hline \multirow[t]{2}{*}{ Variáveis } & \multicolumn{2}{|c|}{$\begin{array}{l}\text { Com doença } \\
\text { renal crônica } \\
(N=105)\end{array}$} & \multicolumn{2}{|c|}{$\begin{array}{l}\text { Sem doença } \\
\text { renal crônica } \\
(\mathrm{N}=281)\end{array}$} & \multicolumn{2}{|c|}{$\begin{array}{c}\text { Total } \\
(\mathrm{N}=386)\end{array}$} & \multirow[t]{2}{*}{$\begin{array}{c}\text { Valor } \\
\mathbf{p}\end{array}$} \\
\hline & $\mathbf{N}$ & $\%$ & $\mathbf{N}$ & $\%$ & $\mathbf{N}$ & $\%$ & \\
\hline \multicolumn{7}{|l|}{ Tabagismo ( $\mathrm{N}=368$ ) } & \multirow[t]{4}{*}{$<0,001$} \\
\hline Sim & 11 & 11,1 & 80 & 29,7 & 91 & 24,7 & \\
\hline Parou & 43 & 43,4 & 84 & 31,2 & 127 & 34,5 & \\
\hline Não & 45 & 45,5 & 105 & 39,0 & 150 & 40,8 & \\
\hline \multicolumn{7}{|l|}{ Etilismo } & \multirow[t]{3}{*}{0,614} \\
\hline Sim & 8 & 7,6 & 26 & 9,3 & 34 & 8,8 & \\
\hline Não & 97 & 92,4 & 255 & 90,7 & 352 & 91,2 & \\
\hline \multicolumn{7}{|c|}{ Acompanhamento em serviço de saúde $(N=321)$} & \multirow[t]{9}{*}{$<0,001$} \\
\hline Ambulatório SUS & 38 & 42,2 & 67 & 29,0 & 105 & 32,7 & \\
\hline UBS & 32 & 35,6 & 55 & 23,8 & 87 & 27,1 & \\
\hline Clínica de diálise & 5 & 5,6 & 0 & 0,0 & 5 & 1,6 & \\
\hline PAD & 2 & 2,2 & 2 & 0,9 & 4 & 1,2 & \\
\hline Convênio & 0 & 0,0 & 4 & 1,7 & 4 & 1,2 & \\
\hline Ambulatório particular & 2 & 2,2 & 2 & 0,9 & 4 & 1,2 & \\
\hline Não especificado & 0 & 0,0 & 4 & 1,7 & 4 & 1,2 & \\
\hline Não faz & 11 & 12,2 & 97 & 42,0 & 108 & 33,6 & \\
\hline \multicolumn{7}{|c|}{ Número de medicamentos de uso contínuo } & \multirow[t]{2}{*}{$<0,001$} \\
\hline Mediana $\left(1^{\circ} .-3^{\circ}\right.$. quartis) & \multicolumn{2}{|c|}{$3.0(1.0-5.0)$} & \multicolumn{2}{|c|}{$1.0(0.0-3.0)$} & \multicolumn{2}{|c|}{$1,0(0,0-3,0)$} & \\
\hline
\end{tabular}


Natália Alencar de Pinho

Observa-se, pelos dados na Tabela 2, que os indivíduos sem doença renal crônica se destacaram por serem fumantes $(29,7 \%$ vs $11,1 \%, p<0,001)$; e por não fazerem acompanhamento em serviço de saúde $(42,0 \%$ vs $12,2 \%, p<0,001)$. A frequência de etilismo não diferiu entre os grupos. Os locais de acompanhamento de saúde mais citados foram "ambulatórios do Sistema Único de Saúde" (32,7\%) e "Unidades Básicas de Saúde" (27,1\%). Entre os pacientes com doença renal crônica, apenas 5,6\% faziam acompanhamento em clínicas de diálise e 12,2\% não faziam acompanhamento de saúde em nenhum serviço.

Em relação ao uso contínuo de medicamentos, os que tinham doença renal crônica faziam uso de número maior, comparados com aqueles sem doença renal crônica $(3,0(1,0-5,0)$ vs $1,0(0,0-3,0)$, $\mathrm{p}<0,001)$.

Tabela 3 - Principais antecedentes de saúde, pessoais e familiares, dos pacientes internados em uma clínica médica, com e sem doença renal crônica. São Paulo, 2013.

\begin{tabular}{|c|c|c|c|c|c|c|c|}
\hline \multirow[t]{2}{*}{ Variáveis } & \multicolumn{2}{|c|}{$\begin{array}{l}\text { Com doença } \\
\text { renal crônica } \\
(N=105)\end{array}$} & \multicolumn{2}{|c|}{$\begin{array}{l}\text { Sem doença } \\
\text { renal crônica } \\
(N=281)\end{array}$} & \multicolumn{2}{|c|}{$\begin{array}{c}\text { Total } \\
(\mathrm{N}=386)\end{array}$} & \multirow[t]{2}{*}{$\begin{array}{c}\text { Valor } \\
\mathbf{p}\end{array}$} \\
\hline & $\mathbf{N}$ & $\%$ & $\mathbf{N}$ & $\%$ & $\mathbf{N}$ & $\%$ & \\
\hline & \multicolumn{4}{|c|}{ Antecedentes pessoais } & & & \\
\hline $\begin{array}{l}\text { Doença renal crônica } \\
\text { Hipertensão arterial }\end{array}$ & 56 & 53,3 & 0 & 0,0 & 56 & 14,5 & $<0,001$ \\
\hline Sim & 79 & 75,2 & 130 & 46,3 & 209 & 54,1 & \\
\hline Não & 26 & 24,8 & 151 & 53,7 & 177 & 45,9 & \\
\hline Diabetes & & & & & & & $<0,001$ \\
\hline Sim & 52 & 49,5 & 63 & 22,4 & 115 & 29,8 & \\
\hline Não & 53 & 50,5 & 218 & 77,6 & 271 & 70,2 & \\
\hline Dislipidemia & & & & & & & 0,041 \\
\hline Sim & 25 & 23,8 & 42 & 14,9 & 67 & 17,4 & \\
\hline Não & 80 & 76,2 & 239 & 85,1 & 319 & 82,6 & \\
\hline Acidente vascular encefálico & & & & & & & \\
\hline $\operatorname{Sim}$ & 14 & 13,3 & 20 & 7,1 & 34 & 8,8 & 0,055 \\
\hline Não & 91 & 86,7 & 261 & 92,9 & 352 & 91,2 & \\
\hline Infarto agudo do miocárdio & & & & & & & \\
\hline Sim & 15 & 14,3 & 17 & 6,0 & 32 & 8,3 & 0,009 \\
\hline Não & 90 & 85,7 & 264 & 94,0 & 354 & 91,7 & \\
\hline Insuficiência cardíaca congestiva & & & & & & & $<0,001$ \\
\hline Sim & 19 & 18,1 & 12 & 4,3 & 31 & 8,0 & \\
\hline Não & 86 & 81,9 & 269 & 95,7 & 355 & 92,0 & \\
\hline & & edente & amilia & & & & \\
\hline Hipertensão arterial & & & & & & & 0,489 \\
\hline Sim & 36 & 34,3 & 86 & 30,6 & 122 & 31,6 & \\
\hline Não consta & 69 & 65,7 & 195 & 69,4 & 264 & 68,4 & \\
\hline Diabetes & & & & & & & 0,087 \\
\hline Sim & 32 & 30,5 & 62 & 22,1 & 94 & 24,4 & \\
\hline Não consta & 73 & 69,5 & 219 & 77,9 & 292 & 75,6 & \\
\hline Doença renal crônica & & & & & & & 0,331 \\
\hline Sim & 2 & 1,9 & 2 & 0,7 & 4 & 1,0 & \\
\hline Não consta & 103 & 98,1 & 279 & 99,3 & 382 & 99,0 & \\
\hline
\end{tabular}


Natália Alencar de Pinho

Com relação aos antecedentes de saúde, maioria expressiva $(89,5 \%)$ e pouco mais da metade $(55,2 \%)$ dos pacientes com e sem doença renal crônica, respectivamente, apresentavam pelo menos uma comorbidade. Porém, quanto aos antecedentes familiares, as frequências encontradas foram bem menores: $42,9 \%$ para os com doença renal crônica e 38,8\% naqueles sem doença renal crônica.

Dos 105 pacientes identificados pelos critérios adotados como doentes renais crônicos, cerca da metade (53,3\%) já apresentava antecedente pessoal da doença registrado em prontuário (Tabela 3). Houve diferença significativa $(p<0,05)$ entre os grupos com e sem doença renal crônica quanto a ter antecedentes pessoais para as seguintes comorbidades: hipertensão arterial (75,2\% vs 46,3\%); diabetes (49,5\% vs 22,4\%); dislipidemia (23,8\% vs 14,9\%); infarto agudo do miocárdio (14,3\% vs 6,0\%); e insuficiência cardíaca congestiva (18,1\% vs $4,3 \%)$.

As frequências de antecedente pessoal de acidente vascular encefálico, assim como de antecedentes familiares de hipertensão arterial, diabetes e doença renal crônica, não foram diferentes entre os grupos. 
Natália Alencar de Pinho

Tabela 4 - Principais medicamentos de uso contínuo dos pacientes internados em uma clínica médica, com e sem doença renal crônica. São Paulo, 2013.

\begin{tabular}{|c|c|c|c|c|c|c|c|}
\hline \multirow[t]{2}{*}{ Classes medicamentosas } & \multicolumn{2}{|c|}{$\begin{array}{l}\text { Com doença } \\
\text { renal crônica } \\
(N=105)\end{array}$} & \multicolumn{2}{|c|}{$\begin{array}{c}\text { Sem doença } \\
\text { renal crônica } \\
(\mathrm{N}=281)\end{array}$} & \multicolumn{2}{|c|}{$\begin{array}{c}\text { Total } \\
(\mathrm{N}=386)\end{array}$} & \multirow{2}{*}{$\begin{array}{c}\text { Valor } \\
\mathbf{p}\end{array}$} \\
\hline & $\mathbf{N}$ & $\%$ & $\mathbf{N}$ & $\%$ & $\mathbf{N}$ & $\%$ & \\
\hline \multicolumn{7}{|l|}{ Anti-hipertensivos } & \\
\hline Sim & 74 & 70,5 & 102 & 36,3 & 176 & 45,6 & \\
\hline Não & 31 & 29,5 & 179 & 63,7 & 210 & 54,4 & \multirow{4}{*}{0,008} \\
\hline Antiagregantes plaquetários & & & & & & & \\
\hline Sim & 28 & 26,7 & 42 & 14,9 & 70 & 18,1 & \\
\hline Não & 77 & 73,3 & 239 & 85,1 & 316 & 81,9 & \\
\hline Antidiabéticos orais & & & & & & & \multirow{3}{*}{0,197} \\
\hline Sim & 18 & 17,1 & 34 & 12,1 & 52 & 13,5 & \\
\hline Não & 87 & 82,9 & 247 & 87,9 & 334 & 86,5 & \\
\hline Estatinas & & & & & & & \multirow{3}{*}{0,030} \\
\hline $\operatorname{Sim}$ & 19 & 18,1 & 28 & 10,0 & 47 & 12,2 & \\
\hline Não & 86 & 81,9 & 253 & 90,0 & 339 & 87,8 & \\
\hline Insulina & & & & & & & \multirow[t]{3}{*}{$<0,001$} \\
\hline Sim & 25 & 23,8 & 12 & 4,3 & 37 & 9,6 & \\
\hline Não & 80 & 76,2 & 269 & 95,7 & 349 & 90,4 & \\
\hline \multicolumn{8}{|l|}{$\begin{array}{l}\text { Medicamentos de ação } \\
\text { cardíaca* }^{*}\end{array}$} \\
\hline Sim & 17 & 16,2 & 16 & 5,7 & 33 & 8,5 & \multirow[t]{2}{*}{0,001} \\
\hline Não & 88 & 83,8 & 265 & 94,3 & 353 & 91,5 & \\
\hline Psicotrópicos & & & & & & & 0,486 \\
\hline Sim & 8 & 7,6 & 16 & 5,7 & 24 & 6,2 & \\
\hline Não & 97 & 92,4 & 265 & 94,3 & 362 & 93,8 & \\
\hline
\end{tabular}

Faziam uso contínuo de medicamentos $84,8 \%$ e $82,6 \%$ dos pacientes com e sem doença renal crônica, respectivamente. Segundo os dados da Tabela 4, a classe medicamentosa mais utilizada pelos pacientes, antes do processo de hospitalização, foi a de anti-hipertensivos (45,6\%), seguida de frequências bem menores pelos antiagregantes plaquetários $(18,1 \%)$ e antidiabéticos orais $(13,5 \%)$. Foram estatisticamente significantes $(p<0,05)$ as diferenças entre os pacientes com doença renal crônica e os sem doença renal crônica na utilização das seguintes classes medicamentosas: anti-hipertensivos $(70,5 \%$ vs $36,3 \%)$; antiagregantes plaquetários (26,7\%s vs $14,9 \%)$; estatinas (18,1\% vs $10,0 \%)$; insulina (23,8\%s vs $4,3 \%)$; e medicamentos de ação cardíaca $(16,2 \%$ vs $5,7 \%)$. 
Natália Alencar de Pinho

Tabela 5 - Principais diagnósticos médicos dos pacientes internados em uma clínica médica, com e sem doença renal crônica. São Paulo, 2013.

\begin{tabular}{|c|c|c|c|c|c|c|c|}
\hline \multirow[t]{2}{*}{ Diagnósticos médicos } & \multicolumn{2}{|c|}{$\begin{array}{c}\text { Com doença } \\
\text { renal crônica } \\
(\mathrm{N}=105)\end{array}$} & \multicolumn{2}{|c|}{$\begin{array}{c}\text { Sem doença } \\
\text { renal crônica } \\
(\mathrm{N}=281)\end{array}$} & \multicolumn{2}{|c|}{$\begin{array}{c}\text { Total } \\
(\mathrm{N}=386)\end{array}$} & \multirow[t]{2}{*}{$\begin{array}{c}\text { Valor } \\
\mathbf{p}\end{array}$} \\
\hline & $\mathbf{N}$ & $\%$ & $\mathbf{N}$ & $\%$ & $\mathbf{N}$ & $\%$ & \\
\hline \multicolumn{8}{|l|}{ Hipertensão arterial } \\
\hline Sim & 85 & 81,0 & 142 & 50,5 & 227 & 58,8 & \\
\hline Não & 20 & 19,0 & 139 & 49,5 & 159 & 41,2 & \\
\hline Doenças respiratórias & & & & & & & 0,098 \\
\hline Sim & 28 & 26,7 & 100 & 35,6 & 128 & 33,2 & \\
\hline Não & 77 & 73,3 & 181 & 64,4 & 258 & 66,8 & \\
\hline Diabetes & & & & & & & $<0,001$ \\
\hline Sim & 53 & 50,5 & 71 & 25,3 & 124 & 32,1 & \\
\hline Não & 52 & 49,5 & 210 & 74,7 & 262 & 67,9 & \\
\hline \multicolumn{7}{|c|}{ Infarto agudo do miocárdio/ angina } & 0,636 \\
\hline Sim & 24 & 22,9 & 58 & 20,6 & 82 & 21,2 & \\
\hline Não & 81 & 77,1 & 223 & 79,4 & 304 & 78,8 & \\
\hline Dislipidemia & & & & & & & 0,126 \\
\hline Sim & 26 & 24,8 & 50 & 17,8 & 76 & 19,7 & \\
\hline Não & 79 & 75,2 & 231 & 82,2 & 310 & 80,3 & \\
\hline Acidente vascular encefálico & & & & & & & 0,293 \\
\hline Sim & 22 & 21,0 & 46 & 16,4 & 68 & 17,6 & \\
\hline Não & 83 & 79,0 & 235 & 83,6 & 318 & 82,4 & \\
\hline $\begin{array}{l}\text { Insuficiência cardíaca } \\
\text { congestiva }\end{array}$ & & & & & & & $<0,001$ \\
\hline Sim & 31 & 29,5 & 29 & 10,3 & 60 & 15,5 & \\
\hline Não & 74 & 70,5 & 252 & 89,7 & 326 & 84,5 & \\
\hline
\end{tabular}

Segundo os dados apresentados na Tabela 5, a hipertensão arterial foi o diagnóstico médico anotado na maioria dos prontuários durante a hospitalização $(58,8 \%)$, seguida pelas doenças respiratórias $(33,2 \%)$ e pelo diabetes melito $(32,1 \%)$. Houve diferenças estatisticamente significantes $(p<0,05)$ entre os pacientes com doença renal crônica e os sem doença renal crônica na presença dos diagnósticos médicos: hipertensão arterial (81,0\% vs $50,5 \%)$, diabetes $(50,5 \%$ vs $25,3 \%)$ e insuficiência cardíaca congestiva $(29,5 \%$ vs $10,3 \%)$. 
Tabela 6 - Exames laboratoriais dos pacientes internados em uma clínica médica, com e sem doença renal crônica. São Paulo, 2013.

\begin{tabular}{|c|c|c|c|c|c|}
\hline \multirow[t]{2}{*}{$\begin{array}{c}\text { Exames } \\
\text { laboratoriais }\end{array}$} & & $\begin{array}{l}\text { Com doença } \\
\text { renal crônica }\end{array}$ & $\begin{array}{l}\text { Sem doença } \\
\text { renal crônica }\end{array}$ & Total & \multirow[t]{2}{*}{$\begin{array}{c}\text { Valor } \\
\mathbf{p}\end{array}$} \\
\hline & $\mathbf{N}$ & $\mathrm{Mec}$ & $\operatorname{lna}\left(1^{\circ}\right.$. e $3^{\circ}$. qu & is) & \\
\hline $\begin{array}{l}\text { Potássio sérico } \\
(\mathrm{mEq} / \mathrm{l})\end{array}$ & 384 & $4,6(4,1-5,3)$ & $4,1(3,8-4,4)$ & $4,2(3,8-4,6)$ & $<0,001$ \\
\hline $\begin{array}{l}\text { Ureia sérica } \\
(\mathrm{mg} / \mathrm{dL})\end{array}$ & 384 & $\begin{array}{l}116,0(83,0- \\
167,5)\end{array}$ & $\begin{array}{c}33,0(24,0- \\
41,0)\end{array}$ & $\begin{array}{l}38,0(28,0- \\
74,0)\end{array}$ & $<0,001$ \\
\hline Hemoglobina (g/dL) & 382 & $11,1(9,3-12,5)$ & $\begin{array}{c}13,3(11,9- \\
14,6)\end{array}$ & $\begin{array}{c}12,9(11,3- \\
14,3)\end{array}$ & $<0,001$ \\
\hline Hematócrito (\%) & 381 & $\begin{array}{c}33,0(28,0- \\
37,0)\end{array}$ & $\begin{array}{c}40,0(36,0- \\
43,0)\end{array}$ & $\begin{array}{c}38,0(33,0- \\
43,0)\end{array}$ & $<0,001$ \\
\hline Glicemia (mg/dL) & 204 & $\begin{array}{c}127,0(105,0- \\
200,0)\end{array}$ & $\begin{array}{c}114,5(98,0- \\
152,5)\end{array}$ & $\begin{array}{c}118,0(98,0- \\
161,0)\end{array}$ & 0,152 \\
\hline $\begin{array}{l}\text { Albumina sérica } \\
(\mathrm{g} / \mathrm{dL})\end{array}$ & 152 & $3,1(2,8-3,4)$ & $3,7(3,3-4,0)$ & $3,6(3,1-4,0)$ & $<0,001$ \\
\hline $\begin{array}{l}\text { Fósforo sérico } \\
\text { (mg/dL) }\end{array}$ & 147 & $4,9(3,7-6,0)$ & $3,5(2,7-4,1)$ & $3,8(3,0-5,0)$ & $<0,001$ \\
\hline Colesterol (mg/dL) & 100 & $\begin{array}{c}155,0(129,0- \\
171,0)\end{array}$ & $\begin{array}{c}162,5(139,5- \\
205,0)\end{array}$ & $\begin{array}{c}162,5(135,0- \\
195,0)\end{array}$ & 0,158 \\
\hline HDL (mg/dL) & 99 & $\begin{array}{c}33,0(29,5- \\
45,0)\end{array}$ & $\begin{array}{c}39,0(30,5- \\
53,5)\end{array}$ & $\begin{array}{l}37,0(30,0- \\
52,5)\end{array}$ & 0,337 \\
\hline LDL (mg/dL) & 97 & $\begin{array}{c}84,0(75,0- \\
100,0)\end{array}$ & $\begin{array}{c}98,0(71,0- \\
124,5)\end{array}$ & $\begin{array}{c}93,0(73,0- \\
120,0)\end{array}$ & 0,347 \\
\hline $\begin{array}{l}\text { Triglicérides } \\
(\mathrm{mg} / \mathrm{dL})\end{array}$ & 92 & $\begin{array}{c}124,0(96,5- \\
174,0)\end{array}$ & $\begin{array}{c}138,0(108,5- \\
201,0)\end{array}$ & $\begin{array}{c}132,0(106,0- \\
197,0)\end{array}$ & 0,311 \\
\hline Ácido úrico (mg/dL) & 27 & $7,5(6,5-8,9)$ & $5,5(4,4-6,7)$ & $6,7(5,1-8,1)$ & 0,008 \\
\hline Proteinúria (n/\%) & 177 & 84,5 & 39,5 & 54,2 & $<0,001$ \\
\hline
\end{tabular}

Observa-se, pelos dados da Tabela 6, que os pacientes com doença renal crônica foram significativamente diferentes $(p<0,05)$ daqueles sem doença renal crônica por apresentarem, na análise sanguínea, maiores valores de potássio $(4,6(4,1-5,3)$ vs 4,1 (3,8 $4,4) \mathrm{mEq} / \mathrm{l})$, ureia $(116,0(83,0-167,5)$ vs $33,0(24,0-41,0) \mathrm{mg} / \mathrm{dL})$, fósforo $(4,9(3,7-6,0)$ vs $3,5(2,7-4,1) \mathrm{mg} / \mathrm{dL})$, e ácido úrico $(7,5$ $(6,5-8,9)$ vs $5,5(4,4-6,7) \mathrm{mg} / \mathrm{dL})$.

Em contrapartida, foram significativamente inferiores $(p<$ $0,05)$, para os pacientes com doença renal crônica, os valores de hemoglobina $(11,1 \quad(9,3$ - 12,5) vs $13,3(11,9$ - 14,6) $\mathrm{g} / \mathrm{dL})$, hematócrito $(33,0(28,0-37,0)$ vs $40,0(36,0-43,0) \%)$ e albumina 
Natália Alencar de Pinho

sérica $(3,1(2,8-3,4)$ vs 3,7 $(3,3-4,0) \mathrm{g} / \mathrm{dL})$.

Houve ainda diferença entre os grupos com relação à proteinúria: $84,5 \%$ dos pacientes com doença renal crônica apresentaram análise de proteinúria positiva, contra $39,5 \%$ dos sem doença renal crônica $(p<0,001)$.

Destaca-se ainda que os pacientes com doença renal crônica tinham níveis de ureia, fósforo e ácido úrico séricos superiores ao limite de normalidade. A hemoglobina e o hematócrito foram compatíveis com anemia, tanto para homens como para mulheres. Os valores da fração Colesterol HDL foram inferiores ao limite de normalidade para os grupos com e sem doença renal crônica.

Tabela 7 - Valores de creatinina sérica nos primeiros dez dias de internação dos pacientes internados em uma clínica médica, com e sem doença renal crônica. São Paulo, 2013.

\begin{tabular}{|c|c|c|c|c|}
\hline Dias & & $\begin{array}{c}\text { Com doença renal } \\
\text { crônica }\end{array}$ & $\begin{array}{c}\text { Sem doença renal } \\
\text { crônica }\end{array}$ & Valor $p$ \\
\hline & $\mathbf{N}$ & Creatinina (mg/dL, & ina $\left(1^{\circ}\right.$. e $3^{\circ}$. quartis)) & \\
\hline 0 & 284 & $3,0(2,1-5,1)$ & $0,9(0,7-1,0)$ & $<0,001$ \\
\hline 1 & 282 & $2,9(1,8-4,7)$ & $0,8(0,7-1,0)$ & $<0,001$ \\
\hline 2 & 222 & $2,6(1,8-5,0)$ & $0,8(0,7-1,0)$ & $<0,001$ \\
\hline 3 & 184 & $2,8(1,8-4,7)$ & $0,8(0,7-1,0)$ & $<0,001$ \\
\hline 4 & 173 & $2,4(1,5-3,7)$ & $0,8(0,7-1,0)$ & $<0,001$ \\
\hline 5 & 157 & $2,7(1,8-4,4)$ & $0,8(0,7-0,9)$ & $<0,001$ \\
\hline 6 & 152 & $2,3(1,7-4,0)$ & $0,8(0,6-1,0)$ & $<0,001$ \\
\hline 7 & 102 & $2,0(1,6-2,9)$ & $0,8(0,7-1,0)$ & $<0,001$ \\
\hline 8 & 96 & $2,4(1,6-3,4)$ & $0,8(0,7-0,9)$ & $<0,001$ \\
\hline 9 & 68 & $2,6(1,6-3,4)$ & $0,8(0,6-1,0)$ & $<0,001$ \\
\hline 10 & 69 & $2,4(1,4-3,2)$ & $0.7(0.7-1.0)$ & $<0,001$ \\
\hline
\end{tabular}


Figura 1 - Distribuição interquartílica dos valores de creatinina sérica nos primeiros dez dias de internação dos indivíduos com e sem doença renal crônica. São Paulo, 2013.

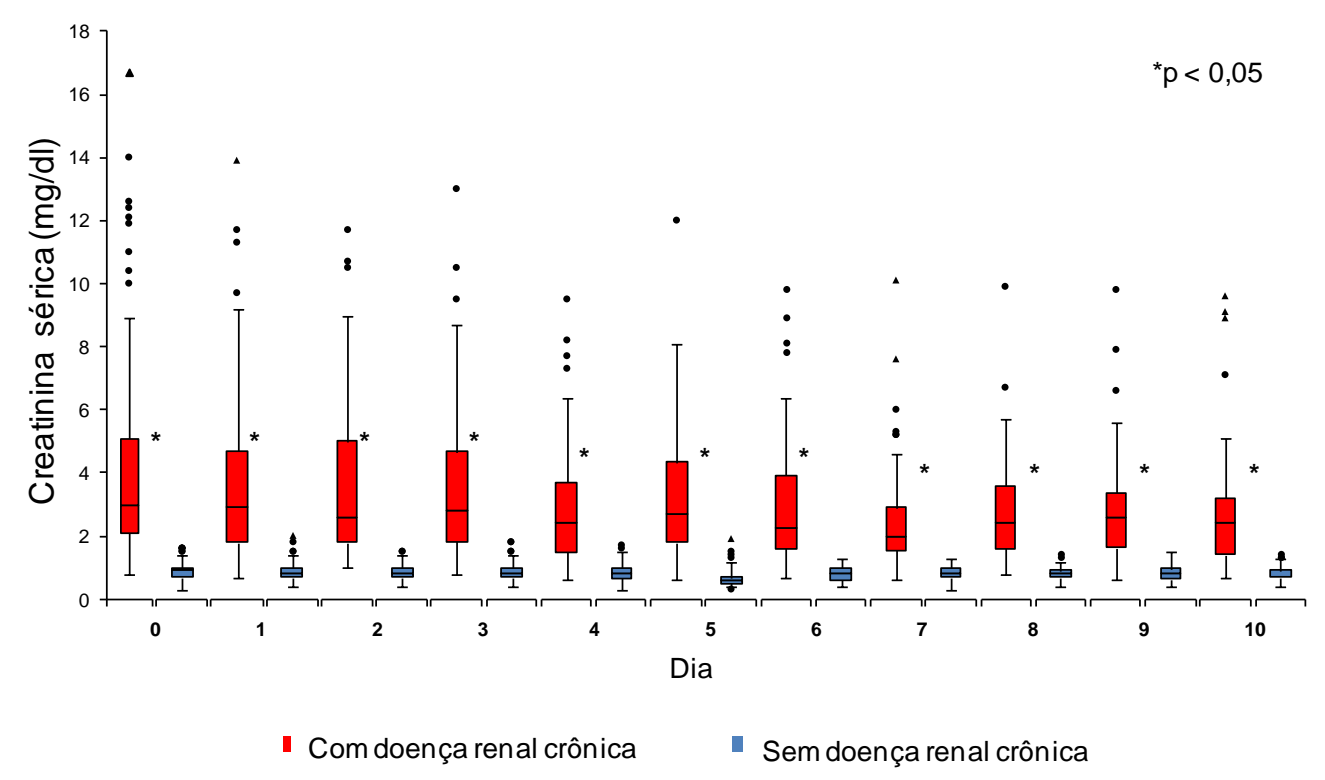

Em relação à creatinemia na admissão hospitalar, quase a totalidade $(93,3 \%)$ dos pacientes com doença renal crônica e apenas $3,2 \%$ dos sem doença renal crônica apresentaram valores acima do limite da normalidade. Conforme dados da Tabela 7 e Figura 1, os valores de creatinina sérica apresentaram diferença significativa $(p<$ $0,05)$ entre os grupos, sendo superiores para indivíduos com doença renal crônica nos primeiros dez dias de internação. 
Tabela 8 - Valores de pressão arterial nos primeiros dez dias de internação dos pacientes internados em uma clínica médica, com e sem doença renal crônica. São Paulo, 2013.

\begin{tabular}{|c|c|c|c|c|c|c|c|c|c|c|}
\hline \multirow[t]{3}{*}{ Dia } & \multicolumn{6}{|c|}{ Com doença renal crônica } & \multirow{2}{*}{\multicolumn{2}{|c|}{$\begin{array}{c}\text { Sem doença renal crônica } \\
\text { Pressão arterial } \\
\text { (mmHg, média } \pm d p)\end{array}$}} & \multirow{2}{*}{\multicolumn{2}{|c|}{ Valor $p$}} \\
\hline & $\begin{array}{c}\mathrm{N} \\
\text { (PAS) }\end{array}$ & $\begin{array}{c}\mathrm{N} \\
\text { (PAD }\end{array}$ & $\begin{array}{r}\text { Press } \\
(\mathrm{mmHg}\end{array}$ & $\begin{array}{l}\text { erial } \\
a \pm d p)\end{array}$ & $\begin{array}{c}\mathbf{N} \\
\text { (PAS) }\end{array}$ & $\begin{array}{c}\mathrm{N} \\
(\mathrm{PAD})\end{array}$ & & & & \\
\hline & & & Sistólica & Diastólica & & & Sistólica & Diastólica & Sistólica & Diastólica \\
\hline 1 & 103 & 103 & $129,9 \pm 24,2$ & $77,1 \pm 14,9$ & 273 & 271 & $127,6 \pm 23,5$ & $77,0 \pm 13,8$ & 0,399 & 0,917 \\
\hline 2 & 100 & 99 & $131,4 \pm 21,6$ & $79,1 \pm 14,3$ & 267 & 268 & $129,0 \pm 21,6$ & $76,0 \pm 14,3$ & 0,343 & 0,065 \\
\hline 3 & 97 & 97 & $127,4 \pm 22,8$ & $77,1 \pm 13,7$ & 257 & 255 & $129,8 \pm 23,6$ & $77,4 \pm 13,1$ & 0,377 & 0,843 \\
\hline 4 & 96 & 96 & $128,7 \pm 21,4$ & $76,3 \pm 11,8$ & 241 & 241 & $129,9 \pm 22,7$ & $76,6 \pm 12,9$ & 0,644 & 0,857 \\
\hline 5 & 92 & 92 & $127,4 \pm 20,5$ & $75,3 \pm 11,4$ & 221 & 220 & $126,9 \pm 21,8$ & $76,2 \pm 13,1$ & 0,855 & 0,581 \\
\hline 6 & 87 & 89 & $130,2 \pm 24,0$ & $76,4 \pm 13,5$ & 196 & 194 & $126,8 \pm 22,2$ & $77,0 \pm 11,8$ & 0,244 & 0,724 \\
\hline 7 & 71 & 71 & $129,6 \pm 20,9$ & $76,4 \pm 11,8$ & 171 & 170 & $126,3 \pm 22,0$ & $75,0 \pm 12,5$ & 0,282 & 0,406 \\
\hline 8 & 61 & 62 & $128,9 \pm 24,6$ & $74,5 \pm 10,8$ & 142 & 142 & $123,8 \pm 20,1$ & $76,4 \pm 12,4$ & 0,123 & 0,287 \\
\hline 9 & 53 & 53 & $128,8 \pm 23,4$ & $74,3 \pm 13,3$ & 113 & 113 & $122,8 \pm 22,6$ & $75,6 \pm 13,5$ & 0,116 & 0,543 \\
\hline 10 & 46 & 45 & $125,9 \pm 21,2$ & $73,4 \pm 13,5$ & 99 & 97 & $123,9 \pm 18,6$ & $76,5 \pm 11,7$ & 0,557 & 0,154 \\
\hline
\end{tabular}

Os dados da Tabela 8 mostram os valores de pressão arterial nos dez primeiros dias da internação do total de indivíduos com e sem doença renal crônica, os quais não diferiram entre os grupos. 
Tabela 9 - Valores de pressão arterial dos pacientes internados em uma clínica médica, com e sem doença renal crônica, que apresentaram medidas registradas do primeiro ao décimo dia de internação. São Paulo, 2013.

Dia

Com doença renal crônica

\section{Sem doença renal crônica}

\begin{tabular}{|c|c|c|c|c|}
\hline & \multicolumn{4}{|c|}{ Pressão arterial (mmHg, média \pm dp) } \\
\hline & Sistólica $(\mathrm{N}=35)$ & Diastólica (N= 34) & Sistólica $(\mathrm{N}=82)$ & Diastólica $(\mathrm{N}=80)$ \\
\hline 1 & $126,8 \pm 23,1$ & $74,9 \pm 12,1$ & $124,6 \pm 25,7$ & $77,9 \pm 13,6$ \\
\hline 2 & $125,4 \pm 21,8$ & $75,4 \pm 13,4$ & $125,8 \pm 18,4$ & $76,7 \pm 11,9$ \\
\hline 3 & $126,6 \pm 24,4$ & $77,8 \pm 13,9$ & $129,5 \pm 25,24$ & $77,3 \pm 14,5$ \\
\hline 4 & $130,7 \pm 22,6$ & $76,4 \pm 10,8$ & $126,3 \pm 20,8 ¥$ & $75,4 \pm 12,4$ \\
\hline 5 & $129,0 \pm 22,8$ & $75,6 \pm 12,8$ & $124,3 \pm 19,8$ & $76,7 \pm 12,0$ \\
\hline 6 & $135,5 \pm 29,1 * \#$ & $77,7 \pm 13,4$ & $123,1 \pm 20,7$ & $77,1 \pm 10,9$ \\
\hline 7 & $131,5 \pm 21,1 *$ & $76,0 \pm 11,8$ & $123,0 \pm 17,8$ & $74,3 \pm 11,7$ \\
\hline 8 & $131,5 \pm 24,2$ * & $74,6 \pm 11,8$ & $121,0 \pm 20,9$ & $74,8 \pm 13,3$ \\
\hline 9 & $128,7 \pm 22,1$ * & $74,6 \pm 11,9$ & $121,3 \pm 22,9$ & $74,7 \pm 14,2$ \\
\hline 10 & $126,2 \pm 22,0$ * & $73,5 \pm 13,0$ & $123,8 \pm 19,1$ & $76,5 \pm 11,8$ \\
\hline
\end{tabular}

\# Valor de $\mathrm{p}<<0,05$ em relação à pressão arterial sistólica do respectivo dia: pacientes com doença renal crônica vs $v$ à à pressão arterial sistólica dos dias $1,2,3$ e 10 no grupo com doença renal crônica.

६ Valor de $\mathrm{p}<0,05$ em relação à pressão arterial sistólica dos dias 5 a 10 no grupo sem doença renal crônica

$¥$ Valor de $p<0,05$ em relação à pressão arterial sistólica dos dias 8 e 9 no grupo sem doença renal crônica. 
Figura 2 - Comparação dos valores de pressão arterial dos pacientes internados em uma clínica médica, com e sem doença renal crônica, que apresentaram medidas registradas do primeiro ao décimo dia de internação. São Paulo, 2013.

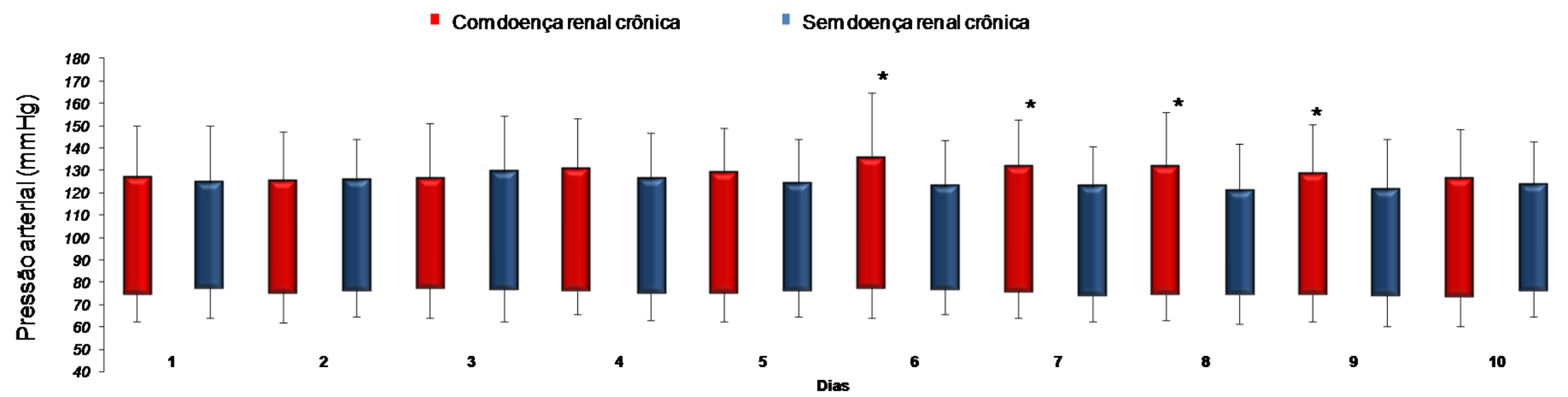

*Valor de p $<0,05$ em relação à pressão arterial sistólica do respectivo dia : pacientes com doença renal crônica vs sem doença renal crônica. 
Natália Alencar de Pinho

Figura 3 - Variação da pressão arterial dos pacientes com doença renal crônica internados em uma clínica médica que apresentaram medidas registradas do primeiro ao décimo dia de internação. São Paulo, 2013.
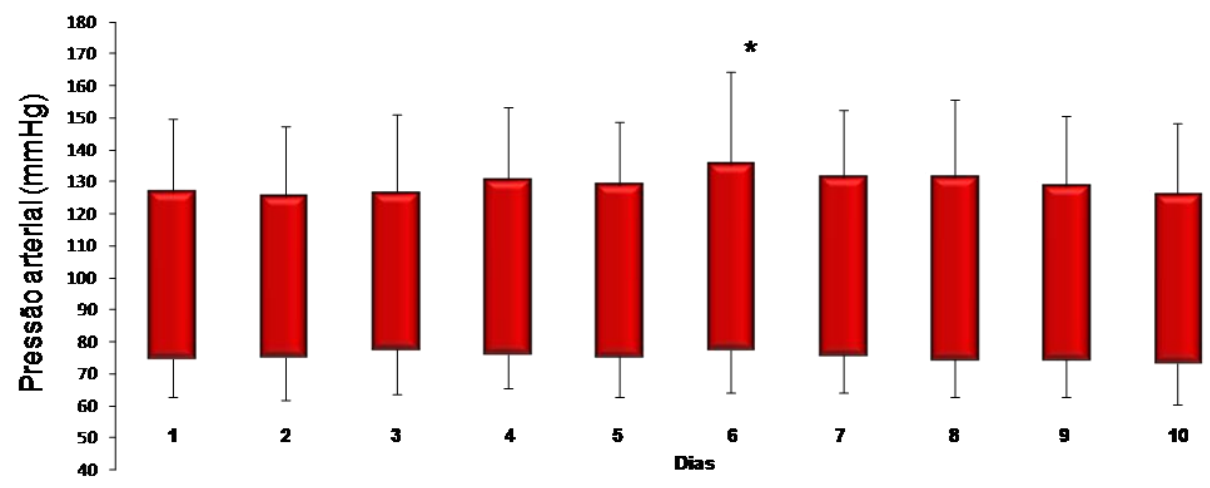

*Valor de $p<0,05$ em relação à pressão arterialdos dias 1, 2, 3 e 10.

Figura 4 - Variação da pressão arterial dos pacientes sem doença renal crônica internados em uma clínica médica que apresentaram medidas registradas do primeiro ao décimo dia de internação. São Paulo, 2013.
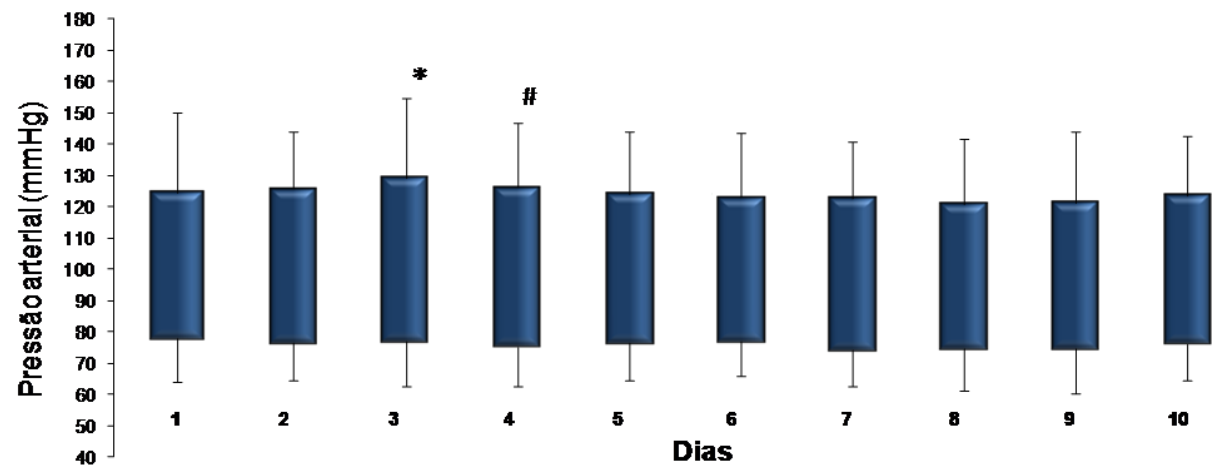

* Valor de $p<0,05$ em relação à pressão arterial dos dias 5 a 10. \#Valor de $\mathrm{p}<0,05 \mathrm{em}$ relação à pressão arterial dos dias 8 e 9 .

Os dados da Tabela 9 apresentam os valores de pressão arterial de pacientes com e sem doença renal crônica que apresentaram valores registrados do primeiro ao décimo dia de internação. Os resultados das análises de comparação entre os grupos, assim como os da análise intragrupo, são ilustrados pelas Figuras 2 a 4. 
Conforme dados apresentados na Figura 2, houve diferença significativa $(p<0,05)$ das pressões arteriais sistólicas entre os grupos, as quais foram mais elevadas para os pacientes com doença renal crônica em relação aos sem a doença: 135,5 $\pm 29,1$ vs $123,1 \pm 20,7 \mathrm{mmHg}$ no sexto dia de internação; 131,5 $\pm 21,1$ vs $123,0 \pm 17,8 \mathrm{mmHg}$ no sétimo dia de internação; 131,5 $\pm 24,2$ vs $121,0 \pm 20,9 \mathrm{mmHg}$ no oitavo dia de internação; e 128,7 $\pm 22,1$ vs $121,3 \pm 22,9 \mathrm{mmHg}$ no nono dia de internação. As pressões arteriais diastólicas não apresentaram diferença significativa entre os grupos.

A Figura 3 mostra que a pressão arterial sistólica dos pacientes com doença renal crônica foi superior no sexto dia, diferindo significativamente dos valores obtidos nos primeiros três dias e no décimo dia de internação. Não houve variação significativa da pressão arterial diastólica.

Para os pacientes sem doença renal crônica, a pressão arterial sistólica foi mais elevada no terceiro dia de internação, com diferença significativa $(p<0,05)$ em relação aos valores do quinto ao décimo dia (Figura 4). Não houve variação significativa da pressão arterial diastólica. 
Natália Alencar de Pinho

Tabela 10 - Principais diagnósticos de enfermagem dos pacientes com e sem doença renal crônica na admissão e na alta em clínica médica. São Paulo, 2013.

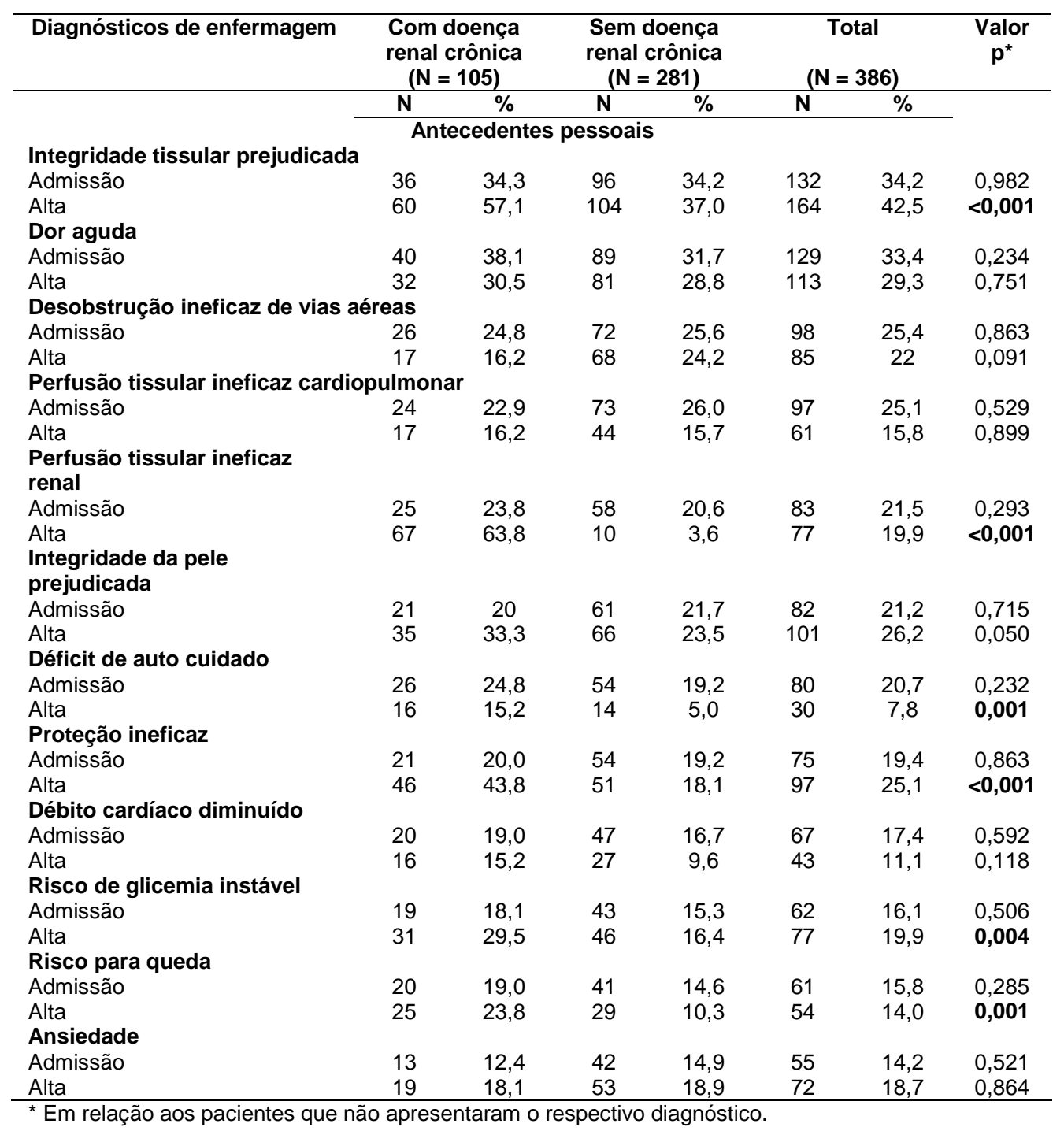

Os diagnósticos de enfermagem com frequência superior a $15 \%$ na admissão ou na alta da enfermaria de clínica médica são apresentados na Tabela 10. Observa-se que o diagnóstico "Integridade tissular prejudicada" foi o mais frequente, tanto na admissão quanto na alta hospitalar.

Os seguintes diagnósticos de enfermagem foram mais presentes $(p<0,05)$ em pacientes com doença renal crônica na alta, quando comparados aos sem doença renal crônica: "Integridade tissular prejudicada" (57,1\% vs $37,0 \%)$; "Perfusão tissular ineficaz 
Natália Alencar de Pinho

renal" (63,8\% vs 3,6\%); "Déficit de auto cuidado" (15,2\% vs 5,0\%); e "Proteção ineficaz" (43,8\% vs 18,1\%).

$\mathrm{Na}$ avaliação de enfermagem precedente à alta, os pacientes com doença renal crônica também foram mais identificados ( $p$ < $0,05)$ com risco de glicemia instável $(29,5 \%$ vs,4\%) e para queda $(23,8 \%$ vs $10,3 \%)$.

Tabela 11 - Desfechos da hospitalização dos pacientes internados em uma clínica médica, com e sem doença renal crônica. São Paulo, 2013.

\begin{tabular}{|c|c|c|c|c|c|c|c|}
\hline \multirow[t]{2}{*}{$\begin{array}{l}\text { Desfechos da } \\
\text { hospitalização }\end{array}$} & \multicolumn{2}{|c|}{$\begin{array}{l}\text { Com doença } \\
\text { renal crônica } \\
(N=105) \\
\end{array}$} & \multicolumn{2}{|c|}{$\begin{array}{c}\text { Sem doença } \\
\text { renal crônica } \\
(\mathrm{N}=281)\end{array}$} & \multicolumn{2}{|c|}{$\begin{array}{c}\text { Total } \\
(\mathrm{N}=386) \\
\end{array}$} & \multirow[t]{2}{*}{$\begin{array}{c}\text { Valor } \\
\mathbf{p}\end{array}$} \\
\hline & $\mathbf{N}$ & $\%$ & $\mathbf{N}$ & $\%$ & $\mathbf{N}$ & $\%$ & \\
\hline Terapia renal substitutiva & 27 & 25,7 & 0 & 0 & 27 & 7,0 & \\
\hline Internação em UTI & & & & & & & 0,118 \\
\hline $\operatorname{Sim}$ & 16 & 15,2 & 27 & 9,6 & 43 & 11,1 & \\
\hline Não & 89 & 84,8 & 254 & 90,4 & 343 & 88,9 & \\
\hline Internação em semi-intensiva & & & & & & & 0,242 \\
\hline Sim & 14 & 13,3 & 26 & 9,3 & 40 & 10,4 & \\
\hline Não & 91 & 86,7 & 255 & 90,7 & 346 & 89,6 & \\
\hline Desfecho & & & & & & & $<0,001$ \\
\hline Alta & 90 & 85,7 & 262 & 93,2 & 352 & 91,2 & \\
\hline Óbito & 13 & 12,4 & 4 & 1,4 & 17 & 4,4 & \\
\hline $\begin{array}{l}\text { Transferência para outro } \\
\text { hospital }\end{array}$ & 1 & 1,0 & 13 & 4,6 & 14 & 3,6 & \\
\hline Perda de seguimento & 1 & 1,0 & 2 & 0,7 & 3 & 0,8 & \\
\hline Encaminhamento pós alta* $(\mathrm{N}$ & $V=343$ & & & & & & 0,104 \\
\hline UBS & 12 & 18,2 & 55 & 19,9 & 67 & 19,5 & \\
\hline Ambulatórios & 12 & 18,2 & 22 & 7,9 & 34 & 9,9 & \\
\hline Hospital de nível terciário & 5 & 7,6 & 24 & 8,7 & 29 & 8,5 & \\
\hline Assistência domiciliar & 5 & 7,6 & 13 & 4,7 & 18 & 5,2 & \\
\hline Outros\# & 1 & 1,5 & 17 & 6,1 & 18 & 5,2 & \\
\hline Não consta & 31 & 47,0 & 146 & 52,7 & 177 & 51,6 & \\
\hline Tempo de internação (dias) & & & & & & & $<0,001$ \\
\hline Mediana $\left(1^{\circ} .-3^{\circ}\right.$. quartis) & $11,0(8$ & $-18,0)$ & $9,0(6$ & $-12,0)$ & $9,0(7$ & $-13,0)$ & \\
\hline $\begin{array}{l}\text { Siglas: SUS, sistema único de saúd } \\
\text { domiciliária; UTI, unidade de terapia } \\
\text { *Para os indivíduos que sobrevivera } \\
\text { \# Centro de atenção psicossocial (1 } \\
\text { transmissíveis/ síndrome da imunod }\end{array}$ & $\begin{array}{l}\text { de; UBS, } \\
\text { ia intensi } \\
\text { am, exce }\end{array}$ & nidade b & sica de & $\begin{array}{l}\text { aúde; PA } \\
\text { itutiva ( } r \\
\text { pecializa }\end{array}$ & progra & de ass & $\begin{array}{l}\text { tência } \\
\text { almente }\end{array}$ \\
\hline
\end{tabular}

Os dados da Tabela 11 mostram que $11,1 \%$ e $10,4 \%$ dos pacientes passaram pela unidade de terapia intensiva e pela unidade semi-intensiva, respectivamente, e que estas variáveis não diferiram entre os grupos.

O tempo de internação foi significativamente superior $(p<$ $0,05)$ para pacientes com doença renal crônica em relação aos sem 
a doença $(11,0(8,0-18,0)$ dias vs $9,0(6,0-12,0)$ dias $)$. O desfecho da hospitalização também apresentou diferença estatisticamente significativa $(p<0,05)$ entre os grupos, com maior proporção de óbitos entre indivíduos com doença renal crônica (12,4\% vs 1,4\%).

Os locais de encaminhamento pós-alta mais frequentes foram as UBS (18,2\%) e os ambulatórios (9,2\%). Destaca-se que esta informação esteve ausente em mais da metade $(51,6 \%)$ dos prontuários de pacientes que receberam alta e não faziam terapia renal substitutiva, sendo que 57 (32,2\%) pertenciam a pacientes que não faziam acompanhamento de saúde prévio à hospitalização.

Entre os pacientes com doença renal crônica terminal, 96,3\% realizaram diálise durante a internação. Destes, 17 (65,4\%) iniciaram terapia renal substitutiva durante a internação, sendo que 10 (58,8\%) não tinham antecedente de doença renal crônica registrado em prontuário. A modalidade de terapia dialítica utilizada foi a hemodiálise, sendo que um paciente também foi submetido à diálise peritoneal. Com exceção de um paciente que evoluiu a óbito, estes pacientes foram encaminhados a clínicas de diálise após a alta hospitalar.

Tabela 12 - Preditores de doença renal crônica em pacientes internados em uma clínica médica segundo análise multivariada. São Paulo, 2013.

\begin{tabular}{|c|c|c|c|c|}
\hline Variáveis & Odds ratio & Intervalo & nnfiança & Valor $p$ \\
\hline Idade (por ano adicional) & 1,019 & 1,003 & 1,036 & 0,024 \\
\hline Hipertensão arterial & 2,032 & 1,128 & 3,660 & 0,018 \\
\hline Diabetes & 2,097 & 1,232 & 3,570 & 0,006 \\
\hline Insuficiência cardíaca congestiva & 2,665 & 1,173 & 6,056 & 0,019 \\
\hline
\end{tabular}

O modelo de regressão logística múltipla incluiu as seguintes variáveis: estado civil, tabagismo, idade e antecedentes pessoais significativamente associados à doença renal crônica na análise univariada. Observou-se que a cada ano adicional na idade, a 
Natália Alencar de Pinho

chance de doença renal crônica foi de 1,9\%. Ter hipertensão arterial ou diabetes elevou em cerca de duas vezes, e insuficiência cardíaca, 2,6 vezes, a chance de possuir doença renal crônica.

\subsection{FATORES ASSOCIADOS À HIPERTENSÃO ARTERIAL NA DOENÇA RENAL CRÔNICA}

Tabela 13 - Características biossociais dos hipertensos internados em uma clínica médica, com e sem doença renal crônica. São Paulo, 2013.

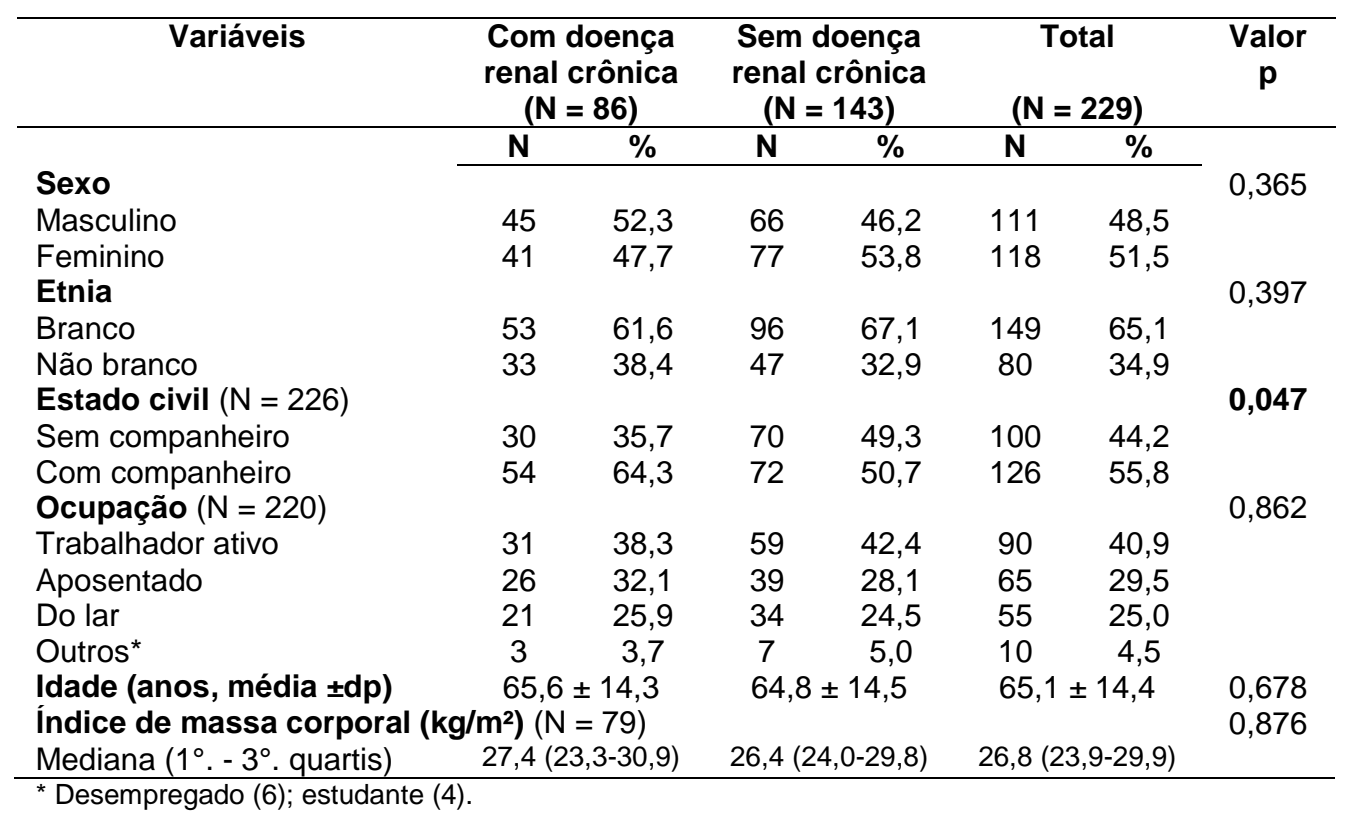

Dos 386 pacientes que compuseram a amostra, mais da metade $(59,3 \%)$ apresentou hipertensão arterial definida pela presença de diagnóstico médico ou antecedente pessoal desta doença.

Os dados da Tabela 13 mostram que os hipertensos com e sem doença renal crônica foram semelhantes em relação a: discreto predomínio do sexo feminino (51,5\%); maioria de etnia branca $(65,1 \%)$; e ocupação com trabalhadores ativos (40,9\%). O índice de massa corporal foi compatível com sobrepeso $(26,8(23,9-29,9)$ $\left.\mathrm{kg} / \mathrm{m}^{2}\right)$; e a faixa etária correspondeu à sexta década de vida $(65,1 \pm$ 
Natália Alencar de Pinho

14,4 anos) para ambos os grupos.

Houve diferença estatisticamente significante $(p<0,05)$ em relação ao estado civil. Os hipertensos com doença renal crônica se distinguiram, em relação aos sem doença renal crônica, por viverem mais com companheiro $(64,3 \%$ vs $50,7 \%)$.

Tabela 14 - Hábitos de vida, acompanhamento em serviço de saúde e uso contínuo de medicamentos dos hipertensos internados em uma clínica médica, com e sem doença renal crônica. São Paulo, 2013.

\begin{tabular}{|c|c|c|c|c|c|c|c|}
\hline \multirow[t]{2}{*}{ Variáveis } & \multicolumn{2}{|c|}{$\begin{array}{l}\text { Com doença } \\
\text { renal crônica } \\
(\mathrm{N}=86)\end{array}$} & \multicolumn{2}{|c|}{$\begin{array}{c}\text { Sem doença } \\
\text { renal crônica } \\
(N=143)\end{array}$} & \multicolumn{2}{|c|}{$\begin{array}{c}\text { Total } \\
(\mathrm{N}=229) \\
\end{array}$} & \multirow{3}{*}{$\begin{array}{c}\begin{array}{c}\text { Valor } \\
\mathbf{p}\end{array} \\
0,022\end{array}$} \\
\hline & $\mathbf{N}$ & $\%$ & $\mathbf{N}$ & $\%$ & $\mathbf{N}$ & $\%$ & \\
\hline \multicolumn{7}{|l|}{ Tabagismo $(\mathrm{N}=221)$} & \\
\hline Sim & 8 & 9,9 & 35 & 25,0 & 43 & 19,5 & \\
\hline Parou & 35 & 43,2 & 53 & 37,9 & 88 & 39,8 & \\
\hline Não & 38 & 46,9 & 52 & 37,1 & 90 & 40,7 & \\
\hline Etilismo & & & & & & & 0,805 \\
\hline Sim & 7 & 8,1 & 13 & 9,1 & 20 & 8,7 & \\
\hline Não & 79 & 91,9 & 130 & 90,9 & 209 & 91,3 & \\
\hline \multicolumn{7}{|c|}{ Acompanhamento em serviço de saúde $(\mathrm{N}=194)$} & 0,001 \\
\hline Ambulatório SUS & 31 & 42,5 & 43 & 35,5 & 74 & 38,1 & \\
\hline UBS & 29 & 39,7 & 43 & 35,5 & 72 & 37,1 & \\
\hline Clínica de diálise & 4 & 5,5 & 0 & 0,0 & 4 & 2,1 & \\
\hline PAD & 2 & 2,7 & 1 & 0,8 & 3 & 1,5 & \\
\hline Ambulatório particular & 2 & 2,7 & 1 & 0,8 & 3 & 1,5 & \\
\hline Convênio & 0 & 0,0 & 2 & 1,7 & 2 & 1,0 & \\
\hline Não especificado & 0 & 0,0 & 4 & 3,3 & 4 & 2,1 & \\
\hline Não faz & 5 & 6,8 & 27 & 22,3 & 32 & 16,5 & \\
\hline \multicolumn{8}{|c|}{ Número de medicamentos de uso contínuo } \\
\hline Mediana $\left(1^{\circ} .-3^{\circ}\right.$. quartis) & \multicolumn{2}{|c|}{$4,0(2,0-5,0)$} & \multicolumn{2}{|c|}{$2,0(0,5-4,0)$} & \multicolumn{2}{|c|}{$3,0(1,0-5,0)$} & $<0,001$ \\
\hline
\end{tabular}

Observa-se, pelos dados da Tabela 14, que os hipertensos sem doença renal crônica foram diferentes daqueles com doença renal crônica $(p<0,05)$, por serem fumantes $(25,0$ vs $9,9 \%)$; e por não fazerem acompanhamento em serviço de saúde (22,3\% vs $6,8 \%$ ). Por outro lado, os hipertensos com doença renal crônica faziam uso contínuo de número maior de medicamentos $(p<0,05)$, comparados àqueles sem doença renal crônica $(4,0(2,0-5,0)$ vs $2,0(0,5-4,0))$. 
Natália Alencar de Pinho

Tabela 15 - Principais antecedentes de saúde, pessoais e familiares, dos hipertensos internados em uma clínica médica, com e sem doença renal crônica. São Paulo, 2013.

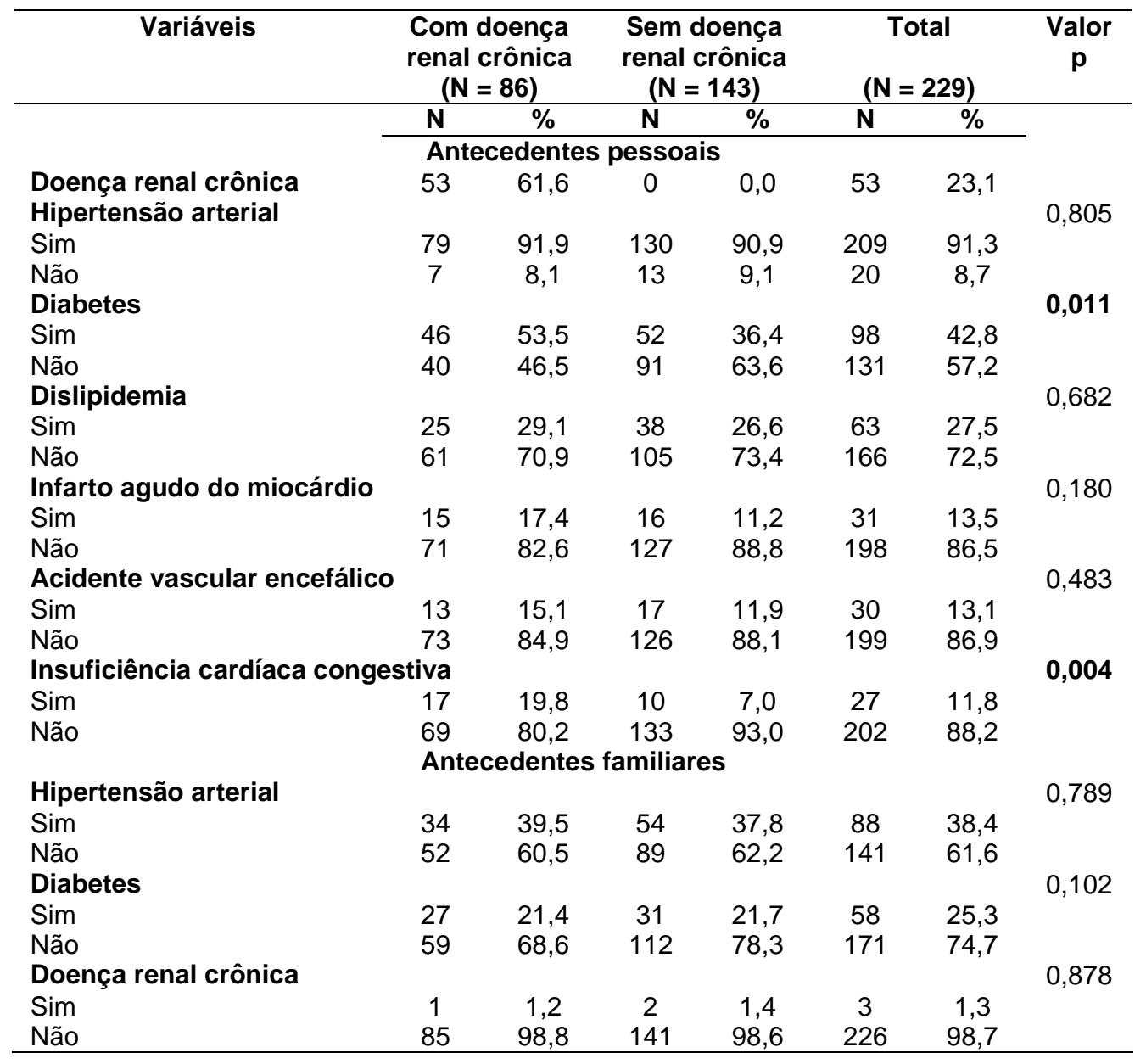

No que concerne aos antecedentes de saúde, quase a totalidade dos indivíduos com e sem doença renal crônica (95,3\% e 92,3\%, respectivamente) apresentava pelo menos uma comorbidade. Os dados apresentados na Tabela 15 mostram diferença significativa $(p<0,05)$ entre os grupos com e sem doença renal crônica, quanto a ter antecedentes pessoais para as seguintes comorbidades: diabetes $(53,5 \%$ vs $36,4 \%)$ e insuficiência cardíaca congestiva $(19,8 \%$ vs $7,0 \%)$. Os hipertensos com e sem doença renal crônica foram semelhantes quanto à presença de antecedente pessoal de hipertensão arterial, infarto agudo do miocárdio, acidente vascular encefálico e dislipidemia. 
Natália Alencar de Pinho

Tinham antecedentes familiares de hipertensão arterial, diabetes melito ou doença renal crônica $46,5 \%$ dos hipertensos com doença renal crônica e 44,8\% dos sem doença renal crônica. Não houve diferença entre os grupos.

Tabela 16 - Principais medicamentos de uso contínuo dos hipertensos internados em uma clínica médica, com e sem doença renal crônica. São Paulo, 2013.

\begin{tabular}{|c|c|c|c|c|c|c|c|}
\hline \multirow[t]{2}{*}{ Classes medicamentosas } & \multicolumn{2}{|c|}{$\begin{array}{c}\text { Com doença } \\
\text { renal crônica } \\
(\mathrm{N}=86)\end{array}$} & \multicolumn{2}{|c|}{$\begin{array}{l}\text { Sem doença } \\
\text { renal crônica } \\
(N=143)\end{array}$} & \multicolumn{2}{|c|}{$\begin{array}{c}\text { Total } \\
\text { (N = 229) }\end{array}$} & \multirow{3}{*}{$\begin{array}{c}\begin{array}{c}\text { Valor } \\
\text { p }\end{array} \\
0.041\end{array}$} \\
\hline & $\mathbf{N}$ & $\%$ & $\mathbf{N}$ & $\%$ & $\mathbf{N}$ & $\%$ & \\
\hline \multicolumn{7}{|l|}{ Anti-hipertensivos } & \\
\hline Sim & 68 & 79,1 & 95 & 66,4 & 163 & 71,2 & \\
\hline Não & 18 & 20,9 & 48 & 33,6 & 66 & 28,8 & \\
\hline \multicolumn{7}{|l|}{ Antiagregantes plaquetários } & 0,340 \\
\hline Sim & 26 & 30,2 & 35 & 24,5 & 61 & 26,6 & \\
\hline Não & 60 & 69,8 & 108 & 75,5 & 168 & 73,4 & \\
\hline \multicolumn{7}{|l|}{ Antidiabéticos orais } & 0,688 \\
\hline Sim & 15 & 17,4 & 28 & 19,6 & 43 & 18,8 & \\
\hline Não & 71 & 82,6 & 115 & 80,4 & 186 & 81,2 & \\
\hline \multicolumn{7}{|l|}{ Estatinas } & 0,432 \\
\hline Sim & 18 & 20,9 & 24 & 16,8 & 42 & 18,3 & \\
\hline Não & 68 & 79,1 & 119 & 83,2 & 187 & 81,7 & \\
\hline \multicolumn{7}{|l|}{ Insulina } & $<0,001$ \\
\hline Sim & 21 & 24,4 & 10 & 7,0 & 31 & 13,5 & \\
\hline Não & 65 & 75,6 & 133 & 93,0 & 198 & 86,5 & \\
\hline \multicolumn{7}{|c|}{ Medicamentos de ação cardíaca* } & 0,056 \\
\hline Sim & 16 & 18,6 & 14 & 9,8 & 30 & 13,1 & \\
\hline Não & 70 & 81,4 & 129 & 90,2 & 199 & 86,9 & \\
\hline \multicolumn{7}{|l|}{ Psicotrópicos } & 0,903 \\
\hline Sim & 7 & 8,1 & 11 & 7,7 & 18 & 7,9 & \\
\hline Não & 79 & 91,9 & 132 & 92,3 & 211 & 92,1 & \\
\hline
\end{tabular}

Segundo os dados da Tabela $16,71,1 \%$ dos hipertensos faziam uso contínuo de medicamentos anti-hipertensivos, sendo esta frequência superior entre os hipertensos com doença renal crônica comparados aos sem doença renal crônica $(79,1 \%$ vs $66,4 \%, p=$ $0,041)$. Houve ainda diferença significativa $(p<0,05)$ entre os grupos no que se refere ao tratamento por insulina, com frequência de $24,4 \%$ vs $7,0 \%$, para hipertensos com e sem doença renal crônica, respectivamente. 
Natália Alencar de Pinho

Tabela 17 - Número e classe de medicamentos anti-hipertensivos de uso contínuo dos hipertensos internados em uma clínica médica, com e sem doença renal crônica. São Paulo, 2013.

\begin{tabular}{|c|c|c|c|c|c|c|c|}
\hline \multirow[t]{2}{*}{ Variáveis } & \multicolumn{2}{|c|}{$\begin{array}{c}\text { Com doença } \\
\text { renal crônica } \\
(N=86)\end{array}$} & \multicolumn{2}{|c|}{$\begin{array}{c}\text { Sem doença } \\
\text { renal crônica } \\
(N=143)\end{array}$} & \multicolumn{2}{|c|}{$\begin{array}{c}\text { Total } \\
(\mathrm{N}=229) \\
\end{array}$} & \multirow[t]{2}{*}{$\begin{array}{c}\text { Valor } \\
\mathbf{p}\end{array}$} \\
\hline & $\mathbf{N}$ & $\%$ & $\mathbf{N}$ & $\%$ & $\mathbf{N}$ & $\%$ & \\
\hline \multicolumn{7}{|c|}{ Número de anti-hipertensivos } & \multirow[t]{5}{*}{0,001} \\
\hline Nenhum & 18 & 20,9 & 48 & 33,6 & 66 & 28,8 & \\
\hline Um & 13 & 15,1 & 40 & 28,0 & 53 & 23,1 & \\
\hline Dois a três & 40 & 46,5 & 45 & 31,5 & 85 & 37,1 & \\
\hline Mais de três & 15 & 17,4 & 10 & 7,0 & 25 & 10,9 & \\
\hline \multicolumn{7}{|c|}{ Inibidores da enzima conversora de angiotensina } & \multirow[t]{3}{*}{0,849} \\
\hline Sim & 39 & 45,3 & 63 & 44,1 & 102 & 44,5 & \\
\hline Não & 47 & 54,7 & 80 & 55,9 & 127 & 55,5 & \\
\hline \multicolumn{7}{|c|}{ Bloqueadores beta-adrenérgicos } & \multirow[t]{3}{*}{0,010} \\
\hline Sim & 30 & 34,9 & 28 & 19,6 & 58 & 25,3 & \\
\hline Não & 56 & 65,1 & 115 & 80,4 & 171 & 74,7 & \\
\hline \multicolumn{7}{|l|}{ Diuréticos tiazídicos } & \multirow[t]{3}{*}{0,328} \\
\hline Sim & 13 & 15,1 & 29 & 20,3 & 42 & 18,3 & \\
\hline Não & 73 & 84,9 & 114 & 79,7 & 187 & 81,7 & \\
\hline \multicolumn{7}{|c|}{ Bloqueadores dos canais de cálcio } & \multirow[t]{3}{*}{0,001} \\
\hline Sim & 25 & 29,1 & 16 & 11,2 & 41 & 17,9 & \\
\hline Não & 61 & 70,9 & 127 & 88,8 & 188 & 82,1 & \\
\hline \multicolumn{7}{|l|}{ Diuréticos de alça } & \multirow[t]{3}{*}{$<0,001$} \\
\hline Sim & 26 & 30,2 & 15 & 10,5 & 41 & 17,9 & \\
\hline Não & 60 & 69,8 & 128 & 89,5 & 188 & 82,1 & \\
\hline \multicolumn{7}{|c|}{ Diuréticos poupadores de potássio } & \multirow[t]{3}{*}{0,134} \\
\hline Sim & 7 & 8,1 & 5 & 3,5 & 12 & 5,2 & \\
\hline Não & 79 & 91,9 & 138 & 96,5 & 217 & 94,8 & \\
\hline \multicolumn{7}{|c|}{ Antagonistas do receptor de angiotensina II } & \multirow[t]{3}{*}{0,764} \\
\hline Sim & 5 & 5,8 & 7 & 4,9 & 12 & 5,2 & \\
\hline Não & 81 & 94,2 & 136 & 95,1 & 217 & 94,8 & \\
\hline \multicolumn{7}{|l|}{ Vasodilatadores diretos } & \multirow[t]{3}{*}{0,015} \\
\hline Sim & 8 & 9,3 & 3 & 2,1 & 11 & 4,8 & \\
\hline Não & 78 & 90,7 & 140 & 97,9 & 218 & 95,9 & \\
\hline \multicolumn{7}{|l|}{ Inibidores alfa-adrenérgicos } & \multirow[t]{3}{*}{0,530} \\
\hline Sim & 3 & 3,5 & 3 & 2,1 & 6 & 2,6 & \\
\hline Não & 83 & 96,5 & 140 & 97,9 & 223 & 97,4 & \\
\hline
\end{tabular}

Os dados da Tabela 17 revelam que os hipertensos com doença renal crônica faziam uso contínuo de maior número de medicamentos anti-hipertensivos $(p=0,001)$ do que os hipertensos sem doença renal crônica, com frequência de $46,5 \%$ vs $31,5 \%$, para dois a três medicamentos, e de $17,4 \%$ vs $7,0 \%$, para quatro medicamentos ou mais.

As classes de anti-hipertensivos mais utilizadas foram os inibidores da enzima conversora de angiotensina (44,5\%), os bloqueadores beta-adrenérgicos $(25,3 \%)$ e os diuréticos tiazídicos 
Natália Alencar de Pinho

$(18,3 \%)$. Houve diferença significativa $(p<0,05)$ entre os hipertensos com e sem doença renal crônica no consumo dos seguintes anti-hipertensivos: bloqueadores beta-adrenérgicos (34,9\% vs 19,6\%); bloqueadores dos canais de cálcio $(29,1 \%$ vs $11,2 \%)$; diuréticos de alça $(30,2 \%$ vs $10,5 \%)$; e vasodilatadores diretos $(9,3 \%$ vs $2,1 \%)$.

Tabela 18 - Principais diagnósticos médicos dos hipertensos internados em uma clínica médica, com e sem doença renal crônica. São Paulo, 2013.

\begin{tabular}{|c|c|c|c|c|c|c|c|}
\hline \multirow[t]{2}{*}{ Diagnósticos médicos } & \multicolumn{2}{|c|}{$\begin{array}{c}\text { Com doença } \\
\text { renal crônica } \\
(\mathrm{N}=86)\end{array}$} & \multicolumn{2}{|c|}{$\begin{array}{l}\text { Sem doença } \\
\text { renal crônica } \\
(N=143)\end{array}$} & \multicolumn{2}{|c|}{$\begin{array}{c}\text { Total } \\
\text { (N = 229) }\end{array}$} & \multirow{3}{*}{$\begin{array}{c}\begin{array}{c}\text { Valor } \\
\mathbf{p}\end{array} \\
0,719\end{array}$} \\
\hline & $\mathbf{N}$ & $\%$ & $\mathbf{N}$ & $\%$ & $\mathbf{N}$ & $\%$ & \\
\hline \multicolumn{7}{|l|}{ Hipertensão arterial } & \\
\hline $\operatorname{Sim}$ & 85 & 98,8 & 142 & 99,3 & 227 & 99,1 & \\
\hline Não & 1 & 1,2 & 1 & 0,7 & 2 & 0,9 & \\
\hline Diabetes & & & & & & & 0,029 \\
\hline Sim & 47 & 54,7 & 57 & 39,9 & 104 & 45,4 & \\
\hline & 39 & 45,3 & 86 & 60,1 & 125 & 54,6 & \\
\hline \multicolumn{7}{|c|}{ Infarto agudo do miocárdio/ angina } & 0,204 \\
\hline $\operatorname{Sim}$ & 22 & 25,6 & 48 & 33,6 & 70 & 30,6 & \\
\hline Não & 64 & 74,4 & 95 & 66,4 & 159 & 69,4 & \\
\hline \multicolumn{7}{|l|}{ Dislipidemia } & 0,845 \\
\hline $\operatorname{Sim}$ & 26 & 30,2 & 45 & 31,5 & 71 & 31,0 & \\
\hline Não & 60 & 69,8 & 98 & 68,5 & 158 & 69,0 & \\
\hline \multicolumn{7}{|l|}{ Doenças respiratórias } & 0,343 \\
\hline $\operatorname{Sim}$ & 22 & 25,6 & 45 & 31,5 & 67 & 29,3 & \\
\hline Não & 64 & 74,4 & 98 & 68,5 & 162 & 70,7 & \\
\hline \multicolumn{7}{|l|}{ Doenças cerebrovasculares* } & 0,718 \\
\hline Sim & 21 & 24,4 & 38 & 26,6 & 59 & 25,8 & \\
\hline Não & 65 & 75,6 & 105 & 73,4 & 170 & 74,2 & \\
\hline \multicolumn{7}{|c|}{ Insuficiência cardíaca congestiva } & 0,005 \\
\hline & 29 & 33,7 & 25 & 17,5 & 54 & 23,6 & \\
\hline Não & 57 & 66,3 & 118 & 82,5 & 175 & 76,4 & \\
\hline
\end{tabular}

Os dados apresentados pela Tabela 18 mostram que quase a totalidade dos hipertensos $(99,1 \%)$ teve a hipertensão arterial registrada como um dos diagnósticos da internação. O diabetes melito foi o segundo mais frequente, havendo diferença significativa $(p<0,05)$ na sua ocorrência entre os hipertensos com e sem doença renal crônica $(54,7 \%$ vs 39,9\%). Verificou-se também maior frequência de diagnóstico médico de insuficiência cardíaca congestiva entre os hipertensos com doença renal crônica comparados aos sem doença renal crônica $(33,7 \%$ vs $17,5 \%$, p = $0,005)$. 
Natália Alencar de Pinho

Tabela 19 - Exames laboratoriais dos hipertensos internados em uma clínica médica, com e sem doença renal crônica. São Paulo, 2013.

\begin{tabular}{|c|c|c|c|c|c|}
\hline \multirow[t]{2}{*}{$\begin{array}{c}\text { Exames } \\
\text { laboratoriais }\end{array}$} & & $\begin{array}{l}\text { Com doença } \\
\text { renal crônica }\end{array}$ & $\begin{array}{l}\text { Sem doença } \\
\text { renal crônica }\end{array}$ & Total & \multirow[t]{2}{*}{$\begin{array}{c}\text { Valor } \\
\mathbf{p}\end{array}$} \\
\hline & $\mathbf{N}$ & Mec & ana $\left(1^{\circ}\right.$. e $3^{\circ}$. qu & tis) & \\
\hline $\begin{array}{l}\text { Potássio sérico } \\
(\mathrm{mEq} / \mathrm{l})\end{array}$ & 228 & $4,6(4,1-5,3)$ & $4,0(3,8-4,5)$ & $4,2(3,9-4,7)$ & $<0,001$ \\
\hline $\begin{array}{l}\text { Ureia sérica } \\
(\mathrm{mg} / \mathrm{dL})\end{array}$ & 228 & $\begin{array}{c}113,0(84,0- \\
162,0)\end{array}$ & $\begin{array}{c}36,0(29,0- \\
46,0)\end{array}$ & $\begin{array}{l}47,5(33,5- \\
96,5)\end{array}$ & $<0,001$ \\
\hline Hemoglobina (g/dL) & 225 & $11,3(9,3-12,8)$ & $\begin{array}{c}13,4(12,3- \\
14,6)\end{array}$ & $\begin{array}{c}12,8(11,2- \\
14,2)\end{array}$ & $<0,001$ \\
\hline Hematócrito (\%) & 225 & $\begin{array}{c}33,0(28,0- \\
38,0)\end{array}$ & $\begin{array}{c}40,0(38,0- \\
44,0)\end{array}$ & $\begin{array}{c}39,0(33,0- \\
43,0)\end{array}$ & $<0,001$ \\
\hline $\begin{array}{l}\text { Creatinina sérica } \\
(\mathrm{mg} / \mathrm{dL})\end{array}$ & 177 & $2,8(2,1-5,0)$ & $0,9(0,7-1,1)$ & $1,2(0,8-2,7)$ & $<0,001$ \\
\hline Glicemia (mg/dL) & 120 & $\begin{array}{c}122,0(103,0- \\
195,0)\end{array}$ & $\begin{array}{c}123,0(103,0- \\
161,5)\end{array}$ & $\begin{array}{c}122,5(103,0- \\
174,0)\end{array}$ & 0,896 \\
\hline $\begin{array}{l}\text { Albumina sérica } \\
(\mathrm{g} / \mathrm{dL})\end{array}$ & 76 & $3,3(2,8-3,4)$ & $3,7(3,5-4,1)$ & $3,5(3,1-4,0)$ & $<0,001$ \\
\hline $\begin{array}{l}\text { Fósforo sérico } \\
(\mathrm{mg} / \mathrm{dL})\end{array}$ & 97 & $4,7(3,6-5,7)$ & $3,5(2,8-4,1)$ & $4,0(3,1-5,1)$ & $<0,001$ \\
\hline Colesterol (mg/dL) & 73 & $\begin{array}{c}157,0(134,0- \\
174,0)\end{array}$ & $\begin{array}{c}164,0(144,0- \\
208,0)\end{array}$ & $\begin{array}{c}163,0(142,0- \\
197,0)\end{array}$ & 0,264 \\
\hline HDL (mg/dL) & 72 & $\begin{array}{c}33,0(29,5- \\
45,0)\end{array}$ & $\begin{array}{c}39,0(30,0- \\
54,0)\end{array}$ & $\begin{array}{l}35,5(29,5- \\
53,5)\end{array}$ & 0,328 \\
\hline LDL (mg/dL) & 73 & $\begin{array}{c}84,0(76,0- \\
110,0)\end{array}$ & $\begin{array}{c}96,0(73,5- \\
124,0)\end{array}$ & $\begin{array}{c}93,0(75,0- \\
117,0)\end{array}$ & 0,601 \\
\hline $\begin{array}{l}\text { Triglicérides } \\
\text { (mg/dL) }\end{array}$ & 66 & $\begin{array}{c}126,5(96,5- \\
189,5)\end{array}$ & $\begin{array}{c}138,0(108,0- \\
201,0)\end{array}$ & $\begin{array}{c}134,0(106,0- \\
198,0)\end{array}$ & 0,625 \\
\hline Ácido úrico (mg/dL) & 19 & $7,5(6,9-8,5)$ & $6,3(5,5-7,7)$ & $7,0(6,0-8,1)$ & 0,072 \\
\hline Proteinúria (n/\%) & 113 & 85,1 & 30,3 & 53,1 & $<0,001$ \\
\hline
\end{tabular}

Observa-se pelos dados da Tabela 19 que os hipertensos com doença renal crônica foram significativamente diferentes $(p<$ $0,05)$ daqueles sem doença renal crônica por apresentarem, na análise sanguínea, maiores valores de potássio $(4,6(4,1-5,3)$ vs $4,1(3,8$ - 4,4) $\mathrm{mEq} / \mathrm{l})$; ureia $(113,0(84,0$ - 162,0) vs $36,0(29,0-$ $46,0) \mathrm{mg} / \mathrm{dL})$; creatinina sérica $(2,8(2,1-5,0)$ vs $0,9(0,7-1,1)$ $\mathrm{mg} / \mathrm{dL})$; e fósforo $(4,7(3,6-5,7)$ vs $3,5(2,8-4,1) \mathrm{mg} / \mathrm{dL})$.

Foram significativamente inferiores $(p<0,05)$, para os hipertensos com doença renal crônica, os valores e hemoglobina $(11,3(9,3-12,8) \mathrm{g}$ vs $13,4(12,3-14,6) \mathrm{g} / \mathrm{dL}) ;$ hematócrito $(33,0$ $(28,0-38,0)$ vs $40,0(38,0-44,0) \%)$; e albumina sérica $(3,3(2,8-$ 
$3,4)$ vs $3,7(3,5-4,1) \mathrm{g} / \mathrm{dL})$.

Houve maior proporção $(p<0,05)$ de indivíduos com proteinúria entre os hipertensos com doença renal crônica, comparados aos sem doença renal crônica (85,1\% vs 30,3\%).

Os hipertensos com doença renal crônica apresentaram níveis de ureia, creatinina e ácido úrico séricos superiores ao limite de normalidade; já a hemoglobina e hematócrito foram compatíveis com anemia, tanto para homens como para mulheres. Os valores da fração Colesterol HDL foram inferiores aos limites de normalidade, para os hipertensos com e sem doença renal crônica. 
Tabela 20 - Valores de pressão arterial nos primeiros dez dias de hospitalização dos hipertensos internados em uma clínica médica, com e sem doença renal crônica. São Paulo, 2013.

\begin{tabular}{|c|c|c|c|c|c|c|c|c|c|c|}
\hline \multirow[t]{3}{*}{ Dia } & \multirow{3}{*}{$\begin{array}{c}\mathbf{N} \\
\text { (PAS) }\end{array}$} & \multirow{3}{*}{$\begin{array}{c}N \\
\text { (PAD } \\
\text { ) }\end{array}$} & \multirow{2}{*}{\multicolumn{2}{|c|}{$\begin{array}{c}\text { Com doença renal crônica } \\
\text { Pressão arterial } \\
\text { (mmHg, média } \pm d p)\end{array}$}} & \multirow{3}{*}{$\begin{array}{c}\mathbf{N} \\
\text { (PAS) }\end{array}$} & \multirow{3}{*}{$\begin{array}{c}\mathbf{N} \\
(\mathrm{PAD})\end{array}$} & \multirow{2}{*}{\multicolumn{2}{|c|}{$\begin{array}{c}\text { Sem doença renal crônica } \\
\text { Pressão arterial } \\
\text { (mmHg, média } \pm \text { dp) }\end{array}$}} & \multirow{2}{*}{\multicolumn{2}{|c|}{ Valor de $p$}} \\
\hline & & & & & & & & & & \\
\hline & & & Sistólica & Diastólica & & & Sistólica & Diastólica & Sistólica & Diastólica \\
\hline 1 & 84 & 84 & $130,4 \pm 22,6$ & $77,5 \pm 13,6$ & 136 & 136 & $132,1 \pm 24,6$ & $78,2 \pm 14,4$ & 0,605 & 0,700 \\
\hline 2 & 81 & 80 & $130,3 \pm 21,7$ & $77,9 \pm 13,6$ & 135 & 135 & $133,0 \pm 21,1$ & $77,6 \pm 13,7$ & 0,381 & 0,884 \\
\hline 3 & 80 & 80 & $128,2 \pm 23,4$ & $77,6 \pm 13,8$ & 126 & 125 & $134,5 \pm 23,3$ & $79,7 \pm 12,9$ & 0,060 & 0,267 \\
\hline 4 & 78 & 78 & $128,4 \pm 20,7$ & $76,5 \pm 11,9$ & 122 & 122 & $131,5 \pm 22,3$ & $77,5 \pm 12,3$ & 0,325 & 0,607 \\
\hline 5 & 76 & 76 & $126,1 \pm 19,2$ & $75,1 \pm 11,1$ & 110 & 109 & $128,4 \pm 20,7$ & $76,5 \pm 12,7$ & 0,474 & 0,442 \\
\hline 6 & 72 & 73 & $128,9 \pm 23,5$ & $76,3 \pm 13,2$ & 101 & 101 & $127,1 \pm 22,5$ & $76,9 \pm 11,7$ & 0,624 & 0,753 \\
\hline 7 & 60 & 60 & $129,8 \pm 20,1$ & $77,0 \pm 11,4$ & 91 & 91 & $126,4 \pm 21,8$ & $74,4 \pm 12,3$ & 0,334 & 0,198 \\
\hline 8 & 50 & 50 & $129,4 \pm 25,3$ & $74,3 \pm 11,5$ & 80 & 80 & $125,3 \pm 21,1$ & $76,3 \pm 12,1$ & 0,322 & 0,345 \\
\hline 9 & 44 & 44 & $129,5 \pm 24,0$ & $75,4 \pm 13,8$ & 63 & 64 & $126,5 \pm 22,7$ & $75,9 \pm 13,4$ & 0,522 & 0,863 \\
\hline 10 & 39 & 38 & $127,4 \pm 20,5$ & $74,6 \pm 13,0$ & 55 & 54 & $126,1 \pm 20,4$ & $76,4 \pm 11,3$ & 0,769 & 0,483 \\
\hline
\end{tabular}

Os dados da Tabela 20 mostram os valores de pressão arterial do total de hipertensos com e sem doença renal crônica nos dez primeiros dias da internação. Não houve diferença dos níveis tensionais diários entre os grupos. 
Tabela 21 - Valores de pressão arterial dos hipertensos internados em uma clínica médica, com e sem doença renal crônica, que apresentaram medidas registradas do primeiro ao décimo dia de internação. São Paulo, 2013.

\begin{tabular}{|c|c|c|c|c|}
\hline \multirow[t]{3}{*}{ Dia } & \multicolumn{2}{|c|}{ Com doença renal crônica } & \multicolumn{2}{|c|}{ Sem doença renal crônica } \\
\hline & \multicolumn{4}{|c|}{ Pressão arterial $(\mathrm{mmHg}$, média $\pm \mathrm{dp})$} \\
\hline & Sistólica $(\mathrm{N}=31)$ & Diastólica $(\mathrm{N}=30)$ & Sistólica $(\mathrm{N}=43)$ & Diastólica $(\mathrm{N}=42)$ \\
\hline 1 & $128,6 \pm 22,8$ & $77,0 \pm 11,0$ & $130,5 \pm 28,8$ 屯 & $79,0 \pm 14,6$ \\
\hline 2 & $124,8 \pm 21,7$ & $76,3 \pm 13,9$ & $130,4 \pm 16,6 c$ & $78,0 \pm 11,9$ \\
\hline 3 & $126,2 \pm 24,9$ * \# & $78,4 \pm 14,7$ & $136,4 \pm 22,7 ¥$ & $81,3 \pm 14,0$ \\
\hline 4 & $129,4 \pm 21,6$ & $76,1 \pm 11,1$ & $128,1 \pm 20,4$ & $75,3 \pm 11,1$ \\
\hline 5 & $127,5 \pm 21,5$ & $75,7 \pm 12,8$ & $127,1 \pm 21,4$ & $76,7 \pm 11,6$ \\
\hline 6 & $134,4 \pm 28,7$ * & $78,2 \pm 13,1$ & $123,3 \pm 20,4$ & $76,4 \pm 10,1$ \\
\hline 7 & $130,8 \pm 20,4$ & $76,6 \pm 12,0$ & $124,1 \pm 17,8$ & $74,6 \pm 11,0$ \\
\hline 8 & $130,3 \pm 24,7$ & $74,3 \pm 12,5$ & $122,9 \pm 22,5$ & $74,8 \pm 12,7$ \\
\hline 9 & $127,2 \pm 22,5$ & $75,0 \pm 12,3$ & $124,9 \pm 22,1$ & $74,1 \pm 14,0$ \\
\hline 10 & $126,2 \pm 21,4$ & $74,3 \pm 12,7$ & $126,5 \pm 21,4$ & $77,2 \pm 11,4$ \\
\hline
\end{tabular}

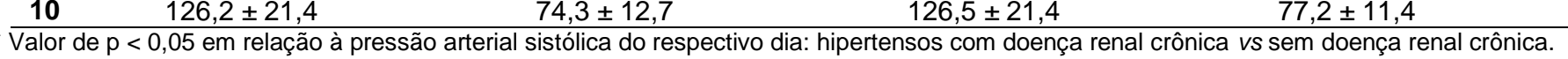

\# Valor de $p<0,05$ em relação à pressão arterial sistólica dos dias 2 e 10 no grupo com doença renal crônica.

$\$$ Valor de $p<0,05$ em relação à pressão arterial sistólica do dia 8 no grupo sem doença renal crônica.

$¥$ Valor de $p<0,05$ em relação à pressão arterial sistólica dos dias 4 a 10 no grupo sem doença renal crônica. 
Figura 5 - Comparação dos valores de pressão arterial dos hipertensos com e sem doença renal crônica que apresentaram medidas registradas do primeiro ao décimo dia de internação. São Paulo, 2013.

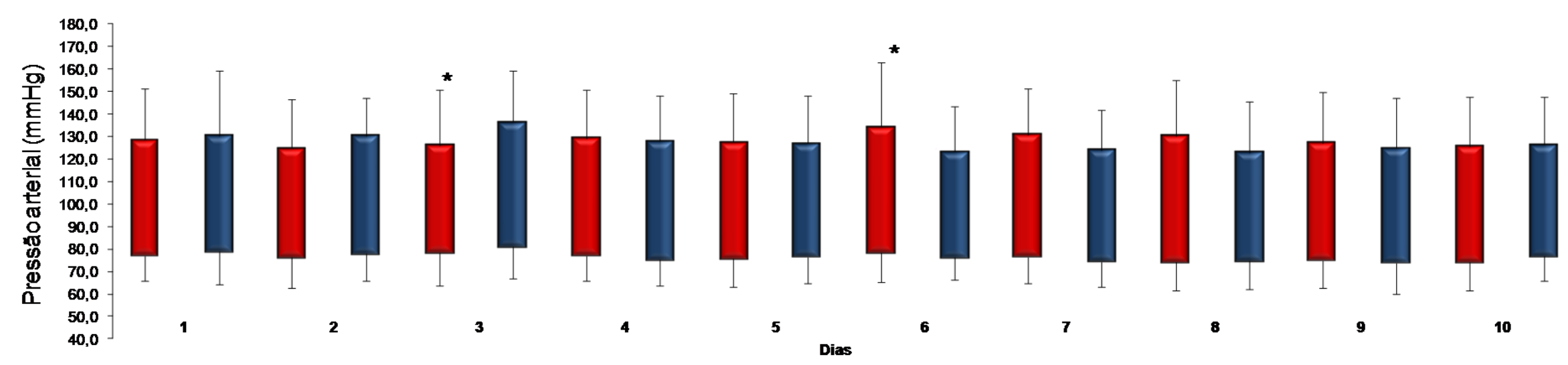

*Valor de $p<0,05$ em relação à pressão arterial sistólica do respectivo dia : pacientes com doença renal crônica vs sem doença renal crônica. 
Natália Alencar de Pinho

Figura 6 - Variação da pressão arterial dos pacientes com doença renal crônica internados em uma clínica médica que apresentaram medidas registradas do primeiro ao décimo dia de internação. São Paulo, 2013.

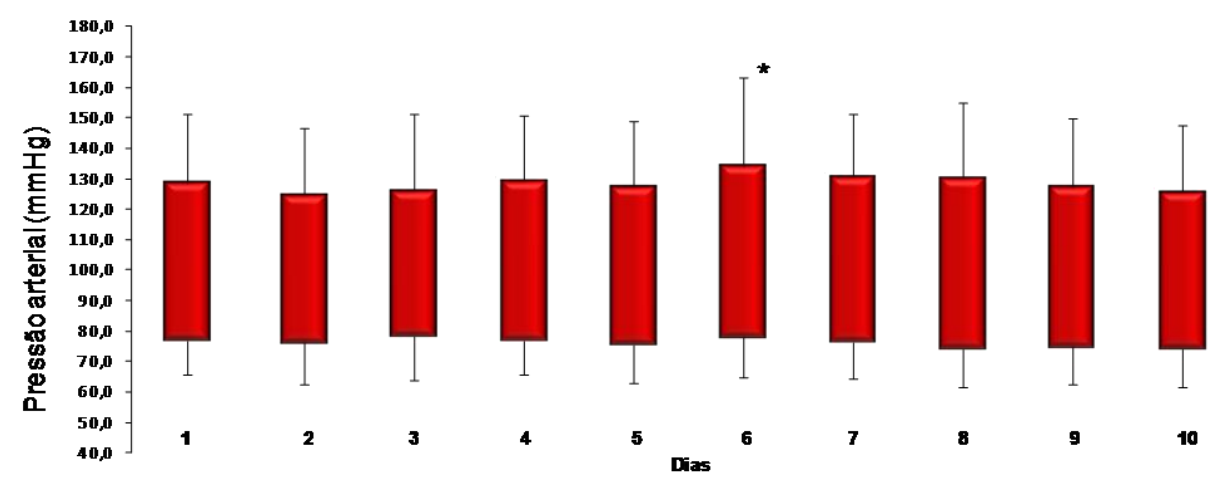

*Valor de $p<0,05$ em relação à pressão arterial dos dias 2 e 10.

Figura 7 - Variação da pressão arterial dos pacientes sem doença renal crônica internados em uma clínica médica que apresentaram medidas registradas do primeiro ao décimo dia de internação. São Paulo, 2013.

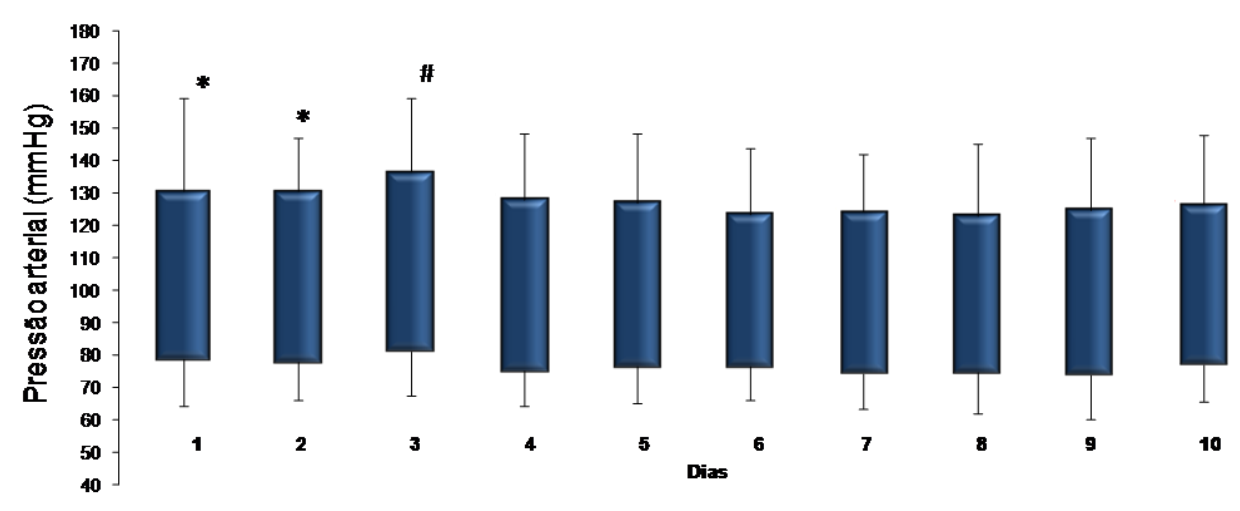

* Valor de $p<0,05$ em relação à pressão arterial do dia 8

\#Valor de $p<0,05$ em relaçãoà pressão arterialdos dias 4 a 10

Os dados da Tabela 21 mostram as médias de pressão arterial de hipertensos com e sem doença renal crônica que apresentaram valores registrados do primeiro ao décimo dia de internação. Os resultados das análises de comparação entre os grupos, assim como os da análise intragrupo, são apresentados nas Figuras 5 a 7 .

Na comparação entre os hipertensos com e sem doença renal crônica (Figura 5), a pressão arterial sistólica de hipertensos com 
doença renal crônica foi significativamente $(p<0,05)$ inferior à dos hipertensos sem doença renal crônica no terceiro dia $(126,2 \pm 24,9$ vs $136,4 \pm 22,7 \mathrm{mmHg}$ ) e significativamente superior no sexto dia $(134,4 \pm 20,4$ vs $123,3 \pm 20,4 \mathrm{~mm} \mathrm{Hg})$. As pressões arteriais diastólicas não apresentaram diferença significativa entre os grupos.

A Figura 6 mostra que a pressão arterial sistólica de hipertensos com doença renal crônica foi mais elevada no sexto dia, diferindo significativamente $(p<0,05)$ dos valores obtidos no segundo e no décimo dia de hospitalização. Não houve variação da pressão arterial diastólica.

Para hipertensos sem doença renal crônica (Figura 7), a pressão arterial sistólica foi significativamente superior $(p<0,05)$, nos primeiros três dias de internação, em relação à pressão arterial obtida no oitavo dia. Destaca-se a pressão arterial do terceiro dia, a qual diferiu significativamente $(p<0,05)$ dos valores do quarto ao décimo dia. Não houve variação da pressão arterial diastólica.

Figura 8 - Controle da hipertensão arterial de hipertensos internados em uma clínica médica, com e sem doença renal crônica. São Paulo, 2013.

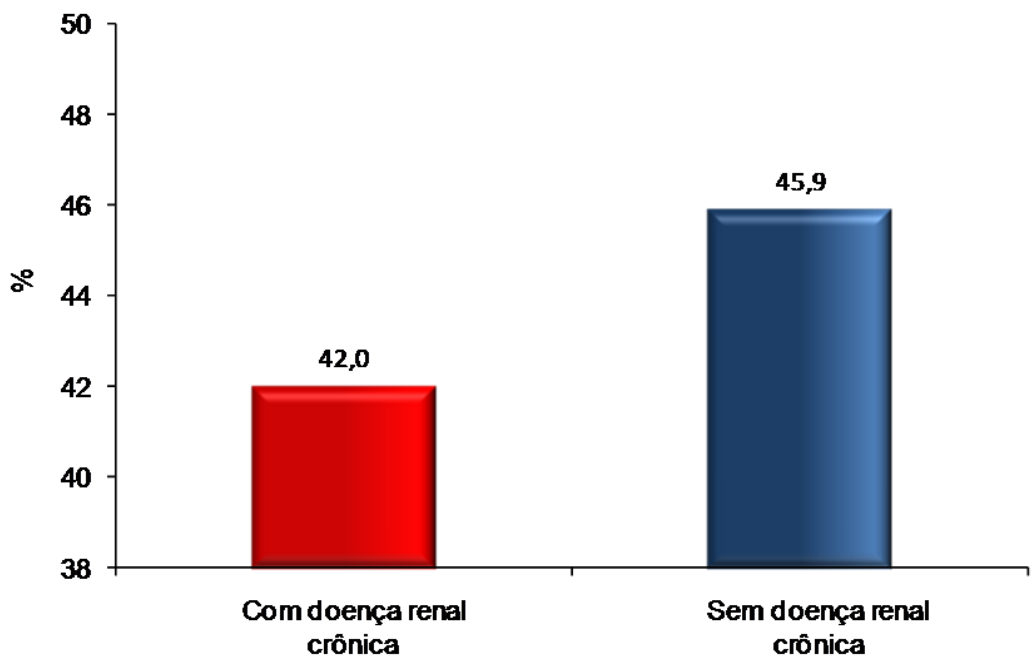


Natália Alencar de Pinho

A Figura 8 apresenta o controle da hipertensão arterial de hipertensos com e sem doença renal crônica, baseado na pressão arterial do primeiro dia de internação. O corte de 130 e $80 \mathrm{mmHg}$, para pressão arterial sistólica e diastólica, respectivamente, foi adotado para hipertensos com doença renal crônica; e o de 140 e 90 $\mathrm{mmHg}$, para pressão arterial sistólica e diastólica, respectivamente, para os sem doença renal crônica. A frequência de controle dos hipertensos em geral foi de 44,5\%, não havendo diferença significativa entre os grupos.

Tabela 22 - Desfechos da hospitalização dos hipertensos internados em uma clínica médica com e sem doença renal crônica. São Paulo, 2013.

\begin{tabular}{|c|c|c|c|c|c|c|c|}
\hline \multirow[t]{2}{*}{$\begin{array}{l}\text { Desfechos da } \\
\text { hospitalização }\end{array}$} & \multicolumn{2}{|c|}{$\begin{array}{l}\text { Com doença } \\
\text { renal crônica } \\
(N=86)\end{array}$} & \multicolumn{2}{|c|}{$\begin{array}{l}\text { Sem doença } \\
\text { renal crônica } \\
(N=143)\end{array}$} & \multicolumn{2}{|c|}{$\begin{array}{c}\text { Total } \\
(\mathbf{N}=229) \\
\end{array}$} & \multirow[t]{2}{*}{$\begin{array}{c}\text { Valor } \\
\mathbf{p}\end{array}$} \\
\hline & $\mathbf{N}$ & $\%$ & $\mathbf{N}$ & $\%$ & $\mathbf{N}$ & $\%$ & \\
\hline \multicolumn{7}{|l|}{ Internação em UTI } & 0,716 \\
\hline Sim & 11 & 12,8 & 16 & 11,2 & 27 & 11,8 & \\
\hline Não & 75 & 87,2 & 127 & 88,8 & 202 & 88,2 & \\
\hline \multicolumn{7}{|l|}{ Internação em semi-intensiva } & 0,431 \\
\hline Sim & 12 & 14,0 & 15 & 10,5 & 27 & 11,8 & \\
\hline Não & 74 & 86,0 & 128 & 89,5 & 202 & 88,2 & \\
\hline \multicolumn{7}{|l|}{ Desfecho } & 0,005 \\
\hline Alta & 73 & 84,9 & 130 & 90,9 & 203 & 88,6 & \\
\hline Óbito & 11 & 12,8 & 3 & 2,1 & 14 & 6,1 & \\
\hline $\begin{array}{l}\text { Transferência para outro } \\
\text { hospital }\end{array}$ & 1 & 1,2 & 8 & 5,6 & 9 & 3,9 & \\
\hline Perda de seguimento & 1 & 1,2 & 2 & 1,4 & 3 & 1,3 & \\
\hline \multicolumn{7}{|c|}{ Encaminhamento pós-alta* $(N=193)$} & 0,482 \\
\hline UBS & 9 & 17,0 & 32 & 22,9 & 41 & 21,2 & \\
\hline Ambulatórios & 9 & 17,0 & 14 & 10,0 & 23 & 11,9 & \\
\hline Hospital de nível terciário & 3 & 5,7 & 17 & 12,1 & 20 & 10,4 & \\
\hline Assistência domiciliar & 4 & 7,5 & 10 & 7,1 & 14 & 7,3 & \\
\hline Outros\# & 1 & 1,9 & 5 & 3,6 & 6 & 3,1 & \\
\hline Não consta & 27 & 50,9 & 62 & 44,3 & 89 & 46,1 & \\
\hline \multicolumn{7}{|l|}{ Tempo de internação (dias) } & 0,009 \\
\hline Mediana $\left(1^{\circ} .-3^{\circ}\right.$. quartis $)$ & $10,0($ & $0-16,0)$ & $9,0(6$ & $-12,5)$ & $9,0(7$ & $-13,0)$ & \\
\hline \multicolumn{8}{|c|}{$\begin{array}{l}\text { Siglas: SUS, sistema único de saúde; UBS, unidade básica de saúde; PAD, programa de assistência } \\
\text { domiciliária; UTI, unidade de terapia intensiva; NA, não avaliado. } \\
\text { `Para os indivíduos que sobreviveram, exceto terapia renal substitutiva }(n=193) \text {. } \\
\text { \# Centro de atenção psicossocial (5); serviço de assistência especializada para doenças sexualmente } \\
\text { transmissíveis/ síndrome da imunodeficiência adquirida (1). }\end{array}$} \\
\hline
\end{tabular}

Os dados da Tabela 22 mostram que mais de 10\% dos hipertensos com e sem doença renal crônica estiveram internados em unidades de terapia intensiva e semi-intensiva.

O tempo total de internação foi significativamente superior $(p$ 
$<0,05)$ para hipertensos com doença renal crônica, em relação aos sem a doença $(10,0(8,0$ - 16,0) vs $9,0(6,0$ - 12,5) dias). O desfecho da hospitalização também apresentou diferença estatisticamente significativa $(p<0,05)$ entre os grupos, com maior proporção de óbitos entre os hipertensos com doença renal crônica (12,8\% vs $2,1 \%)$.

Observou-se que 46,1\% dos hipertensos que receberam alta hospitalar (exceto terapia renal substitutiva) não tinham o local de encaminhamento registrado em prontuário, sendo que 12 (13,5\%) não faziam acompanhamento de saúde prévio à hospitalização. Foram encaminhados para terapia renal substitutiva $29,3 \%$ dos hipertensos com doença renal crônica.

\subsection{AVALIAÇÃO DA TAXA DE FILTRAÇÃO GLOMERULAR EM PACIENTES SEM DOENÇA RENAL CRÔNICA}

Figura 9 - Regressão linear dos valores de taxa de filtração glomerular estimada dos pacientes internados em uma clínica médica, sem doença renal crônica, segundo emprego das equações Modification of Diet in Renal Disease abreviada e Chronic Kidney Disease Epidemiology Collaboration. São Paulo, 2013.

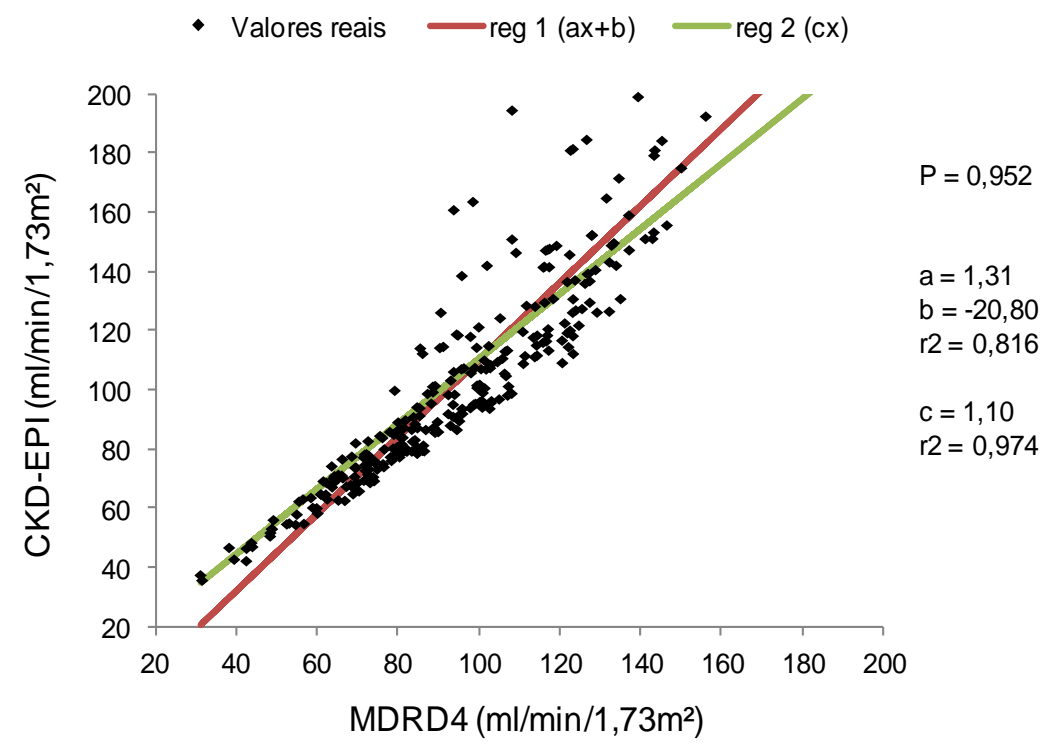

Siglas: CKD-EPI, Chronic Kidney Disease Epidemiology Collaboration: MDRD4, Modification of Diet in Renal Disease abreviada. 
Natália Alencar de Pinho

A mediana e os intervalos interquartis, da taxa de filtração glomerular estimada de pacientes sem doença renal crônica pelas equações, foram de 93,9 $\left(76,2\right.$ - 119,4) $\mathrm{mL} / \mathrm{min} / 1,73 \mathrm{~m}^{2}$, para a MDRD4, e de $92,7(74,2$ - 114,5) mL/min/1,73m², para a CKD-EPI. A Figura 9 ilustra a forte correlação dos valores de taxa de filtração glomerular estimada segundo a utilização destas equações ( $P$ = 0,952). A análise de regressão linear mostrou que a estimativa da taxa de filtração glomerular pela equação CKD-EPI foi discreta, mas sistematicamente inferior àquela estimada pela MDRD4 (c 0,88; r2 = $0,974)$.

Tabela 23 - Classificação da taxa de filtração glomerular estimada dos pacientes internados em uma clínica médica, sem doença renal crônica, segundo emprego das equações Modification of Diet in Renal Disease abreviada e Chronic Kidney Disease Epidemiology Collaboration.. São Paulo, 2013.

\begin{tabular}{|c|c|c|c|c|}
\hline \multirow[t]{2}{*}{ Categoria $\left(\mathrm{mL} / \mathrm{min} / 1,73 \mathrm{~m}^{2}\right)$} & \multicolumn{2}{|c|}{ MDRD4 ( $N=281)$} & \multicolumn{2}{|c|}{ CKD-EPI (N = 281) } \\
\hline & $\mathbf{N}$ & $\%$ & $\mathbf{N}$ & $\%$ \\
\hline$\geq 90$ & 153 & 54,4 & 146 & 52,0 \\
\hline 60 a 89 & 106 & 37,7 & 113 & 40,2 \\
\hline$>60$ & 22 & 7,8 & 22 & 7,8 \\
\hline
\end{tabular}

Segundo dados apresentados na Tabela 23, pouco mais da metade dos pacientes sem doença renal crônica apresentou taxa de filtração glomerular estimada igual ou superior a $90 \mathrm{~mL} / \mathrm{min} / 1,73 \mathrm{~m}^{2}$, seja pela equação MDRD4 (54,4\%) ou pela CKD-EPI $(52,0 \%)$. Apresentaram taxa de filtração glomerular estimada entre 60 e 89 $\mathrm{mL} / \mathrm{min} / 1,73 \mathrm{~m}^{2}, 37,7 \%$ e $40,2 \%$ dos pacientes segundo as equações MDRD4 e CKD-EPI, respectivamente. Vinte e dois pacientes (7,8\%) apresentaram taxa de filtração glomerular estimada inferior a 60 $\mathrm{mL} / \mathrm{min} / 1,73 \mathrm{~m}^{2}$ mediante utilização da MDRD4 ou da CKD-EPI. 
Tabela 24 - Reclassificação da taxa de filtração glomerular estimada dos pacientes internados em uma clínica médica, sem doença renal crônica, segundo emprego das equações Modification of Diet in Renal Disease abreviada e Chronic Kidney Disease Epidemiology Collaboration. São Paulo, 2013.

\begin{tabular}{|c|c|c|c|c|c|c|c|}
\hline \multicolumn{3}{|c|}{$\begin{array}{l}\text { Taxa de filtração glomerular } \\
\text { estimada }\left(\mathrm{mL} / \mathrm{min} / 1,73 \mathrm{~m}^{2}\right)\end{array}$} & \multicolumn{3}{|c|}{ MDRD4 } & \multirow{2}{*}{$\begin{array}{l}\text { Valor } p \\
<0,001\end{array}$} & \multirow{2}{*}{$\begin{array}{c}\text { Kappa } \\
0,854\end{array}$} \\
\hline \multirow{7}{*}{ CKD_EPI } & & & $<60$ & $60-89$ & $\geq 90$ & & \\
\hline & \multirow{2}{*}{$<60$} & $\mathbf{N}$ & 19 & 3 & 0 & & \\
\hline & & $\%$ & $86,4 \%$ & $2,8 \%$ & $0,0 \%$ & & \\
\hline & \multirow{2}{*}{$60-89$} & $\mathbf{N}$ & 3 & 98 & 12 & & \\
\hline & & $\%$ & $13,6 \%$ & $92,5 \%$ & $7,8 \%$ & & \\
\hline & \multirow{2}{*}{$\geq 90$} & $\mathbf{N}$ & 0 & 5 & 141 & & \\
\hline & & $\%$ & $0,0 \%$ & $4,7 \%$ & $92,2 \%$ & & \\
\hline
\end{tabular}

Observa-se, pelos dados da Tabela 24, que houve boa concordância na classificação da taxa de filtração glomerular pelas equações MDRD4 e CKD-EPI (Kappa 0,854). Apenas 23 pacientes sem doença renal crônica (8,2\%) tiveram a taxa de filtração glomerular estimada pela equação MDRD4 reclassificada mediante emprego da equação CDK-EPI. Destes, 65,2\% foram reclassificados para uma faixa inferior e $34,8 \%$ para uma faixa superior. Maior porcentagem de pacientes com taxa de filtração glomerular estimada inferior a $60 \mathrm{~mL} / \mathrm{min} / 1,73 \mathrm{~m}^{2}$ pela equação MDRD4 foi reclassificada pela CKD-EPI, em relação às faixas entre 60 e $89 \mathrm{~mL} / \mathrm{min} / 1,73 \mathrm{~m}^{2}$ e igual e ou superior a $90 \mathrm{~mL} / \mathrm{min} / 1,73 \mathrm{~m}^{2}(13,6 \%$ vs $7,5 \%$ vs $4,7 \%$, p $<0,001)$. 
Natália Alencar de Pinho

Tabela 25 - Características biossociais dos pacientes internados em uma clínica médica, sem doença renal crônica, segundo taxa de filtração glomerular estimada pela equação Modification of Diet in Renal Disease abreviada. São Paulo, 2013.

\begin{tabular}{|c|c|c|c|c|c|c|c|}
\hline \multirow[t]{2}{*}{ Variáveis } & \multicolumn{2}{|c|}{$\begin{array}{c}\mathrm{TFG}<90 \\
\mathrm{~mL} / \mathrm{min} / 1,73 \mathrm{~m} 2 \\
(\mathrm{~N}=128)\end{array}$} & \multicolumn{2}{|c|}{$\begin{array}{c}\text { TFG } \geq 90 \\
\mathrm{~mL} / \mathrm{min} / 1,73 \mathrm{~m} 2 \\
(\mathrm{~N}=153)\end{array}$} & \multicolumn{2}{|c|}{$\begin{array}{c}\text { Total } \\
(\mathrm{N}=281)\end{array}$} & \multirow[t]{2}{*}{ Valor $\mathbf{p}$} \\
\hline & $\mathbf{N}$ & $\%$ & $\mathbf{N}$ & $\%$ & $\mathbf{N}$ & $\%$ & \\
\hline \multicolumn{7}{|l|}{ Sexo } & \multirow[t]{2}{*}{0,063} \\
\hline Masculino & 56 & 43,8 & 84 & 54,9 & 140 & 49,8 & \\
\hline Feminino & 72 & 56,3 & 69 & 45,1 & 141 & 50,2 & \\
\hline \multicolumn{7}{|l|}{ Etnia $(N=280)$} & \multirow[t]{3}{*}{$<0,001$} \\
\hline Branco & 104 & 81,3 & 80 & 52,6 & 184 & 65,7 & \\
\hline Não branco & 24 & 18,8 & 72 & 47,4 & 96 & 34,3 & \\
\hline \multicolumn{7}{|l|}{ Estado civil $(\mathrm{N}=275)$} & \multirow[t]{2}{*}{0,480} \\
\hline Sem companheiro & 63 & 50,4 & 82 & 54,7 & 145 & 52,7 & \\
\hline Com companheiro & 62 & 49,6 & 68 & 45,3 & 130 & 47,3 & \multirow{6}{*}{0,639} \\
\hline \multicolumn{7}{|l|}{ Ocupação (N = 274) } & \\
\hline Trabalhador ativo & 51 & 40,8 & 58 & 38,9 & 109 & 39,8 & \\
\hline Aposentado & 39 & 31,2 & 40 & 26,8 & 79 & 28,8 & \\
\hline Do lar & 27 & 21,6 & 42 & 28,2 & 69 & 25,2 & \\
\hline Outros* & 8 & 6,4 & 9 & 6,0 & 17 & 6,2 & \\
\hline Idade (anos, média $\pm d p$ ) & \multicolumn{2}{|c|}{$63,4 \pm 16,4$} & \multirow{2}{*}{\multicolumn{2}{|c|}{$48,5 \pm 18,6$}} & \multirow{2}{*}{\multicolumn{2}{|c|}{$55,3 \pm 18,9$}} & $<0,001$ \\
\hline \multicolumn{3}{|c|}{ Índice de massa corporal $\left(\mathbf{k g} / \mathbf{m}^{2}\right)(\mathrm{N}=131)$} & & & & & 0,032 \\
\hline Mediana $\left(1^{\circ} .-3^{\circ}\right.$. quartis $)$ & $26,0(2$ & $4-28,7)$ & \multicolumn{2}{|c|}{$24,2(20,6-27,6)$} & \multicolumn{2}{|c|}{$25,0(21,7-28,3)$} & \\
\hline
\end{tabular}

Segundo dados apresentados na Tabela 25, os percentuais de pacientes sem doença renal crônica, com taxa de filtração glomerular estimada pela equação MDRD4 inferior a 90 $\mathrm{mL} / \mathrm{min} / 1,73 \mathrm{~m}^{2}$ e igual ou superior a este valor, foram semelhantes quanto à distribuição do sexo, estado civil e ocupação (50,2\% mulheres, $52,7 \%$ sem companheiro e $39,8 \%$ trabalhador ativo).

Aqueles com taxa de filtração glomerular inferior a 90 $\mathrm{mL} / \mathrm{min} / 1,73 \mathrm{~m}^{2}$ se distinguiram $(\mathrm{p}<0,05)$ dos com taxa de filtração glomerular igual ou superior a este valor por apresentar: menor porcentagem de etnia não branca $(18,8 \%$ vs $47,4 \%)$; idade mais elevada (63,4 $\pm 16,4$ vs 48,5 $\pm 18,6$ anos); e maior índice de massa corporal $\left(26,0(23,4-28,7)\right.$ vs $\left.24,2(20,6-27,6) \mathrm{kg} / \mathrm{m}^{2}\right)$. 
Natália Alencar de Pinho

Tabela 26 - Principais antecedentes pessoais dos pacientes internados em clínica médica, sem doença renal crônica, segundo taxa de filtração glomerular estimada pela equação Modification of Diet in Renal Disease abreviada. São Paulo, 2013.

\begin{tabular}{|c|c|c|c|c|c|c|c|}
\hline \multirow[t]{2}{*}{ Variáveis } & \multicolumn{2}{|c|}{$\begin{array}{c}\mathrm{TFG}<90 \\
\mathrm{~mL} / \mathrm{min} / 1,73 \\
\mathrm{~m} 2 \\
(\mathrm{~N}=128)\end{array}$} & \multicolumn{2}{|c|}{$\begin{array}{c}\mathrm{TFG} \geq 90 \\
\mathrm{~mL} / \mathrm{min} / 1,73 \\
\mathrm{~m} 2 \\
(\mathrm{~N}=153)\end{array}$} & \multicolumn{2}{|c|}{$\begin{array}{c}\text { Total } \\
(\mathrm{N}=\mathbf{2 8 1})\end{array}$} & \multirow[t]{2}{*}{ Valor $\mathbf{p}$} \\
\hline & $\mathbf{N}$ & $\%$ & $\mathbf{N}$ & $\%$ & $\mathbf{N}$ & $\%$ & \\
\hline Hipertensão arterial & & & & & & & $<0,001$ \\
\hline Sim & 81 & 63,3 & 49 & 32,0 & 130 & 46,3 & \\
\hline Não & 47 & 36,7 & 104 & 68,0 & 151 & 53,7 & \\
\hline Tabagismo & & & & & & & 0,007 \\
\hline $\operatorname{Sim}$ & 26 & 21,5 & 54 & 36,5 & 80 & 29,7 & \\
\hline Não & 95 & 78,5 & 94 & 63,5 & 189 & 70,3 & \\
\hline Diabetes & & & & & & & 0,008 \\
\hline Sim & 38 & 29,7 & 25 & 16,3 & 63 & 22,4 & \\
\hline Não & 90 & 70,3 & 128 & 83,7 & 218 & 77,6 & \\
\hline Dislipidemia & & & & & & & $<0,001$ \\
\hline Sim & 31 & 24,2 & 11 & 7,2 & 42 & 14,9 & \\
\hline Não & 97 & 75,8 & 142 & 92,8 & 239 & 85,1 & \\
\hline Acidente vascular encefálico & & & & & & & 0,070 \\
\hline Sim & 13 & 10,2 & 7 & 4,6 & 20 & 7,1 & \\
\hline Não & 115 & 89,8 & 146 & 95,4 & 261 & 92,9 & \\
\hline Infarto agudo do miocárdio & & & & & & & 0,102 \\
\hline $\operatorname{Sim}$ & 11 & 8,6 & 6 & 3,9 & 17 & 6,0 & \\
\hline Não & 117 & 91,4 & 147 & 96,1 & 264 & 94,0 & \\
\hline Insuficiência cardíaca conge & stiva & & & & & & 0,782 \\
\hline Sim & 5 & 3,9 & 7 & 4,6 & 12 & 4,3 & \\
\hline Não & 123 & 96,1 & 146 & 95,4 & 269 & 95,7 & \\
\hline
\end{tabular}

Os dados da Tabela 26 mostram que os pacientes com taxa de filtração glomerular estimada inferior a $90 \mathrm{~mL} / \mathrm{min} / 1,73 \mathrm{~m}^{2}$ apresentaram, em relação aos com taxa de filtração glomerular igual ou superior a este valor, maiores frequências $(p<0,05)$ das comorbidades: hipertensão arterial (63,3\% vs 32,0\%); diabetes melito $(29,7 \%$ vs $16,3 \%)$; e dislipidemia $(24,2 \%$ vs $7,2 \%)$. Por outro lado, os pacientes com estimativas da taxa de filtração glomerular maiores ou iguais a $90 \mathrm{~mL} / \mathrm{min} / 1,73 \mathrm{~m}^{2}$ se destacaram por serem fumantes, em relação aos com taxas de filtração glomerular menores (36,5\% vs $21,5, p=0,007)$. Não houve diferença entre os grupos quanto aos antecedentes pessoais de acidente vascular encefálico, infarto agudo do miocárdio e insuficiência cardíaca congestiva. 
Natália Alencar de Pinho

Tabela 27 - Valores de creatinina sérica nos primeiros dez dias de hospitalização dos pacientes internados em uma clínica médica, sem doença renal crônica, segundo taxa de filtração glomerular estimada pela equação Modification of Diet in Renal Disease abreviada. São Paulo, 2013.

\begin{tabular}{|c|c|c|c|c|}
\hline Dias & & $\begin{array}{c}\text { TFG }<90 \mathrm{~mL} / \mathrm{min} / 1,73 \\
\mathrm{~m} 2\end{array}$ & $\begin{array}{c}\text { TFG } \geq 90 \mathrm{~mL} / \mathrm{min} / 1,73 \\
\mathrm{~m} 2\end{array}$ & Valor $p$ \\
\hline & $\mathbf{N}$ & Creatinina $(\mathrm{mg} / \mathrm{dL}, \mathrm{me}$ & ana $\left(1^{\circ}\right.$. e $3^{\circ}$. quartis)) & \\
\hline 0 & 195 & $1,0(0,9-1,1)$ & $0,7(0,6-0,9)$ & $<0,001$ \\
\hline 1 & 197 & $1,0(0,9-1,1)$ & $0,7(0,6-0,8)$ & $<0,001$ \\
\hline 2 & 137 & $1,0(0,9-1,2)$ & $0,7(0,6-0,8)$ & $<0,001$ \\
\hline 3 & 118 & $1,0(0,8-1,1)$ & $0,7(0,6-0,9)$ & $<0,001$ \\
\hline 4 & 103 & $1,0(0,9-1,2)$ & $0,7(0,6-0,8)$ & $<0,001$ \\
\hline 5 & 91 & $0,9(0,8-1,1)$ & $0,7(0,6-0,8)$ & $<0,001$ \\
\hline 6 & 80 & $1,1(0,9-1,1)$ & $0,7(0,6-0,8)$ & $<0,001$ \\
\hline 7 & 51 & $1,0(0,9-1,0)$ & $0,7(0,6-0,8)$ & $<0,001$ \\
\hline 8 & 51 & $0,9(0,9-1,1)$ & $0,7(0,6-0,8)$ & $<0,001$ \\
\hline 9 & 26 & $1,0(0,9-1,2)$ & $0,7(0,6-0,8)$ & $<0,001$ \\
\hline 10 & 32 & $1,0(0,8-1,3)$ & $0,7(0,6-0,9)$ & 0,004 \\
\hline
\end{tabular}

Entre os pacientes sem doença renal crônica que tiveram medida de creatinina sérica no dia da admissão hospitalar, apresentaram valor superior ao limite de normalidade 3,6\% dos com taxa de filtração glomerular estimada inferior a $90 \mathrm{~mL} / \mathrm{min} / 1,73 \mathrm{~m}^{2} \mathrm{e}$ $1,0 \%$ dos com taxa de filtração glomerular estimada igual ou superior a $90 \mathrm{~mL} / \mathrm{min} / 1,73 \mathrm{~m}^{2}$. Segundo dados da Tabela 27 , os valores de creatinina sérica foram significativamente $(p<0,05)$ maiores para pacientes com taxa de filtração glomerular estimada inferior a 90 $\mathrm{mL} / \mathrm{min} / 1,73 \mathrm{~m}^{2}$ nos dez primeiros dias de internação.

Tabela 28 - Desfechos da hospitalização dos pacientes internados em uma clínica médica, sem doença renal crônica, segundo taxa de filtração glomerular estimada pela equação Modification of Diet in Renal Disease abreviada. São Paulo, 2013.

\begin{tabular}{|c|c|c|c|c|c|c|c|}
\hline \multirow[t]{2}{*}{ Desfechos da hospitalização } & \multicolumn{2}{|c|}{$\begin{array}{c}\text { TFG > 90 } \\
\mathrm{mL} / \mathrm{min} / 1,73 \mathrm{~m} 2 \\
(\mathrm{~N}=153)\end{array}$} & \multicolumn{2}{|c|}{$\begin{array}{c}\text { TFG }<90 \\
\mathrm{~mL} / \mathrm{min} / 1,73 \mathrm{~m} 2 \\
(\mathrm{~N}=128)\end{array}$} & \multicolumn{2}{|c|}{$\begin{array}{c}\text { Total } \\
(\mathrm{N}=\mathbf{2 8 1})\end{array}$} & \multirow[t]{2}{*}{ Valor $p$} \\
\hline & $\mathbf{N}$ & $\%$ & $\mathbf{N}$ & $\%$ & $\mathbf{N}$ & $\%$ & \\
\hline \multicolumn{7}{|l|}{ Internação em UTI } & \multirow[t]{3}{*}{0,598} \\
\hline $\operatorname{Sim}$ & 16 & 10,5 & 11 & 8,6 & 27 & 9,6 & \\
\hline Não & 137 & 89,5 & 117 & 91,4 & 254 & 90,4 & \\
\hline \multicolumn{7}{|l|}{ Internação em semi-intensiva } & \multirow[t]{3}{*}{0,446} \\
\hline Sim & 16 & 10,5 & 10 & 7,8 & 26 & 9,3 & \\
\hline Não & 137 & 89,5 & 118 & 92,2 & 255 & 90,7 & \\
\hline \multicolumn{7}{|l|}{ Desfecho } & \multirow[t]{5}{*}{0,513} \\
\hline Alta & 145 & 95,4 & 117 & 91,4 & 262 & 93,6 & \\
\hline Óbito & 2 & 1,3 & 2 & 1,6 & 4 & 1,4 & \\
\hline $\begin{array}{l}\text { Transferência para outro } \\
\text { hospital }\end{array}$ & 4 & 2,6 & 8 & 6,3 & 12 & 4,3 & \\
\hline Perda de seguimento & 2 & 1,3 & 1 & 0,8 & 3 & 1,1 & \\
\hline \multicolumn{7}{|l|}{ Tempo de internação (dias) } & \multirow[t]{2}{*}{0,457} \\
\hline Mediana $\left(1^{\circ}-3^{\circ}\right.$ quartis $)$ & \multicolumn{2}{|c|}{$9,0(7,0-2,0)$} & \multicolumn{2}{|c|}{$8,0(6,0-12,0)$} & \multicolumn{2}{|c|}{$9,0(6,0-12,5)$} & \\
\hline
\end{tabular}


Natália Alencar de Pinho

Os dados apresentados na Tabela 28 mostram que não houve diferença entre pacientes sem doença renal crônica com taxa de filtração glomerular estimada pela equação MDRD4 inferior a 90 $\mathrm{mL} / \mathrm{min} / 1,73 \mathrm{~m}^{2}$ e igual ou superior a este valor quanto à internação em unidade de terapia intensiva ou semi-intensiva, ao desfecho ou ao tempo de internação. 


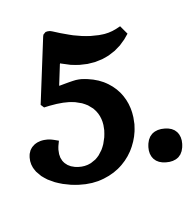

Discussão 


\section{DISCUSSÃO}

\subsection{FATORES ASSOCIADOS À DOENÇA RENAL CRÔNICA}

O principal achado do presente estudo revelou que a doença renal crônica em pacientes internados em uma clínica médica se associou aos principais fatores de risco cardiovascular passíveis de intervenção e modificação: hipertensão arterial e diabetes melito. Tais fatores de risco, além da idade, são reconhecidos mundialmente pelo seu grande impacto no perfil de morbimortalidade.

Outro achado de relevância epidemiológica, embora secundário ao processo de constituição amostral, foi a prevalência de doença renal crônica. Considerando-se a primeira etapa de exclusão dos indivíduos, na qual os critérios se aplicaram ao total da população, se identificou prevalência de doença renal crônica de 15,9\% segundo diagnóstico médico e antecedente pessoal.

O valor encontrado é bem superior aos valores relatados em estudos brasileiros que identificaram a prevalência de hipercreatinemia em amostras populacionais; contudo, ao se considerar a faixa etária dos indivíduos renais crônicos da amostra estudada, equivalente à sexta década de vida, a prevalência de doença renal crônica se aproxima daquela identificada por Lessa et al ${ }^{19} \mathrm{em}$ soteropolitanos com idade superior a 60 anos, a qual foi de 12,9\% (IC 95\%, 4,3; 20,3). Em contrapartida, a prevalência de doença renal crônica encontrada no presente estudo esteve aquém daquela relatada por Yokota et $a^{17}$, a partir da taxa de filtração glomerular estimada pela equação Cockroft-Gault (46,9\%), porém se aproximou da prevalência de $12,8 \%$, para redução moderada à grave.

Embora a comparação da prevalência de doença renal 
Natália Alencar de Pinho

crônica seja comprometida pela especificidade da população do presente estudo e pelos critérios de definição de doença, chama atenção que a doença renal crônica seja tão frequente em indivíduos hospitalizados em uma enfermaria de clínica médica.

Não existem dados consistentes sobre a morbidade hospitalar de indivíduos com doença renal crônica no Brasil. Aqueles originados pelo sistema de tecnologia da informação a serviço do SUS (DATASUS), além de corresponder somente ao diagnóstico principal da internação, se referem aos capítulos e às listas de morbidade da Classificação Internacional de Doenças (CID -10), nos quais as diferentes etiologias da doença renal crônica estão diluídas. Se considerada, por exemplo, a morbidade "insuficiência renal" (não especificada se aguda ou crônica), se verifica que esta representou somente $0,7 \%$ dos diagnósticos principais de internação em $2009^{41}$, enquanto $4,1 \%$ dos indivíduos internados em clínica médica no presente estudo apresentavam insuficiência renal crônica terminal. Desta maneira, se evidencia, de forma inédita, a importância da doença renal crônica na morbidade hospitalar em uma unidade geral de internação no Brasil.

Quanto às características biossociais, houve discreto predomínio do sexo masculino que, embora mais marcado entre indivíduos com doença renal crônica, não apresentou diferença entre os grupos. Os pacientes com e sem doença renal crônica foram ainda semelhantes quanto à etnia (maioria de brancos) e à ocupação profissional (predomínio de trabalhadores ativos).

A relação do gênero com a doença renal crônica tem se mostrado controversa nos estudos. Enquanto a prevalência de doença renal crônica foi mais elevada entre mulheres, em revisão sistemática de estudos de base populacional ${ }^{10}$, os homens constituem a maior parcela de indivíduos em terapia renal substitutiva. Nos Estados Unidos, por exemplo, a prevalência de doença renal crônica, definida por uma taxa de filtração glomerular 
estimada pela equação MDRD4 menor que $60 / \mathrm{mL} / \mathrm{min} / 1,73 \mathrm{~m}^{2}$ ou relação albumina/creatinina urinária maior que $30 \mathrm{mg} / \mathrm{g}$, foi de $12,1 \%$, para homens, e 15,8\%, para mulheres, no período de 2005 a $2010^{102}$. Em contrapartida, em 2010, 57\% dos indivíduos em terapia renal substitutiva neste mesmo país eram homens ${ }^{21}$. No Brasil, os estudos populacionais que avaliaram a prevalência de doença renal crônica definida pela hipercreatinemia identificaram valores maiores para homens: $5,2 \%$ vs $1,6 \%$, em estudo de Lessa $^{19}$, e $8,19 \%$ vs 5,29\%, em estudo de Passos et al. ${ }^{18}$ Os homens representaram 57\% dos indivíduos tratados por diálise, segundo censo da Sociedade Brasileira de Nefrologia em $2011^{22}$.

No que concerne à etnia, estudo de Kramer et $a l^{103}$, que avaliou a performance de diferentes equações para estimativa da taxa de filtração glomerular, não identificou, de forma geral, diferenças na prevalência de doença renal crônica entre brancos, negros, chineses e hispânicos. Contudo, outro estudo identificou maior incidência de doença renal crônica (definida por tratamento ou óbito) entre afro-americanos comparados a caucasianos: RR 1,95 (IC 95\% 1,05 - 3,63), ajustado para variáveis sociodemográficas, estilo de vida e comorbidades ${ }^{104}$. Em Salvador (BA), Brasil, Lessa ${ }^{19}$ verificou uma razão de chance ajustada de 4,17 (IC 95\% 1,71 10,15, p 0,002) para hipercreatinemia em negros, comparados aos pardos, e de 1,77 (IC 95\% 0,74 - 4,23, p 0,199), comparados aos brancos. A importante miscigenação da população brasileira pode dificultar a análise de associação de doença renal crônica e etnia em nosso meio. Além disso, os dados sobre esta variável no presente estudo foram coletados retrospectivamente de prontuários, o que não assegura seu autorrelato pelo indivíduo.

Chama a atenção que a proporção de trabalhadores ativos não tenha diferido entre os grupos com e sem doença renal crônica, inclusive pelo fato de que os pacientes com doença renal crônica tenham apresentado média de idade mais elevada. Contudo, a 
amostra foi constituída de indivíduos hospitalizados, os quais apresentavam variedade de doenças crônicas que motivaram ou contribuíram para sua internação. Estudo de Giatti e Barreto ${ }^{105}$, com indivíduos idosos brasileiros, mostrou associação significativa de maior prevalência de doença crônica com aposentadoria.

O índice de massa corporal dos indivíduos estudados não diferiu entre os grupos com e sem doença renal crônica e foi compatível com sobrepeso. O sobrepeso e a obesidade têm se destacado pela crescente prevalência em nível mundial, ao ponto de serem considerados como "epidemia"106. O excesso de peso foi identificado em mais de $50 \%$ dos brasileiros com idade igual ou superior a 35 anos em inquérito do Sistema de Vigilância de Fatores de Risco e Proteção para Doenças Crônicas (VIGITEL) ${ }^{107}$.

A relação do excesso de peso com doenças cardiovasculares é amplamente reconhecida $e$, nos últimos anos, muito se tem investigado sobre sua associação com doença renal crônica. Mecanismos físicos (compressão renal), assim como alterações bioquímicas relacionadas à gordura visceral, têm sido considerados potenciais fatores causais para a queda da taxa de filtração glomerular e proteinúria, contexto agravado pela coexistência de hipertensão e resistência à insulina ${ }^{106} 108$.

Os indivíduos com doença renal crônica apresentaram idade significativamente $(p<0,05)$ mais elevada que aqueles sem doença renal crônica. Este dado é compatível com os diversos estudos sobre prevalência da doença renal crônica, que têm demonstrado a associação desta com a idade. A prevalência de doença renal crônica, identificada pela equação MDRD4 entre indivíduos com idade superior a 65 anos, variou de 5,8 a 51\% em diferentes estudos internacionais. Embora os valores sejam discrepantes, eles foram todos muito superiores aos das faixas etárias inferiores nos respectivos estudos, revelando aumento quase exponencial da prevalência de doença renal crônica com a idade ${ }^{1025}$. Dois estudos 
brasileiros, que utilizaram critérios diferentes para a definição da doença renal crônica (hipercreatinemia e equação MDRD), identificaram uma razão de chance (odds ratio) de 8,7 para indivíduos com idade superior a 60 anos em relação aos demais adultos $^{19} 20$.

Foi também significante $(p<0,05)$ a associação de doença renal crônica com estado civil, com predominância de indivíduos com companheiro neste grupo. A convivência em casal tem sido utilizada como indicativo de apoio familiar, o qual estaria relacionado a melhor adesão ao tratamento de doenças crônicas e a melhores resultados em saúde ${ }^{109} 110$. Tal efeito positivo do estado civil "com companheiro" não foi observado no presente estudo. É possível que fatores como tempo e qualidade da relação em casal, assim como outras redes de suporte social, possam estar envolvidos na melhor gestão do tratamento de doenças crônicas e prevenção de complicações renais.

Quanto aos hábitos de vida, se destacou a maior frequência de tabagistas no grupo sem doença renal crônica. Este achado é contrário aos dos diversos estudos que mostraram associação do tabagismo com desenvolvimento e progressão da doença renal crônica $^{111} 1112113$. Entretanto, o caráter retrospectivo do presente estudo e a coleta de dados em prontuário não permitiu a avaliação de dados relevantes deste hábito como, por exemplo, o tempo de abstinência de fumo para aqueles que referiram parar de fumar. Muitos tabagistas costumam parar de fumar em estágios mais severos da doença, o que contribui para a identificação de menores frequências de fumantes em estudos transversais com doentes renais crônicos ${ }^{42}$. A porcentagem de doentes renais crônicos tabagistas no presente estudo $(11,1 \%)$ foi semelhante àquela encontrada entre pacientes em hemodiálise no Brasil, a qual foi de $12,2 \%{ }^{114}$.

Observou-se maior frequência de acompanhamento em 
serviço de saúde e maior consumo de medicamentos para indivíduos com doença renal crônica. Este dado é coerente com a necessidade de tratamento para a redução da progressão da doença e a prevenção de complicações ${ }^{2} 3115$. A rede pública foi a mais utilizada por ambos os grupos, com destaque para as unidades básicas de saúde. Não foi possível avaliar a especialidade médica de acompanhamento dos indivíduos, devido à irregularidade de seu registro em prontuário. Todavia, chama a atenção o fato que $12,2 \%$ dos indivíduos com doença renal crônica não faziam acompanhamento de saúde, ainda que $36,4 \%$ destes tenha apresentado antecedente de doença renal crônica registrado em prontuário.

De forma geral, a prevalência de fatores de risco cardiovascular, definida pela presença de antecedentes de saúde pessoais ou diagnóstico médico, foi elevada na amostra estudada. A exceção foi a dislipidemia, cuja frequência de 19,7\% de diagnóstico médico se revelou próxima às prevalências de 21 a $24 \%$ relatadas por diferentes estudos populacionais no Brasil ${ }^{17} 116117$. Verificou-se, no presente estudo, a associação de doença renal crônica com diversas comorbidades.

Enquanto a prevalência de hipertensão arterial em estudos brasileiros se mostrou em torno de $30 \%{ }^{36} 37$, esta doença foi relatada como antecedente pessoal e diagnóstico médico de $54,1 \%$ e $58,8 \%$ dos pacientes no presente estudo, respectivamente, fato que pode estar relacionado à faixa etária mais elevada. Estudos que avaliaram a prevalência de hipertensão arterial em idosos identificaram frequências importantes, da ordem de 60\%, no Bambuí Health and Ageing Study (MG-Brasil) ${ }^{118}$, e de $50 \%$, em estudo conduzido em Campinas (SP), Brasil ${ }^{119}$. Porém, em tais estudos as populações tinham faixa etária mais elevada. Deve-se considerar que a população estudada estava internada, e que a contribuição de complicações inerentes à hipertensão arterial não deve ser 
descartada. As doenças cardíacas e cerebrovasculares foram as mais relatadas como antecedentes pessoais e diagnósticos médicos desta população.

Os pacientes com doença renal crônica se distinguiram por apresentar mais antecedente pessoal (75,2\% vs 46,3\%) e diagnóstico de hipertensão arterial (81,0\% vs 50,5\%) em relação aos sem a doença. Em realidade, a hipertensão arterial tem sido considerada uma afecção onipresente na doença renal crônica. Isto ocorre porque, além de constituir uma das causas mais importantes para a instalação e o desenvolvimento da doença, a hipertensão arterial é uma consequência da doença renal crônica ${ }^{120}$.

Dados norte-americanos, provenientes do Kidney Early Evaluation Program (KEEP), identificaram prevalências crescentes de hipertensão arterial, segundo estimativa da taxa de filtração glomerular pela equação MDRD4, no período de 1994 a 2004: $56,6 \%$ para estimativa superior a $100 \mathrm{~mL} / \mathrm{min} / 1,73 \mathrm{~m}^{2} ; 72,4 \%$ para a faixa de 60 a $70 \mathrm{~mL} / \mathrm{min} / 1,73 \mathrm{~m}^{2}$; e 95,6\% para estimativa inferior a $30 \mathrm{~mL} / \mathrm{min} / 1,73 \mathrm{~m}^{2}$. A mesma tendência foi observada em amostra do National Health and Nutrition Examinatiion Survey (NHANES), segundo mesmos critérios e período de estudo, embora as frequências tenham sido inferiores às daquelas observadas no KEEP: $24,8 \%$ para estimativa superior a $100 \mathrm{~mL} / \mathrm{min} / 1,73 \mathrm{~m}^{2} ; 49,6 \%$ para a faixa de 60 a $70 \mathrm{~mL} / \mathrm{min} / 1,73 \mathrm{~m}^{2}$; e $97,5 \%$ para estimativa inferior a $30 \mathrm{~mL} / \mathrm{min} / 1,73 \mathrm{~m}^{2}{ }^{121}$.

A frequência do diagnóstico médico de hipertensão arterial em indivíduos com doença renal crônica no presente estudo se assemelhou à prevalência identificada por Biavo et al ${ }^{14}$ em indivíduos idosos sob tratamento hemodialítico, a qual foi de 85,3\%. Tal achado impressiona pela elevada prevalência de hipertensão arterial entre estes indivíduos, comparável àquela de doentes renais crônicos em estágio terminal, provavelmente relacionada com maior morbidade hospitalar para doentes renais crônicos hipertensos. 
Natália Alencar de Pinho

As prevalências de antecedente pessoal e diagnóstico médico de diabetes melito identificadas neste estudo $(29,8 \%$ e $32,1 \%$, respectivamente) foram mais elevadas do que as prevalências relatadas por inquérito telefônico para a população adulta $(5,2 \%)$ e idosa (15,5\% para idade entre 55 e 64 anos; 18,8 para idade entre 65 e 74 anos; e 17,6\% para idade igual ou superior a 75 anos) no Brasil $^{122}$. Tal achado pode estar relacionado à maior morbidade hospitalar de indivíduos diabéticos. Em estudo de Mendes et al ${ }^{123}$, sobre os fatores relacionados ao diabetes em população idosa na cidade de São Paulo (SP), Brasil, a prevalência de diabetes melito, em indivíduos hospitalizados ao menos uma vez nos doze meses que antecederam a pesquisa, foi de $26,3 \%, 1,63$ vezes mais elevada que a dos que não sofreram nenhuma hospitalização (IC 95\% 1,20 2,23, p 0,0029).

A presença de diabetes melito também foi significativamente superior entre pacientes com doença renal crônica: $49,5 \%$ vs $22,4 \%$, para antecedente pessoal; e $50,5 \%$ vs $25,3 \%$, para diagnóstico médico. De fato, a prevalência de diabetes melito entre doentes renais crônicos tem se mostrado superior à dos indivíduos sem doença renal crônica. No estudo do NHANES $1 I^{53}$, a prevalência de diabetes melito foi de $19 \%$ entre indivíduos com hipercreatinemia, contra 4,8\% entre indivíduos com creatinina sérica normal. A mesma observação foi obtida no estudo de Framingham, no qual 23,5\% e $11,9 \%$ dos indivíduos com e sem doença renal crônica, respectivamente, apresentavam diabetes melito ${ }^{124}$.

A prevalência de diabetes em doentes renais crônicos encontrada no presente estudo foi mais elevada do que a relatada em diversos trabalhos com esta população ${ }^{53} 124125$, ou ainda, do que a prevalência relatada em amostra de indivíduos em terapia renal substitutiva no Brasil $(30,6 \%)^{114}$, sugerindo, a exemplo da hipertensão arterial, a maior morbidade hospitalar desses indivíduos. Há ainda a possibilidade de que o diabetes melito venha adquirindo 
maior importância na etiologia e na comorbidade na doença renal crônica no Brasil. Estudo de Burmeister et al $^{126}$, identificou prevalência de diabetes melito de cerca de $40 \%$ para pacientes hemodialisados em Porto Alegre (RS), Brasil, a qual variou de 56,8 a $20,0 \%$ entre os diferentes tipos de serviço. Esta observação pode estar ligada à transição epidemiológica, com maior prevalência e menor mortalidade por diabetes melito em algumas regiões brasileiras.

A dislipidemia se associou à doença renal crônica, segundo critério de antecedente pessoal (com doença renal crônica 23,8\% vs sem doença renal crônica 14,9\%, $p=0,041)$. De fato, indivíduos com doença renal crônica apresentam alterações do perfil lipídico, com aumento de frações lipídicas aterogênicas, especialmente na vigência de proteinúria e hipoalbuminemia. O estudo Atherosclerosis Risk In Communities identificou valores significativamente $(p<0,05)$ mais elevados de colesterol total e triglicérides, assim como menores valores de HDL, para doentes renais crônicos, segundo estratificação da taxa de filtração glomerular a partir da estimativa pela equação MDRD4 ${ }^{127}$. A mesma observação foi obtida em estudo NHANES III, no qual $90 \%$ e $50 \%$ dos indivíduos com doença renal crônica com síndrome nefrótica apresentaram aumento do colesterol total e diminuição do $\mathrm{HDL}$, respectivamente, contra $20 \%$ para aumento do colesterol total e $15 \%$ para diminuição do HDL na população em geral $^{53}$.

Não houve, porém, diferença entre os grupos com relação ao diagnóstico médico de dislipidemia. Além disso, a prevalência de dislipidemia nos indivíduos com doença renal crônica foi muito inferior àquela relatada, por exemplo, nas IV Diretrizes Brasileiras Sobre Dislipidemias e Prevenção da Aterosclerose, do Departamento de Aterosclerose da Sociedade Brasileira de Cardiologia, a qual chegou até a $90 \%$. A necessidade de duas avaliações do perfil lipídico com intervalo mínimo de uma semana 
para identificação da dislipidemia pode explicar a baixa frequência deste diagnóstico durante a hospitalização ${ }^{128}$.

Observou-se que as doenças cardíacas e cerebrovasculares foram as mais relatadas como antecedentes pessoais e diagnósticos médicos para o total da amostra do estudo. Esta observação é congruente com o fato que estas doenças figuram como a primeira causa de morte e segunda causa de morbidade hospitalar dos brasileiros. Dados provenientes do DATASUS indicam que as doenças cardiovasculares corresponderam, em 2010, a 30,6 e $13,4 \%$ do total de óbitos e internações de adultos com idade igual ou superior a vinte anos, respectivamente ${ }^{41}$. A alta prevalência de fatores de risco cardiovascular identificada na amostra estudada pode justificar a importante frequência de doenças cardiovasculares nestes indivíduos.

Houve associação significativa da doença renal crônica com antecedente de infarto agudo do miocárdio e insuficiência cardíaca congestiva. Esta observação é corroborada por diversos estudos, que mostraram maiores incidências de eventos cardiovasculares em indivíduos com doença renal crônica ${ }^{56} 57$. 63 . Todavia, somente a insuficiência cardíaca congestiva manteve significância estatística quando analisada pelo critério de diagnóstico médico na internação.

Estudos têm sugerido que a insuficiência cardíaca congestiva pode ser uma importante causa de lesão renal progressiva, isto porque cerca de $50 \%$ dos indivíduos com esta afecção têm doença renal crônica ${ }^{129}$. Em contrapartida, estudo em amostra proveniente do NHANES III identificou prevalências de insuficiência cardíaca congestiva de 39,9 e 54,1\% para doentes renais crônicos com e sem diabetes, respectivamente, as quais foram significativamente $(p<$ $0,05)$ inferiores a de pacientes sem estas doenças ${ }^{130}$. Tais evidências, associadas a dados provenientes da pesquisa básica, indicam um "círculo vicioso", no qual a doença renal crônica e a insuficiência renal crônica interagem, agravando as lesões 
Natália Alencar de Pinho

mutuamente $^{129}$.

A prevalência de insuficiência cardíaca congestiva de $29,5 \%$ para indivíduos com doença renal crônica encontrada pelo presente estudo foi superior àquela identificada em doentes renais crônicos atendidos por um plano de saúde nos Estados Unidos, a qual foi de $13,1 \%$. Contudo, ela se aproximou das prevalências em doentes renais crônicos que morreram até o final do seguimento neste mesmo trabalho: 22,2\%, para estágio 3, e 32,7\%, para estágio 4 de doença renal crônica ${ }^{131}$.

A maior frequência de uso contínuo de medicamentos entre indivíduos com doença renal crônica é compatível com a maior morbidade destes indivíduos antes da hospitalização e foi significante $(p<0,05)$ para as classes medicamentosas para 0 tratamento da hipertensão arterial, diabetes melito, dislipidemia e afecções cardíacas. No que concerne à terapia para o diabetes, somente a insulina apresentou diferença significativa com doença renal crônica. De fato, a adoção da insulinoterapia é indicada precocemente em indivíduos com doença renal crônica, segundo algoritmo de tratamento para o diabetes tipo 2 da Sociedade Brasileira de Diabetes ${ }^{132}$.

Quase metade dos indivíduos com doença renal crônica não tinha antecedente pessoal da doença registrado em prontuário. Contudo, $87,8 \%$ dos doentes renais crônicos referiram acompanhamento em saúde prévio à hospitalização. Além disso, a prevalência, segundo antecedente pessoal dos principais fatores de risco para doença renal crônica, hipertensão arterial e diabetes melito, foi muito elevada neste grupo. Tais fatos chamam a atenção para uma possível deficiência na atenção à saúde destes indivíduos.

Enquanto a prevalência de doença renal crônica foi de 18,4\% e $15,1 \%$ para hipertensos e diabéticos, respectivamente, em amostra representativa da população norte-americana ${ }^{133}$, dados 
provenientes do sistema de informações do HIPERDIA indicam prevalência da ordem de $5 \%$ para esta população ${ }^{74}$. Estudo transversal, que avaliou a taxa da filtração glomerular a partir do clearance de creatinina em hipertensos com e sem diabetes cadastrados no HIPERDIA em um centro de saúde em São Luís (MA), Brasil, verificou que $24,6 \%$ e 18,3\%, respectivamente, apresentavam valores inferiores a $60 \mathrm{~mL} / \mathrm{min}^{134}$. Estes dados sugerem que a doença renal crônica continua subdiagnosticada no Brasil, o que contribuiria para a ocorrência de diagnóstico da doença na internação, já na vigência de complicações cardíacas ou falência renal.

Os antecedentes familiares de hipertensão arterial, diabetes ou doença renal crônica não se associaram à doença renal crônica neste estudo. A frequência de antecedente familiar de doença renal crônica foi de 1,0\%, muito inferior àquela identificada em segmento de população soteropolitana, a qual foi de $15, \%$, para homens, e de $21,3 \%$, para mulheres. Todavia, a exemplo do observado no presente estudo, a história familiar de doença renal crônica não se associou à hipercreatinemia no estudo em Salvador (BA), Brasil ${ }^{19}$. Este achado pode estar ligado ao desconhecimento dos antecedentes familiares pelos indivíduos, já que muitos estudos têm sugerido maior risco de doença renal crônica na vigência de história familiar da doença ${ }^{135} 136$.

Quanto aos exames laboratoriais, se observou valores significativamente $(p<0,05)$ maiores de creatinina, potássio, ureia, fósforo e ácido úrico séricos, assim como menores valores de hemoglobina, hematócrito e albumina sérica em indivíduos com doença renal crônica. Este fato é compatível os distúrbios bioquímicos e hematológicos associados à diminuição da função renal.

Um achado relevante, pelo seu potencial impacto na morbimortalidade, foram as alterações nas análises de fósforo 
sérico, hemoglobina e hematócrito dos indivíduos com doença renal crônica. Cabe ressaltar que somente dois indivíduos com doença renal crônica no presente estudo faziam uso contínuo de quelantes de fósforo, dois faziam uso de eritropoetina e dois de sulfato ferroso.

Diversos estudos têm evidenciado a associação do aumento dos níveis séricos de fósforo com eventos cardiovasculares e mortalidade. Estudo com doentes renais crônicos, provenientes da amostra do Multi-Ethnic Study of Atherosclerosis (MESA), identificou associações estatisticamente significantes $(p<0,05)$ da concentração sérica de fósforo com calcificação de artérias coronarianas, aorta descendente e válvula mitral ${ }^{137}$. Estudo com doentes renais crônicos, no noroeste dos Estados Unidos, identificou um hazard ratio para ocorrência de infarto agudo do miocárdio, segundo incremento de $1 \mathrm{mg} / \mathrm{dL}$ do fósforo sérico, de 1,35 (IC 95\% 1,09-166), e para mortalidade de 1,24 (IC 95\% 1,13-1,37) ${ }^{138}$. Além disso, o aumento do fósforo sérico pode participar na gênese de doenças ósseas na doença renal crônica ${ }^{139}$.

A anemia é um problema muito prevalente entre indivíduos com doença renal crônica. Estudo norte-americano, com doentes renais crônicos em estágios de 3 a 5, mostrou que 47,7\% apresentavam hemoglobina igual ou inferior a $12 \mathrm{mg} / \mathrm{dL}$ e que $8,9 \%$ apresentavam valores iguais ou inferiores a $10 \mathrm{mg} / \mathrm{dL}^{140}$. No Brasil, Canziani et $a l^{141}$ identificaram prevalência de anemia (hemoglobina inferior a $11 \mathrm{mg} / \mathrm{dL}$ ) de $18 \%$ para 401 pacientes renais crônicos em estágios de 2 a 5 atendidos em ambulatórios. Dados provenientes do censo brasileiro de diálise, de 2011, indicaram que $39,3 \%$ dos pacientes apresentavam hemoglobina inferior a $11 \mathrm{mg} / \mathrm{dL}^{22}$.

A exemplo do fósforo sérico, a anemia tem sido apontada como importante fator de risco para morbimortalidade em doentes renais crônicos. No estudo Atherosclerosis Risk in Communities ${ }^{142}$, verificou-se que a associação de doença renal crônica com anemia aumentou significativamente $(p<0,05) \quad 0$ hazard ratio para 
Natália Alencar de Pinho

mortalidade por doença coronariana (doença renal crônica, 2,67 vs doença renal crônica e anemia, 4,38) e o hazard ratio para mortalidade por todas as causas (doença renal crônica, 1,72 vs doença renal crônica e anemia, 3,49) em seguimento médio de doze anos. Estudo prospectivo histórico (média de 2,1 anos), com homens com doença renal crônica não dialítica, identificou, além de aumento da mortalidade por todas as causas na vigência de anemia, o incremento do risco para evolução para falência renal em indivíduos cuja hemoglobina média para o período foi compreendida entre $11 \mathrm{e}$ 12 mg/dL (HR 1,81, IC 95\% 1,07 - 3,05) ou inferior a 11 mg/dL (HR 2,96, IC 95\% 1,70 - 5,14), comparados aos indivíduos com hemoglobina superior a $13 \mathrm{mg} / \mathrm{dL}^{143}$.

Embora a mediana de albumina sérica de indivíduos com doença renal crônica não tenha sido inferior ao valor de referência para o laboratório no qual foi realizado o presente estudo, os valores de albuminemia para este grupo foram significativamente inferiores àqueles dos indivíduos sem doença renal crônica. Menores valores de albumina sérica, mesmo compreendidos na faixa de normalidade, têm sido associados à mortalidade de indivíduos em geral. Revisão sistemática sobre estudos longitudinais identificou aumento de $24 \%$ no risco de mortalidade a cada decréscimo de $0,25 \mathrm{~g} / \mathrm{dL}$ da albumina sérica, chegando a $56 \%$ para pacientes em hemodiálise ${ }^{144}$. Estudo Framingham Offspring, por sua vez, verificou um hazard ratio de 1,52 (IC95\% 1,01 - 2,29) para a ocorrência de infarto agudo do miocárdio em indivíduos com albumina sérica entre 2,6 e 4,4 g/dL, comparado ao grupo com valores entre 4,7 e $5,9 \mathrm{~g} / \mathrm{dL}^{145}$.

Observou-se que o nível de colesterol HDL foi inferior ao limite de normalidade para indivíduos com e sem doença renal crônica no presente estudo. Este dado é relevante, pois a relação inversa do HDL com a ocorrência de doença coronariana tem sido demonstrada por diversos estudos longitudinais ${ }^{146}$.

A grande maioria dos indivíduos com doença renal crônica 
apresentou proteinúria, havendo diferença significativa $(p<05)$ em relação aos indivíduos sem doença renal crônica. De fato, a proteinúria (ou albuminúria) tem sido utilizada como marcador de lesão renal e foi incluída em 2009 no sistema de classificação da doença renal crônica da Kidney Disease - Improving Global Outcomes $^{8}$ devido à sua relação com o prognóstico da doença. Estudos que avaliaram esta relação identificaram o decréscimo anual mais acentuado da taxa de filtração glomerular, assim como maior risco de evolução para falência renal, morbimortalidade cardiovascular e mortalidade por todas as causas na vigência de proteinúria $^{147148}$.

Ainda que a presença de proteinúria tenha sido significativamente inferior para indivíduos sem doença renal crônica, a prevalência de $40 \%$ encontrada neste estudo não é negligenciável, mesmo considerando que tal alteração também possa estar presente em quadros de infecção do trato urinário ${ }^{149}$.

Embora as associações de exames laboratoriais com doença renal crônica identificadas pelo presente estudo sejam suportadas pela literatura, muitos indivíduos não apresentaram valores para estas variáveis. Desta forma, as associações podem ter sido influenciadas por um viés de seleção dos indivíduos com maior risco para uma alteração bioquímica e hematológica (critério de demanda de exames pelo médico na internação).

Quantos aos níveis pressóricos, a comparação da pressão arterial dos pacientes que apresentaram valores registrados nos primeiros dez dias de internação mostrou que aqueles com doença renal crônica tinham pressão arterial mais elevada, sobretudo no período do sexto ao nono dia. Este dado é compatível com o maior número de hipertensos neste grupo.

Em relação aos diagnósticos de enfermagem presentes na admissão e na alta, se observou que os diagnósticos "Integridade 
tissular prejudicada", definido pelo "dano a membranas mucosas, córnea, pele ou tecidos subcutâneos"150, e "Dor aguda" foram os mais frequentes entre os pacientes internados em uma clínica médica. Estes diagnósticos também foram os mais comuns em trabalho de Fontes e Cruz $^{151}$, o qual avaliou os diagnósticos de enfermagem presentes nas primeiras 24 horas de internação, nesta mesma enfermaria de clínica médica em agosto de 2004, em amostra de conveniência. As frequências encontradas pelo presente estudo foram, contudo, inferiores àquelas encontradas por Fontes e Cruz: $34,2 \%$ vs $63,3 \%$, para integridade tissular prejudicada; e $33,4 \%$ vs $66,7 \%$, para dor aguda, considerando os valores correspondentes à admissão em clínica médica no presente estudo.

Verificou-se que os diagnósticos de enfermagem que apresentaram associação com doença renal crônica foram aqueles identificados na alta. Entre os diagnósticos de enfermagem reais que se associaram significativamente $(p<0,05)$ com doença renal crônica, houve predomínio daqueles pertencentes ao domínio de segurança e proteção: "Integridade tissular prejudicada" e "Proteção ineficaz".

Muitos fatores relacionados à doença renal crônica e às suas complicações podem explicar tal associação. No que concerne à integridade tissular, as alterações produzidas pela doença renal crônica (e altamente prevalentes em seu estágio terminal) podem ser identificadas no tecido subcutâneo pelas equimoses espontâneas ligadas à disfunção plaquetária urêmica e pelas doenças calcificantes resultantes dos distúrbios no metabolismo de cálcio e fósforo ${ }^{144}$. Além disso, a descontinuidade da integridade tissular pode estar relacionada à presença de cateteres para hemodiálise ou diálise peritoneal.

A doença renal crônica e a uremia são ainda responsáveis por alterações em outros sistemas orgânicos, que podem suscetibilizar os indivíduos a doenças e lesões. Estudo de Capellari e Almeida ${ }^{152}$ 
identificou, como principais características definidoras para o diagnóstico de enfermagem "Proteção ineficaz", em pacientes hemodialisados, a deficiência imunitária, a alteração neurossensorial, a dispneia, o prurido e a desnutrição.

O diagnóstico "Perfusão tissular ineficaz renal" foi significativamente mais frequente em indivíduos com doença renal crônica na alta, o que é coerente com o quadro clínico destes pacientes. Contudo, este diagnóstico foi suprimido do repertório do NANDA na edição 2009-2011 ${ }^{150}$. A associação de doença renal crônica com o diagnóstico "Risco para glicemia instável" também é compatível com a maior ocorrência de diabetes melito neste grupo.

Os diagnósticos "Risco para queda" e "Déficit no autocuidado" (banho, higiene, alimentação, vestir-se, arrumar-se) também se associaram significativamente $(p<0,05)$ com a doença renal crônica. Uma possível explicação seria a idade mais elevada deste grupo. A importante prevalência de doenças crônico-degenerativas em pessoas idosas acarreta a diminuição de sua funcionalidade física e mental, fato que contribui para a ocorrência de quedas e a dependência ${ }^{153} 154$. Entretanto, fatores relacionados à doença renal crônica podem ter seu papel. Sabe-se, por exemplo, que indivíduos com doença renal crônica têm maior risco de queda devido à fraqueza muscular, à desnutrição, à inatividade e à neuropatia periférica. Além disso, as quedas nestes indivíduos podem ser muito deletérias, na medida em que os distúrbios no metabolismo mineral e ósseo estão relacionados à elevada incidência de fraturas ${ }^{155}$.

Os diagnósticos de enfermagem se referem às respostas humanas, presentes ou potenciais, às condições de saúde e processos vitais de um indivíduo, uma família ou uma comunidade $^{150}$. O presente trabalho avaliou os doentes renais crônicos de forma global; portanto, as análises de associação realizadas não puderam identificar em qual medida a gravidade da doença renal crônica influencia a resposta do indivíduo à doença, 
Natália Alencar de Pinho

considerando que a doença renal crônica evolui de forma assintomática até seus estágios mais avançados.

Quanto às associações observadas em relação aos desfechos da internação, o maior tempo de internação dos pacientes com doença renal crônica é compatível com a maior morbidade neste grupo. Não há dados na literatura sobre este tema referentes a doentes renais crônicos; contudo, o tempo de internação identificado para estes pacientes (mediana de 11 dias) foi semelhante ao de pacientes hospitalizados por causas cardiovasculares em um hospital no Rio de Janeiro (RJ), Brasil, cuja mediana foi de 12 dias; e superior à média de internação de pacientes admitidos no Instituto do Coração de São Paulo (SP), Brasil, por insuficiência cardíaca descompensada $(8,45 \pm 19 \text { dias })^{156} 157$. Estes dados sugerem que a doença renal crônica implica em hospitalizações prolongadas, a exemplo das doenças cardiovasculares, fato que pode estar ligado à maior complexidade dos problemas de saúde e à ocorrência de complicações intra-hospitalares.

Ainda mais clamorosa, a elevada ocorrência de óbitos entre pacientes com doença renal crônica em relação aos sem a doença ilustrou, em nosso meio, a importante relação da doença renal crônica com mortalidade evidenciada por inúmeros estudos internacionais ${ }^{59} 606162$. A porcentagem de óbitos verificados neste grupo $(12,4 \%)$ se mostrou superior às de pacientes internados por acidente vascular isquêmico $(2,6 \%)$, doenças cardiovasculares $(6,3 \%)$ e insuficiência cardíaca descompensada (10\%) em outros estudos $^{156} 157158$. Na doença renal, relatório do Censo Brasileiro de Diálise estimou uma taxa de mortalidade de cerca de $20 \%$, para indivíduos em diálise em 2011. No presente estudo, somente um paciente com doença renal crônica que evoluiu a óbito $(7,7 \%)$ estava em estágio terminal da doença. Frente a estes dados, se verifica a importante mortalidade na doença renal crônica, mesmo em estágios menos avançados da doença. 
Cerca de $60 \%$ dos pacientes com doença renal crônica terminal iniciou o tratamento dialítico durante a internação. Destes, mais da metade $(58,8 \%)$ não tinha antecedente de doença renal crônica. Esta frequência é semelhante àquela encontrada por Godinho et $a^{159}$ em pacientes que iniciaram hemodiálise crônica em hospital público de Salvador, BA-Brasil, a qual foi de 57\%. -Contudo, ela é bem superior à frequência de referência tardia de cerca de $30 \%$ relatada por estudos em países desenvolvidos ${ }^{160161}$.

Pesquisas internacionais têm mostrado que a referência tardia de doentes renais crônicos ao serviço nefrológico está relacionada ao aumento da morbimortalidade em diálise. Na França, estudo incluindo 1391 pacientes consecutivos de um único centro, no período de 1989 a 2000, identificou associação significativa $(p<0,0001)$ de referência tardia (tempo inferior a seis meses antes do início do tratamento dialítico) com maior frequência de sintomas, uso de acesso central para hemodiálise, maior tempo de hospitalização no início do tratamento e menor ocorrência de transplantes. A razão de chance para a presença de comorbidade cardiovascular no grupo referido tardiamente foi de quase o dobro em relação àquele referido precocemente (OR 1,83 (IC 95\% 1,31 2,56), $p<0,001)$. A mortalidade ajustada para a presença de comorbidades e a idade também foi superior no primeiro grupo, com odds ratio de 1,54 (IC 95\%1,26-1,85, p<0,0001) ${ }^{160}$. Metanálise de estudos observacionais $^{162}$ identificou risco relativo de 1,99 (IC 95\% $1,66$ - 2,39; $p<0,0001)$ para mortalidade de indivíduos referidos tardiamente ao serviço nefrológico, assim como maior duração da hospitalização no início da terapia renal substitutiva, a qual foi, em média, 12 dias mais longa (IC 95\% 8,0 - 16,1, p 0,0007).

Estudo de revisão sistemática ${ }^{163}$, cujo objetivo foi verificar os fatores que contribuíram para a referência tardia de doentes renais crônicos ao serviço nefrológico, identificou associação de características individuais (idade mais elevada, presença de 
Natália Alencar de Pinho

comorbidades e condição socioeconômica precária) e de deficiências no sistema de saúde (notadamente aqueles relacionados à articulação dos serviços de assistência primária e serviços nefrológicos) com a referência tardia em 18 estudos observacionais.

A frequência de pacientes que iniciaram terapia renal substitutiva e que não tinham antecedente pessoal de doença renal crônica identificada pelo presente estudo é compatível com a afirmativa de que uma parcela importante de brasileiros doentes renais crônicos é referida tardiamente ao serviço nefrológico e sugere uma deficiência na atenção à saúde brasileira ${ }^{115}$, fato que pode contribuir para a piora de seus desfechos.

Quanto ao encaminhamento para serviços de saúde pós-alta, cerca de um terço dos pacientes que não faziam acompanhamento prévio não dispunham desta informação em seu prontuário. Para pacientes com doença renal crônica, esta porcentagem foi bem inferior (6,5\%), revelando que a importância de seguimento destes pacientes tem sido levada em conta em nosso meio. Entretanto, não foi possível identificar a especialidade do serviço de encaminhamento, devido à ausência desta informação na grande maioria dos prontuários. Como discutido anteriormente, a referência precoce de doentes renais crônicos aos serviços nefrológicos é apontada como determinante na redução da morbidade e da mortalidade destes indivíduos.

O modelo de regressão logística múltipla revelou que a doença renal crônica em pacientes internados em uma clínica médica se associou aos principais fatores de risco descritos mundialmente: idade, hipertensão arterial e diabetes melito. Os dois últimos sinalizaram uma razão de chance de mais de $200 \%$ para presença de doença renal crônica nesta população.

A doença renal crônica também mostrou importante associação com insuficiência cardíaca em nosso meio, sendo quase 
três vezes mais frequente nos indivíduos acometidos. Ainda que a diminuição do débito cardíaco motivado pela cardiopatia em si ou seu tratamento possa colaborar na gênese de lesões renais progressivas, cabe ressaltar que as principais etiologias da insuficiência cardíaca congestiva são a hipertensiva e a isquêmica, ambas estritamente ligadas à hipertensão arterial $^{164}$.

\subsection{FATORES ASSOCIADOS À HIPERTENSÃO ARTERIAL NA DOENÇA RENAL CRÔNICA}

Já era previsto, no presente estudo, analisar a amostra estudada em relação à hipertensão arterial, considerando a possibilidade de lesão de órgãos-alvo inerente ao quadro hipertensivo. A hipertensão arterial é uma doença de evolução insidiosa, que progride de forma assintomática na grande maioria dos pacientes, lesando, em última instância, o sistema vascular. Além de ser uma doença preocupante, em função das graves complicações, a hipertensão eleva custos sociais. Seus agravos induzem a aposentadorias precoces e absenteísmo ao trabalho, além do aumento da mortalidade em faixa etária ainda produtiva, caracterizando-se como um grande problema de saúde pública.

A Organização Panamericana de Saúde ${ }^{165}$ destaca que as doenças crônicas não transmissíveis têm causado, atualmente, mais mortes em países de baixa e média renda do que em países ricos, sendo responsáveis por quase dois terços das mortes prematuras, independentemente do sexo. Quase oito milhões de morte no mundo são causadas pela hipertensão, dentre as quais mais de seis milhões ocorrem em países de baixa e média renda, enquanto, em países de alta renda, a doença responde por cerca de 1,6 milhão. $A$ previsão de impacto da hipertensão arterial nas próximas décadas também é alarmante: 
nos países de média renda, comparando com a situação de 2008 , segundo o Banco Mundial (Goulart, 2011, p. 13).

A associação entre hipertensão e doença renal crônica é bem conhecida, considerando que a doença renal é a maior causa de hipertensão arterial secundária. Os principais mecanismos patogênicos da hipertensão na doença renal crônica são a sobrecarga de volume e a maior ativação do Sistema Renina Angiotensina Aldosterona ${ }^{34}$.

Portanto, identificar o papel da hipertensão arterial e suas relações com a doença renal crônica no presente estudo merece destaque, inclusive pelos resultados já exibidos terem evidenciado sua importante associação com a doença renal. Dessa forma, a seguir serão apresentados os resultados encontrados.

Iniciando pela caracterização biossocial dos pacientes hipertensos com e sem doença renal crônica, se observou associações semelhantes àquelas obtidas na comparação da totalidade da amostra, descritas anteriormente. A exceção foi a idade, que não apresentou diferença estatisticamente significante entre hipertensos com e sem doença renal crônica. A média de idade foi de 67,7 anos, para ambos os grupos, cerca de uma década mais elevada do que a média descrita por estudos de base populacional sobre a hipertensão arterial em cidades brasileiras ${ }^{38} 166$ 167. Este achado pode estar ligado ao fato de que a hipertensão arterial, quando não tratada, é responsável por lesões de órgãosalvo, que se desenvolvem ao longo de anos, e que contribuem para a morbidade hospitalar de indivíduos expostos por longo tempo à doença.

As associações encontradas para as variáveis de hábitos de vida, acompanhamento em saúde e uso contínuo de medicamentos por hipertensos com e sem doença renal crônica também foram semelhantes àquelas para a amostra em geral. Chama atenção que $16,5 \%$ dos pacientes hipertensos não faziam acompanhamento de saúde, sendo que $81,3 \%$ destes tinham antecedente pessoal de 
Natália Alencar de Pinho

hipertensão arterial e 18,9\%, antecedente de doença cardiovascular ou renal. A porcentagem de pacientes hipertensos que não tomavam medicamentos anti-hipertensivos foi ainda maior, chegando a quase $30 \%$.

Apesar da existência de medidas comprovadamente eficazes na redução da morbimortalidade cardiovascular devida à elevação dos níveis pressóricos na hipertensão arterial, o controle da doença ainda é baixo ${ }^{34}$. Tal fato tem sido atribuído à baixa adesão ao tratamento anti-hipertensivo. A adesão ao tratamento da hipertensão arterial constitui um verdadeiro desafio na atenção a estes pacientes, uma vez que é resultado da interação de diversas características individuais, estruturais e ligadas à doença. A adesão se refere ao comportamento dos indivíduos e sua congruência com o tratamento de saúde. O comparecimento às consultas e a interrupção do tratamento medicamentoso têm sido aspectos deste comportamento frequentemente utilizados na avaliação da adesão ao tratamento de hipertensos 168169170 .

Observou-se, no presente estudo, que parcela não negligenciável de hipertensos apresentavam comportamentos de falta de adesão ao tratamento anti-hipertensivo, embora tivessem diagnóstico prévio de hipertensão arterial ou de comorbidades compatíveis com lesão de órgãos-alvo. Entretanto, outros aspectos da adesão, além daqueles relacionados ao acompanhamento de saúde e ao uso de medicamentos anti-hipertensivos, podem ser de grande importância nesta população, haja vista que a morbidade cardiovascular foi expressiva nos hipertensos com e sem doença renal crônica. Excluindo-se a hipertensão arterial e a doença renal crônica, 67,2\% dos pacientes hipertensos tinham alguma comorbidade registrada em prontuário.

Os hipertensos com doença renal crônica se distinguiram dos sem doença renal crônica por apresentarem mais diabetes melito e insuficiência cardíaca congestiva, tanto pelo critério de antecedente 
pessoal quanto pelo de diagnóstico médico da internação. De fato, ambas comorbidades têm demonstrado contribuir para a gênese de doença renal crônica, como discutido anteriormente. Ressalta-se, porém, que a coexistência da hipertensão arterial com outros fatores de lesão renal pode ser muito deletéria para o prognóstico destes pacientes, sobretudo quando sem controle. Estudo com hipertensos com nefropatia diabética, cujo tempo de seguimento médio foi de 3,4 anos, identificou um hazard ratio para progressão da doença renal crônica, falência renal ou óbito $66 \%$ maior ( $p<0,001$ ) para indivíduos com pressão arterial igual ou superior a $140 \mathrm{mmHg}$, comparados aos indivíduos com valores de pressão arterial sistólica inferiores a este ${ }^{44}$.

Os hipertensos com doença renal crônica se destacaram, ainda, em relação aos demais, por tomarem maior número de antihipertensivos e por utilizarem as classes de betabloqueadores, bloqueadores de canais de cálcio, diuréticos de alça e vasodilatadores diretos com maior frequência. De forma geral, estes achados são coerentes com as recomendações para o tratamento medicamentoso da hipertensão arterial preconizado pelas $\mathrm{VI}$ Diretrizes Brasileiras de Hipertensão ${ }^{34}$. A principal finalidade do tratamento anti-hipertensivo é a redução da morbidade e mortalidade cardiovasculares. Para tanto, a terapêutica medicamentosa a ser utilizada deve priorizar não só a redução dos níveis da pressão arterial, bem como de eventos cardiovasculares fatais e não fatais.

Frente à meta de pressão arterial mais severa para pacientes com alto e muito alto risco cardiovascular (inclusive doentes renais crônicos), a terapia anti-hipertensiva combinada (dois ou mais medicamentos) é recomendada para este grupo. A utilização mais frequente da classe de betabloqueadores para hipertensos com doença renal crônica pode ser justificada pela elevada prevalência de cardiopatias nestes indivíduos. Já os diuréticos de alça têm indicação reservada aos casos de doença renal crônica severa ou 
insuficiência cardíaca com retenção hídrica. A maior utilização de vasodilatadores diretos por hipertensos com doença renal crônica pode estar ligada à maior dificuldade no controle dos níveis pressóricos, uma vez que este medicamento só é indicado na triterapia, caso não haja alcance dos objetivos propostos com outras associações $^{34}$.

Quanto à terapia com bloqueadores dos canais de cálcio, o uso de medicamentos não-di-hidropirimidínicos são apontados como efetivos na redução da proteinúria em pacientes com nefropatia diabética. Contudo, os bloqueadores dos canais de cálcio dihidropirimidínicos podem agravar a proteinúria de doentes renais crônicos em geral, sendo indicados somente em associação com anti-hipertensivos nefroprotetores, como os inibidores da enzima conversora de angiotensina ou os bloqueadores dos receptores de angiotensina $^{34}$. Verificou-se, no presente estudo, que a grande maioria dos hipertensos com doença renal crônica, que faziam uso de bloqueadores dos canais de cálcio, utilizava os dihidropirimidínicos, sendo que somente $40 \%$ tinham associação com um anti-hipertensivo nefroprotetor. Estes dados revelam que uma parcela destes pacientes poderia estar exposta ao agravo da doença renal devido a um tratamento inadequado da hipertensão, principalmente considerando a elevada prevalência de proteinúria neste grupo.

A avaliação da pressão arterial de pacientes hipertensos, segundo análise de medidas repetidas, mostrou que os valores de pressão arterial sistólica dos hipertensos sem doença renal crônica foram superiores nos primeiros três dias de internação, enquanto o maior valor para os com doença renal crônica foi registrado no sexto dia. Observou-se, inclusive, diferença estatisticamente significativa $(p<0,05)$ entre os grupos, sendo a pressão arterial sistólica mais elevada para hipertensos sem doença renal crônica no terceiro dia de internação e para os com doença renal crônica, no sexto dia. 
A diminuição dos níveis pressóricos sistólicos de hipertensos sem doença renal crônica, observada em relação aos valores dos primeiros dias de internação, pode estar relacionada à adoção de tratamento anti-hipertensivo mais eficaz e melhor controle da pressão arterial no hospital. Tal comportamento dos níveis pressóricos pode, ainda, ser resultado da diminuição do efeito do avental branco ao longo da internação. Mais difícil de explicar, porém, é o aumento da pressão arterial sistólica de hipertensos com doença renal crônica no sexto dia de internação ( $p<0,05)$, com valores compatíveis com descontrole da hipertensão arterial ( $\geq$ $130 / 80 \mathrm{mmHg}$ ) do sexto ao oitavo dia.

Observou-se, no presente estudo, que a frequência de controle da hipertensão arterial de pacientes com e sem doença renal crônica no primeiro dia de internação foi de cerca de $40 \%$, valor compreendido na faixa de controle descrito no Brasil. Estudos de base populacional publicados nos últimos anos apontaram frequências de controle da pressão arterial que oscilam entre 30 e $50 \%{ }^{38} 4647$. No contexto ambulatorial, as frequências de controle da hipertensão arterial se apresentam ainda mais discrepantes. Estudo de Silva et al ${ }^{171}$ identificou que somente 9,9\% dos indivíduos com hipertensão arterial em estágios I e II estavam controlados. Nobre et $a l^{172}$, por sua vez, verificaram a frequência de controle de 53,3\% em hipertensos sob medicação anti-hipertensiva.

Pesquisas têm identificado menor controle da hipertensão arterial entre hipertensos com lesões de órgãos-alvo. Pierin et al ${ }^{109}$ verficaram, por exemplo, que hipertensos com lesões de órgãosalvo representaram menos de um terço dos indivíduos controlados em um ambulatório de hipertensão. Em estudo sobre o controle da hipertensão arterial, segundo metas específicas pela estratificação de risco cardiovascular, somente $32,4 \%$ dos hipertensos com nefropatias e proteinúria maior que $1 \mathrm{~g} / \mathrm{l}$ estavam controlados, comparados a $61,7 \%$ dos hipertensos em estágio I e II com baixo ou 
Natália Alencar de Pinho

médio risco cardiovascular ${ }^{172}$.

Embora a porcentagem de controle da hipertensão arterial tenha sido discretamente menor, para hipertensos com doença renal crônica, não houve diferença estatisticamente significante $(p<0,05)$ em relação aos sem doença renal crônica. Além disso, o corte adotado para hipertensos sem doença renal crônica (< 140/90 $\mathrm{mmHg}$ ) pode não corresponder, para todos, à meta recomendada pelas VI Diretrizes Brasileira de Hipertensão ${ }^{34}$, considerando a elevada prevalência de comorbidades e fatores de risco cardiovascular. Desta forma, o controle da hipertensão arterial, nesta parcela de pacientes, pode ter sido superestimado.

Quantos aos desfechos da hospitalização, observou-se maior número de óbitos e maior tempo de internação para hipertensos com doença renal crônica em relação aos sem doença renal crônica, a exemplo do verificado na amostra em geral.

Frente ao crescente impacto das doenças crônicas não transmissíveis no Brasil, políticas de saúde pública têm sido adotadas para a prevenção e o controle destas condições. Tais políticas incluem desde a regulamentação do uso de tabaco em ambientes públicos, até o oferecimento gratuito de medicamentos para prevenção de eventos cardiovasculares em pacientes de alto risco. Apesar de a mortalidade cardiovascular padronizada para a idade ter diminuído nas últimas décadas, ela é muito superior àquela observada em diversos países (inclusive da América Latina). As causas cardiovasculares representam a principal causa de morte para brasileiros $^{173}$.

A elevada morbimortalidade cardiovascular no Brasil tem sido atribuída principalmente à hipertensão arterial. Além disso, a hipertensão arterial constitui a principal causa de falência renal tratada por diálise no Brasil. Por esse motivo, a atenção à hipertensão arterial é considerada uma prioridade pelo Plano de Ações Estratégicas para o enfrentamento das Doenças Crônicas 
Natália Alencar de Pinho

Não Transmissíveis no Brasil 2011-2022. Este documento traz, como diretrizes, a vigilância da hipertensão (fatores de risco, comorbidades), a integralidade do cuidado e a promoção da saúde. Quanto à doença renal crônica, acredita-se que o tratamento da hipertensão arterial e do diabetes melito, além da redução do consumo de sal, será efetivo no seu enfrentamento ${ }^{174}$.

\subsection{AVALIAÇÃO DA TAXA DE FILTRAÇÃO GLOMERULAR EM PACIENTES SEM DOENÇA RENAL CRÔNICA}

A atual classificação da doença renal crônica, baseada na taxa de filtração glomerular e nos níveis de albuminúria, estimulou o desenvolvimento de técnicas de aferição destes dois elementos, a fim de melhorar sua empregabilidade clínica e epidemiológica. Este fenômeno ocorreu de forma mais pronunciada em relação à avaliação da taxa de filtração glomerular. Tendo em vista as dificuldades associadas à utilização de marcadores exógenos neste procedimento, muitas equações baseadas na creatinina sérica e outros marcadores endógenos foram propostas para obtenção de estimativas fidedignas da taxa de filtração glomerular.

A equação MDRD4 tem sido recomendada por instituições de referência em nefrologia para o rastreamento e o acompanhamento de doentes renais crônicos ${ }^{79}{ }^{81}$. A emissão da estimativa da taxa de filtração glomerular pela equação MDRD4, juntamente com os resultados de aferição da creatinina sérica, tem sido amplamente adotada, inclusive no local no qual foi realizado o presente estudo. Além disso, estudos epidemiológicos têm demonstrado a associação de menores taxas de filtração glomerular, estimada pela equação MDRD4, com morbidade e mortalidade de indivíduos com doença renal crônica ${ }^{56} 57$

Contudo, a taxa de filtração glomerular estimada pela MDRD4 se revelou pouco precisa para indivíduos sem doença renal crônica. 
Natália Alencar de Pinho

Diante disso, a equação CKD-EPI foi desenvolvida, com o objetivo de fornecer estimativa mais fiel da taxa de filtração glomerular, reduzindo a subestimação desta em indivíduos saudáveis ${ }^{85}$.

Verificou-se, no presente estudo, que 7,8\% dos pacientes sem doença renal crônica apresentaram taxa de filtração glomerular estimada por ambas as equações inferior a $60 \mathrm{~mL} / \mathrm{min} / 1,73 \mathrm{~m}^{2}$, embora tenham sido submetidos a um rigoroso critério para evitar inclusão de doentes renais crônicos não diagnosticados na amostra. Ainda que não caracterizada a cronicidade da diminuição da função renal, este dado é relevante, no sentido em que uma importante parcela de pacientes internados em uma unidade geral possa apresentar doença renal crônica subdiagnosticada, sobretudo se considerados os pacientes com proteinúria positiva - ou mesmo aqueles que foram excluídos por instabilidade da creatinina sérica.

Ao contrário do esperado, a regressão linear indicou que a taxa de filtração glomerular estimada pela equação CKD-EPI foi sistematicamente inferior àquela estimada pela equação MDRD4 em pacientes sem doença renal crônica. Todavia, houve concordância segundo coeficiente Kappa da classificação da taxa de filtração glomerular nas faixas inferior a 60 , de 60 a 89 , e igual ou superior a $90 \mathrm{~mL} / \mathrm{min} / 1,73 \mathrm{~m}^{2}$.

A comparação da classificação da taxa de filtração glomerular pelas diferentes equações mostrou que somente pequena parcela dos pacientes sem doença renal crônica foi reclassificada pela CKDEPI em relação à MDRD4 (8,2\%). A reclassificação ocorreu para uma faixa inferior de taxa de filtração glomerular em cerca de dois terços das vezes. Considerando o pequeno número de pacientes reclassificados ( $n=23$ ) e a consequente dificuldade na interpretação da estatística analítica, optou-se por não se realizar a comparação de características individuais que poderiam influenciar tal achado no presente estudo.

A equação MDRD4 foi escolhida para verificação de 
Natália Alencar de Pinho

associações da taxa de filtração glomerular estimada com variáveis biossociais, de morbidade e desfecho dos pacientes sem doença renal crônica pelo fato de já ser reportada pelo Sistema de Apoio Diagnóstico e Terapêutico do hospital no qual foi realizado o estudo.

Quanto às características biossociais de pacientes sem doença renal crônica, se observou que os com taxa de filtração glomerular estimada inferior a $90 \mathrm{~mL} / \mathrm{min} / 1,73 \mathrm{~m}^{2}$ foram significativamente diferentes $(p<0,05)$ daqueles com valores iguais ou inferiores a este, por serem predominante de etnia branca e por terem idade e índice de massa corporal mais elevados.

Estudos comparativos das equações de estimativa da taxa de filtração glomerular têm mostrado que características individuais influenciam seus resultados.

Com relação à etnia, estudo comparativo das equações MDRD4 e CKD-EPI mostrou efeito protetor da etnia negra para presença de taxa de filtração glomerular inferior a $60 \mathrm{~mL} / \mathrm{min} / 1,73 \mathrm{~m}^{2}$ estimada pela equação MDRD4 (OR 0,669 (IC 95\% 0,623 - 0,720)). Contudo, mediante uso da equação CKD-EPI, não houve diferença entre negros e brancos para este desfecho. Diante do fato de que a incidência e prevalência de falência renal são maiores para afrodescendentes, os autores do estudo em questão concluíram que a equação MDRD superestima a taxa de filtração glomerular destes indivíduos ${ }^{175}$. Esta hipótese pode justificar a expressiva porcentagem de não brancos com taxa de filtração glomerular maior ou igual a 90 $\mathrm{mL} / \mathrm{min} / 1,73 \mathrm{~m}^{2}$ observada com a estimativa pela equação MDRD4 no presente estudo. Além disso, tal hipótese explica os menores valores de taxa de filtração glomerular estimados pela equação CKD-EPI em relação à MDRD4.

Estudo que avaliou o desempenho das equações CockroftGault, MDRD4 e CKD-EPI em relação ao padrão-ouro I-iotalamato identificou que todas as equações subestimavam a taxa de filtração glomerular de indivíduos mais velhos (viés por ano adicional na 
idade de $-0,26$ vs $-0,27$ vs $-0,17$, respectivamente). Somente a Cockroft-Gault foi influenciada pelo índice de massa corporal (viés por $\mathrm{kg} / \mathrm{m}^{2}$ adicional no índice de massa corporal de 0,55 (IC95\% $0,23-0,88))^{88}$. Cabe ressaltar, porém, que estudos têm relatado a queda da taxa de filtração glomerular com a idade ${ }^{26}{ }^{27}$, além de maior prevalência de doença renal crônica entre idosos ${ }^{10} 1920$.

A prevalência de fatores de risco cardiovascular e renal (hipertensão arterial, diabetes melito e dislipidemia) foi maior $(p<$ $0,05)$ em pacientes com taxa de filtração glomerular estimada inferior a $90 \mathrm{~mL} / \mathrm{min} / 1,73 \mathrm{~m}^{2}$ em relação aos com valores iguais ou superiores a este. Este achado é semelhante aos de estudos sobre taxa de filtração glomerular estimada em indivíduos sem doença renal crônica.

Estudo com 2746 indivíduos sem doença renal crônica e submetidos à angiografia coronariana em um serviço médico de TelAviv identificou uma maior prevalência de hipertensão arterial com decréscimo da taxa de filtração glomerular estimada pela equação Cockroft-Gault: $42 \%$ para taxa de filtração glomerular estimada maior ou igual a $96 \mathrm{~mL} / \mathrm{min} / 1,73 \mathrm{~m}^{2}, 65 \%$, para a faixa compreendida entre 77 e $69 \mathrm{~mL} / \mathrm{min} / 1,73 \mathrm{~m}^{2}$, e $69 \%$ para valores entre 76 e 60 $\mathrm{mL} / \mathrm{min} / 1,73 \mathrm{~m}^{2}(\mathrm{p}<0,001)$. O mesmo achado foi obtido em relação à hipercolesterolemia (35\% vs 72\% vs 77\%, p < 0,001). Contudo, não houve diferença entre os grupos em relação à prevalência de diabetes $^{176}$.

A taxa de filtração glomerular estimada pela equação CKDEPI também mostrou associação com comorbidades de indivíduos sem doença renal crônica em estudo conduzido com voluntários chineses que se submeteram a um check-up de saúde. Em relação aos indivíduos com taxa de filtração glomerular estimada superior a $90 \mathrm{~mL} / \mathrm{min} / 1,73 \mathrm{~m}^{2}$, os com valores compreendidos entre 60 e 90 $\mathrm{mL} / \mathrm{min} / 1,73 \mathrm{~m}^{2}$ apresentavam maior prevalência $(\mathrm{p}<0,05)$ de hipertensão arterial (38,4\% vs $15,4 \%)$, diabetes $(11,2 \%$ vs $6,1 \%)$, 
Natália Alencar de Pinho

hipercolesterolemia $(40,1 \%$ vs $25,7 \%)$, hipertrigliceridemia $(36,6 \%$ vs $28,5 \%)$, e aumento da fração de colesterol LDL $(34,8 \% \text { vs } 23,0 \%)^{177}$.

A associação de reduções leves da taxa de filtração glomerular com fatores de risco de lesão renal progressiva é de grande relevância, sobretudo se somada ao fato de que taxas de filtração glomerular levemente reduzidas mostraram-se independentemente associadas à diminuição da função renal em cinco anos ${ }^{27}$.

Como observado na comparação de pacientes com e sem doença renal crônica, pacientes com taxa de filtração glomerular inferior a $90 \mathrm{~mL} / \mathrm{min} / 1,73 \mathrm{~m}^{2}$ se distinguiram daqueles com valores iguais ou superiores a este por não serem fumantes $(21,5 \%$ vs $36,5 \%)$. No entanto, é importante considerar a elevada prevalência deste fator de risco em ambos os grupos, a qual foi superior àquela descrita no inquérito VIGITEL de $2010(15,1 \%)^{107}$ ou pela Pesquisa Nacional por Amostra e Domicílios: Tabagismo $2008(17,2 \%)^{178}$.

Os desfechos da internação não se associaram à taxa de filtração glomerular estimada pela equação MDRD4. Considerando que Arbel et al ${ }^{176}$ identificaram a estimativa da taxa de filtração glomerular como único preditor independente de mortalidade em indivíduos sem doença renal crônica em seguimento médio de $419 \pm$ 115 dias (HR 1,38 (IC 95\% 1,19 - 1,60)), a avaliação dos desfechos restrita ao período de hospitalização no presente estudo pode não ter sido suficiente para identificar diferenças na mortalidade dos pacientes segundo taxa de filtração glomerular estimada.

A validade das equações de estimativa da taxa de filtração glomerular ainda não foi suficientemente documentada no Brasil. O único estudo brasileiro publicado sobre a comparação das equações MDRD4 e CKD-EPI com um padrão-ouro verificou que somente a equação CKD-EPI apresentou acurácia dentro de 30\% adequada em relação à taxa de filtração glomerular mensurada a partir da depuração do 51Cr-EDTA (CKD-EPI, 85\% vs MDRD4, 69\%) ${ }^{89}$. 
Entretanto, a amostra deste estudo contou com número reduzido de participantes em relação aos estudos internacionais e se restringiu a indivíduos saudáveis.

A relação da taxa de filtração glomerular estimada com comorbidades e desfechos em longo prazo deve ser mais estudada em nosso meio, considerando que a população brasileira poderia se beneficiar da adoção deste método relativamente simples na detecção precoce da doença renal crônica e no monitoramento de sua evolução. 


\section{6. \\ Considerações Finais}




\section{CONSIDERAÇÕES FINAIS}

As doenças crônicas não transmissíveis constituem um verdadeiro desafio na atenção à saúde. Sua alta prevalência, assim como seu importante impacto na morbimortalidade, as elevou ao patamar de principal problema de saúde pública mundial. Além disso, as doenças crônicas exigem tratamento medicamentoso para toda a vida e profundas mudanças no estilo de vida dos indivíduos acometidos.

A doença renal crônica é, muitas vezes, consequência de outras condições crônicas, como a hipertensão arterial e o diabetes melito. Uma vez instalada, a doença renal crônica concorre para alterações estruturais e funcionais de outros sistemas. A interação de todos estes fatores resulta em complicações ainda maiores, culminando em eventos cardiovasculares, falência renal e morte. Desta forma, a equipe multidisciplinar deve atuar na detecção de fatores de risco, diagnóstico precoce e tratamento da doença renal crônica.

A adesão ao tratamento é um ponto central na atenção à doença renal crônica em todos seus estágios. O controle dos níveis pressóricos e glicêmicos constitui a principal intervenção para prevenção primária e secundária na doença renal crônica. A intervenção do enfermeiro, mediante a educação em saúde e o incentivo à tomada de decisões e ao autocuidado, é de grande valia para o alcance dos objetivos do tratamento.

Cabe ressaltar que a adoção de medidas restritivas, imposta pela doença renal crônica, desde a simples diminuição do sal na alimentação, nos estágios iniciais, até a abolição completa de certos itens alimentares, na falência renal, é, às vezes, tão difícil de vivenciar quanto os sintomas e as complicações propriamente ditos. Diante disto, a identificação de fatores de risco e a intervenção 
precoce na doença renal crônica podem ser importantes ferramentas do enfermeiro na promoção da qualidade de vida destes indivíduos.

Apesar das limitações do presente estudo, ligadas ao seu caráter retrospectivo e à frequente ausência de dados em prontuários, observou-se que a doença renal crônica esteve associada aos principais fatores de risco cardiovasculares. O processo de hospitalização continua a ser a "porta de entrada" no sistema de saúde para uma importante parcela da população. Por este motivo, o reconhecimento dos fatores associados à doença renal crônica, pelos enfermeiros e outros profissionais de saúde, pode ser determinante para a devida continuidade dos cuidados. 


\section{7. \\ Conclusão}




\section{CONCLUSÃO}

Os resultados do presente estudo, realizado com uma amostra de 386 pacientes internados em uma clínica médica de um hospital universitário na cidade de São Paulo, mostraram que, em relação aos dados biossociais, 50,5\% eram do sexo masculino, $64,4 \%$ brancos, $39,3 \%$ trabalhadores ativos, com idade de $58,2 \pm 18,6$ anos e índice de massa corporal de $25,4(21,7-28,4) \mathrm{kg} / \mathrm{m}^{2}$.

Quanto aos hábitos de vida e saúde, 24,7\% eram tabagistas, $8,8 \%$ etilistas e $33,6 \%$ não faziam acompanhamento de saúde. A quantidade de medicamentos de uso contínuo por paciente foi de 1,0 $(0,0-3,0)$. Os antecedentes pessoais mais frequentes foram a hipertensão arterial $(54,1 \%)$, o diabetes melito $(29,8 \%)$ e a dislipidemia $(17,4 \%)$.Os diagnósticos médicos mais presentes foram a hipertensão arterial $(58,8 \%)$, as doenças respiratórias $(33,2 \%)$ e o diabetes melito $(32,1 \%)$. Já os diagnósticos de enfermagem foram a integridade tissular prejudicada (42,5\%), a dor aguda (29,3\%), e a integridade da pele prejudicada $(26,2 \%)$. O tempo de internação foi de $9,0(7,0$ - 13,0) dias; $91,2 \%$ dos pacientes receberam alta hospitalar.

Segundo os critérios do estudo, 105 pacientes (27,2\%), que compuseram a amostra, tinham doença renal crônica. Destes, 56 $(53,3 \%)$ tinham antecedente pessoal da doença. Os pacientes com falência renal representaram $25,7 \%$ deste grupo, sendo que 17 deles $(65,4 \%)$ iniciaram terapia renal substitutiva durante a internação.

Os pacientes com doença renal crônica distinguiram-se $(p<$ $0,05)$ daqueles sem a doença em relação a: viver com companheiro $(59,8 \%$ vs $47,3 \%)$; idade mais elevada $(65,8 \pm 15,6$ vs $55,3 \pm 18,9$ anos); não fumarem (11,1\% vs $29,7 \%)$; menor porcentagem de falta de acompanhamento de saúde (12,2\% vs $42,0 \%)$; e maior número de medicamentos de uso contínuo $(3,0(1,0-5,0)$ vs $1,0(0,0-3,0))$. 
Natália Alencar de Pinho

Quando comparados aos pacientes sem doença renal, os pacientes com doença renal crônica apresentaram mais antecedente pessoal $(p<0,05)$ de hipertensão arterial $(75,2 \%$ vs $46,3 \%)$; diabetes melito $(49,5 \%$ vs $22,4 \%)$; dislipidemia (23,8\% vs $14,9 \%)$; infarto agudo do miocárdio (14,3\% vs 6,0\%); e insuficiência cardíaca congestiva (18,1\% vs 4,3\%). Observou-se, igualmente, maior consumo $(p<0,05)$ de anti-hipertensivos $(70,5 \%$ vs $36,3 \%)$; antiagregantes plaquetários $(26,7 \%$ vs $14,9 \%)$; estatinas $(18,1 \%$ vs $10,0 \%)$; insulina (23,8\% vs $4,3 \%$ ); e medicamentos de ação cardíaca (16,2\% vs 5,7\%) no grupo com doença renal crônica.

Os pacientes com doença renal crônica tiveram maior frequência $(p<0,05)$ de diagnóstico médico de hipertensão arterial (81,0\% vs 50,5\%); diabetes melito (50,5\% vs 25,3\%); e insuficiência cardíaca congestiva em relação aos pacientes sem doença renal. Observaram-se, ainda, diferenças significativas $(p<0,05)$ entre os grupos com e sem doença renal crônica, quanto aos seguintes exames laboratoriais: potássio sérico $(4,6(4,1$ - 5,3) vs 4,1 $(3,8$ $4,4) \mathrm{mEq} / \mathrm{l})$; ureia sérica $(116,0(83,0$ - 167,5) vs 33,0 $(24,0$ - 41,0) $\mathrm{mg} / \mathrm{dL})$; hemoglobina $(11,1(9,3$ - 12,5) vs 13,3 (11,9 - 14,6) g/dL); hematócrito $(33,0(28,0$ - 37,0) vs 40,0 (36,0 - 43,0) \%); albumina sérica $(3,1(2,8-3,4)$ vs $3,7(3,3-4,0) \mathrm{g} / \mathrm{dL})$; fósforo sérico $(4,9(3,7$ - 6,0) vs 3,5 (2,7 - 4,1) mg/dL); ácido úrico $(7,5(6,5$ - 8,9) vs 5,5 $(4,4-6,7) \mathrm{mg} / \mathrm{dL})$; e presença de proteinúria $(84,5 \%$ vs $39,5 \%)$. Os valores de creatinina sérica nos dez primeiros dias de internação foram significativamente superiores $(p<0,001)$ para pacientes com doença renal crônica.

A análise da pressão arterial de pacientes que apresentaram medida da pressão arterial do primeiro ao décimo dia de internação mostrou que os valores do sexto ao décimo dia diferiram significativamente $(p<0,05)$ entre os grupos, sendo superiores para pacientes com doença renal crônica.

Os pacientes com doença renal crônica também se 
distinguiram daqueles sem a doença por apresentarem, na alta, uma maior frequência dos seguintes diagnósticos de enfermagem: integridade tissular prejudicada (57,1\% vs 37,0\%); perfusão tissular ineficaz renal $(63,8 \%$ vs 3,6\%); déficit no autocuidado (15,2\% vs $5,0 \%$ ); proteção ineficaz (43,8\% vs 18,1\%); risco de glicemia instável (18,1\% vs 15,3\%); e risco para queda (19,0\% vs 14,6\%). Observouse que pacientes com doença renal crônica tiveram maior frequência de óbitos (12,4\% vs $1,4 \%)$ e maior tempo de internação $(11,0$ (8,0 $18,0)$ vs $9,0(6,0$ - 12,0) dias) em relação aos pacientes sem a doença.

A análise de regressão logística indicou associação independente da doença renal crônica com as seguintes variáveis (OR, odds ratio; IC, intervalo de confiança de 95\%): idade (OR 1,019, IC 1,003-1,036); hipertensão arterial (OR 2,032, IC 1,1283,660), diabetes (OR 2,097, IC 1,232-3,570) e insuficiência cardíaca congestiva (OR 2,665, IC 1,173-6,056).

A comparação de hipertensos com e sem doença renal crônica indicou que os grupos foram distintos $(p<0,05)$ em relação a: viver com companheiro (64,3\% vs $50,7 \%)$; uso de maior número de medicamentos $(4,0(2,0-5,0)$ vs $2,0(0,5-4,0)$, não fumantes $(9,9 \%$ vs $25 \%$ ); ter antecedentes pessoais para diabetes (53,5\% vs $36,4 \%)$ e insuficiência cardíaca congestiva (19,8\% vs $7,0 \%)$; uso de medicamentos anti-hipertensivos (79,1\% vs $66,4 \%$,); tratamento com insulina $(24,4 \%$ vs $7,0 \%)$; além dos exames laboratoriais, exceto glicemia, perfil lipídico e ácido úrico.

A avaliação da pressão arterial de hipertensos que apresentaram medidas registradas do primeiro ao décimo dia de internação mostrou diminuição $(p<0,05)$ dos níveis pressóricos de hipertensos sem doença renal crônica em relação aos três primeiros dias. Para hipertensos com doença renal crônica, houve aumento significativo $(p<0,05)$ da pressão arterial no sexto dia de internação. Apresentaram controle da hipertensão arterial, no primeiro dia de 
Natália Alencar de Pinho

internação, 44,5\% dos hipertensos, não havendo diferença entre os grupos com e sem doença renal crônica.

A estimativa da taxa de filtração glomerular de pacientes sem doença renal pela equação MDRD4 indicou que 54,4\% tinham taxa de filtração glomerular igual ou superior a 90; 37,7\%, entre 60 e 89; e $7,8 \%$, inferior a $60 \mathrm{~mL} / \mathrm{min} / 1,73 \mathrm{~m}^{2}$. Embora a taxa de filtração glomerular estimada pela equação CKD-EPI tenha se mostrado sistematicamente inferior àquela estimada pela MDRD4 $\left(c=0,88 ; r^{2}\right.$ $=0,974)$; houve boa concordância da classificação da taxa de filtração glomerular pelas duas equações (Kappa =0,854).

$\mathrm{Na}$ comparação entre os grupos com taxa de filtração glomerular estimada pela equação MDRD4 inferior a 90 $\mathrm{mL} / \mathrm{min} / 1,73 \mathrm{~m}^{2}$ e igual ou superior a este valor, observou-se diferença significativa $(p<0,05)$ em relação a: ser de etnia branca (81,3\% vs 52,6\%); ter idade mais elevada $(63,4 \pm 16,4$ vs $48,5 \pm 18,6$ anos); ter maior índice de massa corporal $(26,0(23,4-28,7)$ vs 24,2 $(20,6$ - 27,6) kg/m²); e menor frequência de tabagismo $(21,5 \%$ vs $36,5 \%)$. Além disso, pacientes com taxa de filtração glomerular estimada inferior a $90 \mathrm{~mL} / \mathrm{min} / 1,73 \mathrm{~m}^{2}$ se destacaram $(p<0,05)$ por apresentar maior frequência de hipertensão arterial $(63,3 \%$ vs $32,0 \%)$, diabetes $(29,7 \%$ vs $16,3 \%)$ e dislipidemia $(24,2 \%$ vs $7,2 \%)$.

Conclui-se que a doença renal crônica, em pacientes internados em uma clínica médica de um hospital universitário na cidade de São Paulo, esteve associada aos principais fatores de risco cardiovascular modificáveis e ao envelhecimento. Ela ainda esteve associada ao pior perfil de morbidade e mortalidade intrahospitalar. A estimativa da taxa de filtração glomerular pela equação Modification of Diet in Renal Disease abreviada pareceu distinguir os pacientes sem doença renal quanto à presença de fatores de risco cardiovascular e renal. 
Referências 


\section{REFERÊNCIAS}

1 Lessa I. Doenças crônicas não-transmissíveis no Brasil: um desafio para a complexa tarefa da vigilância. Cien Saude Colet. 2004;9(4):931-43.

2 Bastos MG, Carmo WB, Abrita RR, Almeida EC, Mafra D, Costa $\mathrm{DMN}$, et al. Doença renal crônica: problemas e soluções. J Bras Nefrol. 2004;XXVI(4):202-15.

3 Bastos MG, Bregman R, Kirsztajn GM. Doença renal crônica: frequente e grave, mas também prevenível e tratável. Rev Assoc Med Bras. 2010;56:248-53.

4 Jaar BG, Khatib R, Plantinga L, Boulware LE, Powe NR. Principles of Screening for Chronic Kidney Disease. Clin J Am Soc Nephrol. 2008;3(2):601-9.

5 Levey AS, Coresh J. Chronic kidney disease. The Lancet. 2012;379(9811):165-80.

6 NKF KDOQI Guidelines [Internet]. KDOQI Clinical Practice Guidelines for Chronic Kidney Disease: Evaluation C, and Stratification. Part 1. Definition and classification of stages of chronic kidney disease. [citado 2013 abr 19]. Disponível em: http://www.kidney.org/professionals/KDOQI/guidelines_ckd/p7_ri sk_g15.htm.

7 Levey AS, Jong PE, Coresh J, El Nahas M, Astor BC, Matsushita K et al. The definition, classification, and prognosis of chronic kidney disease: a KDIGO Controversies Conference report. Kidney Int. 2010;80(1):17-28.

8 Kidney Disease - Improving Global Outcomes (KDIGO). Chapter 1: Definition and classification of CKD. Kidney Int Suppl. 2013;3:5-14

9 Rettig RA, Norris K, Nissenson AR. Chronic kidney disease in the United States: a public policy imperative. Clin J Am Soc Nephrol. 2008;3(6):1902-10.

10 Zhang QL, Rothenbacher D. Prevalence of chronic kidney disease in population-based studies: systematic review. BMC Public Health. 2008;8(1):117. 
11 McCullough K, Sharma P, Ali T, Khan I, Smith WCS, MacLeod A et al. Measuring the population burden of chronic kidney disease: a systematic literature review of the estimated prevalence of impaired kidney function. Nephrol Dial Transplant. 2012;27(5):1812-21.

12 Coresh J, Selvin E, Stevens LA, Manzi J, Kusek JW, Eggers P et al. Prevalence of chronic kidney disease in the United States. JAMA. 2007;298(17):2038-47.

13 Coresh J, Byrd-Holt D, Astor BC, Briggs JP, Eggers PW, Lacher $\mathrm{DA}$, et al. Chronic kidney disease awareness, prevalence, and trends among U.S. adults, 1999 to 2000. J Am Soc Nephrol. 2005;16(1):180-8.

14 Cepoi V, Onofriescu M, Segall L, Covic A. The prevalence of chronic kidney disease in the general population in Romania: a study on 60,000 persons. Int Urol Nephrol. 2012;44(1):213-20.

15 Sai $X Y$, Sun YF. Prevalence of chronic kidney disease in China: a cross-sectional survey. The Lancet. 2012;379:815-22.

16 Obrador GT, García-García G, Villa AR, Rubilar X, Olvera N, Ferreira $\mathrm{E}$ et al. Prevalence of chronic kidney disease in the Kidney Early Evaluation Program (KEEP) Mexico and comparison with KEEP US. Kidney Int. 2010;77:S2-S8.

17 Yokota RTC, Iser BPM, Andrade RLM, Santos J, Meiners MMMA, Assis DM et al. Vigilancia de fatores de risco e proteção para doenças e agravos não transmissíveis em município de pequeno porte, Brasil, 2010. Epidemiol Serv Saude. 2012;21(1):55-68.

18 Passos VM, Barreto SM, Lima-Costa MF. Detection of renal dysfunction based on serum creatinine levels in a Brazilian community: the Bambui Health and Ageing Study. Braz J Med Biol Res. 2003;36(3):393-401.

19 Lessa I. Níveis séricos de creatinina: hipercreatinemia em segmento da população adulta de Salvador, Brasil. Rev Bras Epidemiol. 2004;7(2):176-86.

20 Bastos RMR, Bastos MG, Ribeiro LC, Bastos RV, Teixeira MTB. Prevalência da doença renal crônica nos estágios 3, 4 e 5 em adultos. Rev Assoc Med Bras. 2009;55(1):40-4.

21 United States Renal Data System. 2012 Annual Data Report. Atlas of Chronic Kidney Disease \& End-Stage Renal Disease in the United States. An introduction to end-stage renal disease in the U.S. Am J Kidney Dis. 2013;61(1):e165-e92. 
22 Sesso RCC, Lopes AA, Thomé FS, Lugon JR, Watanabe Y, Santos DR. Chronic Dialysis in Brazil-Report of the Brazilian Dialysis Census, 2011. J Bras Nefrol. 2012;34(3):272-7.

23Moura L, Schmidt MI, Duncan BB, Rosa RS, Malta DC, Stevens A et al. Monitoramento da doença renal crônica terminal pelo subsistema de Autorização de Procedimentos de Alta Complexidade-Apac-Brasil, 2000 a 2006. Epidemiol Serv Saude. 2009;18(2):121-31.

24Salgado Filho N, Brito DJA. Doença renal crônica: a grande epidemia deste milênio. J Bras Nefrol. 2006;28(supl 2):1-5.

25 Lamb EJ, O'Riordan SE, Delaney MP. Kidney function in older people: pathology, assessment and management. Clin Chim Acta. 2003;334(1-2):25.

26 Lindeman RD, Tobin J, Shock NW. Longitudinal studies on the rate of decline in renal function with age [Abstract]. J Am Geriatr Soc. 1985;33(4):278.

27 Jiang S, Sun X, Gu H, Chen Y, Xi C, Qiao X et al. Age-related change in kidney function, its influencing factors, and association with asymptomatic carotid atherosclerosis in healthy individuals-A 5-year follow-up study. Maturitas. 2012; 73(3):230-8.

28 Whiting DR, Guariguata L, Weil C, Shaw J. IDF diabetes atlas: global estimates of the prevalence of diabetes for 2011 and 2030. Diabetes Res Clin Pract. 2011;94(3):311-21.

29 Min TZ, Stephens MW, Kumar P, Chudleigh RA. Renal complications of diabetes. Br Med Bull. 2012;104(1):113-27.

30 Amato D, Alvarez-Aguilar C, Castaneda-Limones R, Rodriguez E, Avila-Diaz M, Arreola F et al. Prevalence of chronic kidney disease in an urban Mexican population. Kidney Int. 2005;68:S11-S7.

31 Ritz E, Rychlík I, Locatelli F, Halimi S. End-stage renal failure in type 2 diabetes: A medical catastrophe of worldwide dimensions. Am J Kidney Dis. 1999;34(5):795-808.

32 Burrows NR, Li Y, Geiss LS. Incidence of treatment for end-stage renal disease among individuals with diabetes in the U.S. continues to decline. Diabetes Care. 2010;33(1): 73-7.

33 Reutens AT. Epidemiology of diabetic kidney disease. Med Clin North Am. 2013;97(1):1-18. 
34 Sociedade Brasileira de Cardiologia, Sociedade Brasileira de Hipertensão, Sociedade Brasileira de Nefrologia. VI Diretrizes Brasileiras de Hipertensão. Arq Bras Cardiol. 2010;95(1):I-III.

35 Wolf-Maier K, Cooper RS, Banegas JR, Giampaoli S, Hense H-W, Joffres $\mathrm{M}$ et al. Hypertension prevalence and blood pressure levels in 6 European countries, Canada, and the United States. JAMA. 2003;289(18):2363-9.

36 Passos VMA, Assis TD, Barreto SM. Hipertensão arterial no Brasil: estimativa de prevalência a partir de estudos de base populacional. Epidemiol Serv Saude. 2006;15(1):35-45.

37 Picon RV, Fuchs FD, Moreira LB, Riegel G, Fuchs SC. Trends in Prevalence of Hypertension in Brazil: A Systematic Review with Meta-Analysis. PloS one. 2012;7(10):e48255.

38 Mion Jr D, Pierin AMG, Bensenor IM, Marin JCM, Costa KRA, Henrique LFO et al. Hipertensão arterial na cidade de São Paulo: prevalência referida por contato telefônico. Arq Bras Cardiol. 2010;95:99-106.

39 Almeida Filho $\mathrm{N}$. The concept of health: blind-spot for epidemiology? Rev Bras Epidemiol. 2000;3(1-3):4-20.

40 Lim SS, Vos T, Flaxman AD, Danaei G, Shibuya K, Adair-Rohani $\mathrm{H}$ et al. A comparative risk assessment of burden of disease and injury attributable to 67 risk factors and risk factor clusters in 21 regions, 1990-2010: a systematic analysis for the Global Burden of Disease Study 2010. The Lancet. 2013;380(9859):2224-60.

41 Brasil. Ministério da Saúde. Departamento de Informática do SUS. DATASUS: informações de saude [Internet]. Brasília, 2008. [citado 2013 abr 19]. Disponivel em: www.datasus.gov.br/tabnet/tabnet.htm.

42 Haroun MK, Jaar BG, Hoffman SC, Comstock GW, Klag MJ, Coresh J. Risk factors for chronic kidney disease: a prospective study of 23,534 men and women in Washington County, Maryland. J Am Soc Nephrol. 2003;14(11):2934-41.

43 Perry HM, Miller JP, Fornoff JR, Baty JD, Sambhi MP, Rutan G et al. Early predictors of 15-year end-stage renal disease in hypertensive patients. Hypertension. 1995;25(4):587-94.

44 Bakris GL, Weir MR, Shanifar S, Zhang Z, Douglas J, van Dijk DJ et al. Effects of blood pressure level on progression of diabetic nephropathy: results from the RENAAL study. Arch Intern Med. 163. United States. 2003;163(13):1555-65. 
45 Bloomfield GS, Yi SS, Astor BC, Kramer H, Shea S, Shlipak MG, et al. Blood pressure and chronic kidney disease progression in a multi-racial cohort: the Multi-Ethnic Study of Atherosclerosis. J Hum Hypertens. 2013:1-6.

46 Lyra R, Silva RS, Montenegro Junior RM, Matos MVC, Cézar NJB, Fernandes VO et al. High prevalence of arterial hypertension in a Brazilian Northeast population of low education and income level, and its association with obesity and metabolic syndrome. Rev Assoc Med Bras. 2012; 58: 209-14.

47 Piccini RX, Facchini LA, Tomasi E, Siqueira FV, Silveira DS, Thumé $\mathrm{E}$ et al. Promoção, prevenção e cuidado da hipertensão arterial no Brasil. Rev Saude Publica. 2012; 46: 543-50.

48 Gluba A, Mikhailidis DP, Lip GYH, Hannam S, Rysz J, Banach M. Metabolic syndrome and renal disease. Int J Cardiol. 2012.

49 Peralta CA, Kurella M, Lo JC, Chertow GM. The metabolic syndrome and chronic kidney disease. Curr Opin Nephrol Hypertens. 2006;15(4):361.

50 Chen J, Muntner P, Hamm LL, Jones DW, Batuman V, Fonseca V et al. The metabolic syndrome and chronic kidney disease in US adults. Ann Intern Med. 2004;140(3):167.

51 Kurella M, Lo JC, Chertow GM. Metabolic syndrome and the risk for chronic kidney disease among nondiabetic adults. Clin J Am Soc Nephrol. 2005;16(7):2134-40.

52 Ryu S, Chang Y, Woo HY, Lee KB, Kim SG, Kim DI et al. Timedependent association between metabolic syndrome and risk of CKD in Korean men without hypertension or diabetes. Am J Kidney Dis. 2009;53(1):59.

53 NKF KDOQI Guidelines [Internet]. KDOQI Clinical Practice Guidelines for Chronic Kidney Disease: Evaluation C, and Stratification. Part 7. Stratification of risk for progression of kidney disease and developement of cardiovascular disease. [citado 2011 jan 10]. Disponível em http://www.kidney.org/professionals/KDOQI/guidelines_ckd/p7_risk_ g15.htm.

54 Martin LC, Franco RJS. A doença renal como fator de risco cardiovascular. Arq Bras Cardiol. 2005;85(6):432-6.

55 Zeeuw D, Hillege HL, Jong PE. The kidney, a cardiovascular risk marker, and a new target for therapy. Kidney Int. 2005;68:S25-S9. 
56 So WY, Kong APS, Ma RCW, Ozaki R, Szeto CC, Chan NN et al. Glomerular filtration rate, cardiorenal end points, and all-cause mortality in type 2 diabetic patients. Diabetes Care. 2006;29(9):204652.

57 Weiner DE, Tighiouart H, Amin MG, Stark PC, MacLeod B, Griffith $\mathrm{JL}$ et al. Chronic kidney disease as a risk factor for cardiovascular disease and all-cause mortality: a pooled analysis of communitybased studies. J Am Soc Nephrol. 2004;15(5):1307-15.

58 Sarnak MJ, Levey AS, Schoolwerth AC, Coresh J, Culleton B, Hamm LL et al. Kidney disease as a risk factor for development of cardiovascular disease. Circulation. 2003;108(17):2154-69.

59 Matsushita K, Van der Velde M, Astor BC, Woodward M, Levey AS, Jong PE et al. Association of estimated glomerular filtration rate and albuminuria with all-cause and cardiovascular mortality in general population cohorts: a collaborative meta-analysis. The Lancet. 2010;375(9731):2073-81.

60 Tonelli M, Wiebe N, Culleton B, House A, Rabbat C, Fok M et al. Chronic kidney disease and mortality risk: a systematic review. Clin $\mathrm{J}$ Am Soc Nephrol. 2006;17(7):2034-47.

61 Nitsch D, Grams M, Sang Y, Black C, Cirillo M, Djurdjev O et al. Associations of estimated glomerular filtration rate and albuminuria with mortality and renal failure by sex: a meta-analysis. BMJ. 2013;346:f324.

62 United States Renal Data System. 2012 Annual Data Report. Atlas of Chronic Kidney Disease \& End-Stage Renal Disease in the United States. Morbidity \& Mortality in Patients With CKD. Am J Kidney Dis. 2013;61(1):e65-e74.

63 Go AS, Chertow GM, Fan D, McCulloch CE, Hsu CY. Chronic kidney disease and the risks of death, cardiovascular events, and hospitalization. N Engl J Med. 2004;351(13):1296-305.

64 Almeida FAA, Machado FC, Moura Junior JA, Guimarães AC. Mortalidade global e cardiovascular e fatores de risco de pacientes em hemodiálise. Arq Bras Cardiol. 2010;94(2):201-6.

65 Rayner HC, Pisoni RL, Bommer J, Canaud B, Hecking E, Locatelli $\mathrm{F}$ et al. Mortality and hospitalization in haemodialysis patients in five European countries: results from the Dialysis Outcomes and Practice Patterns Study (DOPPS). Nephrol Dial Transplant. 2004;19(1):10820. 
66 Zhang AH, Cheng LT, Zhu N, Sun LH, Wang T. Comparison of quality of life and causes of hospitalization between hemodialysis and peritoneal dialysis patients in China. Health Qual Life Outcomes. 2007;5(1):49.

67 Marques $A B$, Pereira $D$, Ribeiro R. Motivos e freqüência de internação dos pacientes com IRC em tratamento hemodialítico. Arq Cienc Saude. 2005;12(2):67-72.

68 Levey AS, Atkins R, Coresh J, Cohen EP, Collins AJ, Eckardt KU et al. Chronic kidney disease as a global public health problem: approaches and initiatives-a position statement from Kidney Disease Improving Global Outcomes. Kidney Int. 2007;72(3):247-59.

69 Sesso R, Lopes AA, Thomé FS, Bevilacqua JL, Romão Junior JE, Lugon J. Relatório do censo Brasileiro de diálise, 2008. J Bras Nefrol. 2008;30(4):233-8.

70 Barbosa DA, Gunji CK, Bittencourt ARdC, Belasco AGS, Diccini $\mathrm{S}$, Vattimo $\mathrm{F}$ et al. Co-morbidade e mortalidade de pacientes em início de diálise. Acta Paul Enferm. 2006;19(3):304-9.

71 Toscano CM. As campanhas nacionais para detecção das doenças crônicas não-transmissíveis: diabetes e hipertensão arterial. Cien Saude Colet. 2004;9:885-95.

72 Toscano CM. As campanhas nacionais para detecção das doenças crônicas não-transmissíveis: diabetes e hipertensão arterial. Cien Saude Colet. 2004;9:885-95.

73 Brasil. Ministério da Saúde. Organização Pan-Americana da Saúde. Avaliação do plano de reorganização da atenção à hipertensão arterial e ao diabetes mellitus no Brasil [Internet]. Distrito Federal, 2004. [citado 2013 mar 16]. Disponível em: http://bvsms.saude.gov.br/bvs/publicacoes/diab.pdf.

74 Brasil. Ministério da Saúde. DATASUS: informações de saude. SISHIPERDIA [Internet]. [citado 2013 abr 12]. Disponivel em: www.datasus.gov.br/tabnet/tabnet.htm.

75 Levey AS, Eckardt KU, Tsukamoto Y, Levin A, Coresh J, Rossert $\mathrm{J}$ et al. Definition and classification of chronic kidney disease: a position statement from Kidney Disease: Improving Global Outcomes (KDIGO). Kidney Int. 2005;67(6): 2089-100.

76 Pereira AB, Santos BFC. Avaliação da função renal. In: Ajzen H, Schor N, organizadores. Guias de medicina ambulatorial e hospitalar UNIFESP/ Escola Paulista de Medicina - Nefrologia.Barueri: Editora Manole; 2002. p. 19-22. 
77 Sodré FL, Costa JCB, Lima JCC. Avaliação da função e da lesão renal: um desafio laboratorial. J Bras Patol Med Lab. 2007;43(5):32937.

78 Poggio ED, Rule AD. A critical evaluation of chronic kidney disease-should isolated reduced estimated glomerular filtration rate be considered a 'disease'? Nephrol Dial Transplant. 2009;24(3):698700 .

79 NKF KDOQI Guidelines [Internet]. KDOQI Clinical Practice Guidelines for Chronic Kidney Disease: Evaluation C, and Stratification. Part 5. Evaluation of Laboratory Measurement for Clinical Assessment of Kidney Disease. [citado 2012 dez 20]. Disponível

em: http://www.kidney.org/professionals/KDOQI/guidelines_ckd/p5_I ab_g4.htm.

80 Cockcroft DW, Gault MH. Prediction of creatinine clearance from serum creatinine. Nephron. 1976;16(1):31-41.

81 Kirsztajn GM. Avaliação de Função Renal. J Bras Nefrol. 2009;31(Supl 1):14-20.

82 Levey AS, Bosch JP, Lewis JB, Greene T. A more accurate method to estimate glomerular filtration rate from serum creatinine: a new prediction equation. Ann Intern Med. 1999;130(6):461-70.

83 Levey AS, Greene T, Kusek JW, Beck GJ, Group MS. A simplified equation to predict glomerular filtration rate from serum creatinine. $J$ Am Soc Nephrol. 2000;11(9):155A.

84 Levey AS, Coresh J, Greene T, Marsh J, Stevens LA, Kusek JW et al. Expressing the Modification of Diet in Renal Disease Study equation for estimating glomerular filtration rate with standardized serum creatinine values. Clin Chem. 2007;53(4):766-72.

85 Levey AS, Stevens LA, Schmid CH, Zhang Y, Castro AF, Feldman $\mathrm{HI}$,et al. A new equation to estimate glomerular filtration rate. Ann Intern Med. 2009;150(9):604.

86 Lin J, Knight EL, Hogan ML, Singh AK. A comparison of prediction equations for estimating glomerular filtration rate in adults without kidney disease. Clin J Am Soc Nephrol. 2003;14(10):2573-80.

87 Bostom AG, Kronenberg F, Ritz E. Predictive performance of renal function equations for patients with chronic kidney disease and normal serum creatinine levels. Clin $J$ Am Soc Nephrol. 2002;13(8):2140-4. 
88 Michels WM, Grootendorst DC, Verduijn M, Elliott EG, Dekker FW, Krediet RT. Performance of the Cockcroft-Gault, MDRD, and new CKD-EPI formulas in relation to GFR, age, and body size. Clin $\mathrm{J}$ Am Soc Nephrol. 2010;5(6):1003-9.

89 Soares AA, Eyff TF, Campani RB, Ritter L, Weinert LS, Camargo $\mathrm{JL}$ et al. Performance of the CKD Epidemiology Collaboration (CKDEPI) and the Modification of Diet in Renal Disease (MDRD) Study equations in healthy South Brazilians. Am $J$ Kidney Dis. 2010;55(6):1162-3.

90 Laterza OF, Price CP, Scott MG. Cystatin C: an improved estimator of glomerular filtration rate? Clin Chem. 2002;48(5):699707.

91 Rocha SMM, Almeida MCP. O processo de trabalho da enfermagem em saúde coletiva e a interdisciplinaridade. Rev Lat Am Enfermagem. 2000;8(6):96-101.

92 Hospital Universitário da Universidade de São Paulo [Internet]. São Paulo [citado 2013 abr 19]. Disponível em: www.hu.usp.br.

93 Prefeitura de São Paulo. Subprefeitura do Butantã [Internet]. [citado 2013 mar 23]. Disponível em: http://www.prefeitura.sp.gov.br/cidade/secretarias/subprefeituras /butanta/.

94 Mehta RL, Kellum JA, Shah SV, Molitoris BA, Ronco C, Warnock DG et al. Acute Kidney Injury Network: report of an initiative to improve outcomes in acute kidney injury. Crit Care. 2007;11(2):R31.

95 Singh P, Rifkin DE, Blantz RC. Chronic kidney disease: an inherent risk factor for acute kidney injury? Clin J Am Soc Nephrol. 2010;5(9):1690-5.

96 Chawla LS, Kimmel PL. Acute kidney injury and chronic kidney disease: an integrated clinical syndrome. Kidney Int. 2012.

97 Wu V-C, Huang T-M, Lai C-F, Shiao C-C, Lin Y-F, Chu T-S, et al. Acute-on-chronic kidney injury at hospital discharge is associated with long-term dialysis and mortality. Kidney Int. 2011;80(11):122230.

98 Bihorac A, Yavas S, Subbiah S, Hobson CE, Schold JD, Gabrielli $A$, et al. Long-term risk of mortality and acute kidney injury during hospitalization after major surgery. Ann Surg. 2009;249(5):851-8. 
99 Hostetter TH, Levey AS, Stevens LA. Clinical impact of reporting estimated glomerular filtration rates. Clin Chem. 2010;56(9):1381-3.

100 Sociedade Brasileira de Hipertensão. Sociedade Brasileira de Cardiologia. Sociedade Brasileira de Endocrinologia e Metabologia. Sociedade Brasileira de Diabetes. Associação Brasileira para Estudos da Obesidade. I Diretriz Brasileira de Diagnóstico e Tratamento da Síndrome Metabólica. Arq Bras Cardiol. 2005;84(Suplemento I):3-28.

101 Rosner BA. Fundamentals of biostatistics. 4th ed. New York: Duxbury Press; 1994. 664 p.

102 United States Renal Data System. 2012 Annual Data Report. Atlas of Chronic Kidney Disease \& End-Stage Renal Disease in the United States. CKD in the general population. Am J Kidney Dis. 2013;61(1):e41-e50.

103 Kramer H, Palmas W, Kestenbaum B, Cushman M, Allison M, Astor $\mathrm{B}$ et al. Chronic kidney disease prevalence estimates among racial/ethnic groups: the Multi-Ethnic Study of Atherosclerosis. Clin J Am Soc Nephrol. 2008;3(5):1391-7.

104 Tarver-Carr ME, Powe NR, Eberhardt MS, LaVeist TA, Kington $\mathrm{RS}$, Coresh $\mathrm{J}$ et al. Excess risk of chronic kidney disease among African-American versus white subjects in the United States: a population-based study of potential explanatory factors. Clin J Am Soc Nephrol. 2002;13(9):2363-70.

105 Giatti L, Barreto SM. Saúde, trabalho e envelhecimento no Brasil Health, work, and aging in Brazil. Cad Saude Publica. 2003;19(3):759-71.

106 Hall JE, Henegar JR, Dwyer TM, Liu J, Silva AA, Kuo JJ et al. Is obesity a major cause of chronic kidney disease? Adv Ren Replace Ther. 2004;11(1):41-54.

107 Iser BPM, Yokota RTC, Sá NNB, Moura L, Malta DC. Prevalência de fatores de risco e proteção para doenças crônicas nas capitais do Brasil-principais resultados do Vigitel 2010. Cienc Saude Colet. 2012;17(9):2343-56.

108 Kramer H. Obesity and chronic kidney disease. Contrin Nephrol. 2006;151(R):1.

109 Pierin AMG, Jesus ES, Augusto MAO, Gusmão J, Ortega K, Mion Jr D. Variáveis biopsicossociais e atitudes frente ao tratamento influenciam a hipertensão complicada. Arq Bras Cardiol. 2010;95:648-54. 
110 Maldaner CR, Beuter M, Brondani CM, Budó MDLD, Pauletto MR. Fatores que influenciam a adesão ao tratamento na doença crônica: o doente em terapia hemodialítica. Rev Gaucha Enferm. 2008;29(4):647.

111 Orth SR, Hallan SI. Smoking: a risk factor for progression of chronic kidney disease and for cardiovascular morbidity and mortality in renal patients-absence of evidence or evidence of absence? Clin J Am Soc Nephrol. 2008;3(1):226-36.

112 Shankar A, Klein R, Klein BEK. The association among smoking, heavy drinking, and chronic kidney disease. Am J Epidemiol. 2006;164(3):263-71.

113 Stengel B, Tarver-Carr ME, Powe NR, Eberhardt MS, Brancati FL. Lifestyle factors, obesity and the risk of chronic kidney disease. Epidemiology. 2003;14(4):479-87.

114 Biavo BMM, Martins CTB, Cunha LM, Araujo ML, Ribeiro MMC, Sachs $A$ et al. Nutritional and epidemiological aspects of patients with chronic renal failure undergoing hemodialysis from Brazil, 2010. J Bras Nefrol. 2012;34(3):206-15.

115 Bastos MG, Kirsztajn GM. Doença renal crônica: importância do diagnóstico precoce, encaminhamento imediato $e$ abordagem interdisciplinar estruturada para melhora do desfecho em pacientes ainda não submetidos à diálise. J Bras Nefrol. 2011;33(1):93-108.

116 Martins IS, Marucci MFN, Velásquez-Meléndez G, Coelho LT, Cervato AM. Doenças cardiovasculares ateroscleróticas, dislipidemias, hipertensão, obesidade e diabetes melito em população da área metropolitana da região Sudeste do Brasil. IIIHipertensão. Rev Saude Publica. 1997;31(5):466-71.

117 Souza LJ, Souto Filho JTD, de Souza TF, Reis AFF, Gicovate Neto CG, Bastos DA et al. Prevalência de dislipidemia e fatores de risco em Campos dos Goytacazes-RJ. Arq Bras Cardiol. 2003;81(3):249-56

118 Firmo JOA, Uchôa E, Lima-Costa MF. Projeto Bambuí: fatores associados ao conhecimento da condição de hipertenso entre idosos. Cad de Saude Publica. 2004;20:512-21.

119 Zaitune MPA, Barros MBA, César CLG, Carandina L, Goldbaum M. Hipertensão arterial em idosos: prevalência, fatores associados e práticas de controle no Município de Campinas, São Paulo, Brasil. Cad Saude Publica. 2006;22(2):285-94. 
120 Andersen MJ, Agarwal R. Etiology and management of hypertension in chronic kidney disease. Med Clin North Am. 2005;89(3):525.

121 Rao MV, Qiu Y, Wang C, Bakris G. Hypertension and CKD: Kidney Early Evaluation Program (KEEP) and National Health and Nutrition Examination Survey (NHANES), 1999-2004. Am J Kidney Dis. 2008;51(4 Suppl 2):S30.

122 Maltalii DC, Vilanova RMS. Prevalência de diabetes e hipertensão no Brasil baseada em inquérito de morbidade autoreferida, Brasil, 2006. Rev Saude Publica. 2009;43(Supl 2):74-82.

123 Mendes TAB, Goldbaum M, Segri NJ, Barros MBA, Chester LGC, Carandina $L$ et al. Diabetes mellitus: fatores associados à prevalência em idosos, medidas e práticas de controle e uso dos serviços de saúde em São Paulo, Brasil. Cad Saude Publica. 2011;27(6):1233-43.

124 Parikh NI, Hwang SJ, Larson MG, Meigs JB, Levy D, Fox CS. Cardiovascular disease risk factors in chronic kidney disease: overall burden and rates of treatment and control. Arch Intern Med. 2006;166(17):1884-1891.

125 Fox CS, Muntner P. Trends in diabetes, high cholesterol, and hypertension in chronic kidney disease among US adults: 1988-1994 to 1999-2004. Diabetes Care. 2008;31(7):1337-42.

126 Burmeister JE, Mosmann CB, Bau R, Rosito GA. Prevalence of diabetes mellitus in chronic renal failure patients under haemodialysis in Porto Alegre, Brazil. J Bras Nefrol. 2012;34(2):11721.

127 Muntner P, He J, Astor BC, Folsom AR, Coresh J. Traditional and nontraditional risk factors predict coronary heart disease in chronic kidney disease: results from the atherosclerosis risk in communities study. Clin J Am Soc Nephrol. 2005;16(2):529-38.

128 Sposito AC, Caramelli B, Fonseca FAH, Bertolami MC, Afiune Neto A, Souza AD et al. IV Diretriz brasileira sobre dislipidemias e prevenção da aterosclerose: Departamento de Aterosclerose da Sociedade Brasileira de Cardiologia. Arq Bras Cardiol. 2007;88:2-19.

129 Silverberg D, Wexler D, Blum M, Schwartz D, laina A. The association between congestive heart failure and chronic renal disease. Curr Opin Nephrol Hypertens. 2004;13(2):163-70. 
130 Foley RN, Murray AM, Li S, Herzog CA, McBean AM, Eggers PW et al. Chronic kidney disease and the risk for cardiovascular disease, renal replacement, and death in the United States Medicare population, 1998 to 1999. Clin J Am Soc Nephrol. 2005;16(2):489-95.

131 Keith DS, Nichols GA, Gullion CM, Brown JB, Smith DH. Longitudinal follow-up and outcomes among a population with chronic kidney disease in a large managed care organization. Arch Intern Med. 2004;164(6):659-63.

132 Sociedade Brasileira de Diabetes [Internet]. Algoritmo para o tratamento do diabetes tipo 2. Atualização 2011. Posicionamento Oficial SBD no 3 - 2011. [citado 2013 abr 12] Disponível em: http://www.diabetes.org.br/attachments/posicionamento/posicion amento-sbd-n-03-2011.pdf.

133 Coresh J, Astor BC, Greene T, Eknoyan G, Levey AS. Prevalence of chronic kidney disease and decreased kidney function in the adult US population: Third National Health and Nutrition Examination Survey. Am J Kidney Dis. 2003;41(1):1-12.

134 França AKTC, Santos AM, Calado IL, Milhomem E, Santos PCC, Salgado JVL et al. Glomerular Filtration and Associated Factors in Hypertensive Individuals Treated at Primary Care Level. Arq Bras Cardiol. 2010;94(6):731-8.

135 McClellan WM. Epidemiology and risk factors for chronic kidney disease. Med Clin North Am. 2005;89(3):419-46.

136 Satko SG, Freedman BI. The importance of family history on the development of renal disease. Curr Opin Nephrol Hypertens. 2004;13(3):337-41.

137 Adeney KL, Siscovick DS, Ix JH, Seliger SL, Shlipak MG, Jenny NS et al. Association of serum phosphate with vascular and valvular calcification in moderate CKD. Clin $J$ Am Soc Nephrol. 2009;20(2):381-7.

138 Kestenbaum B, Sampson JN, Rudser KD, Patterson DJ, Seliger SL, Young B et al. Serum phosphate levels and mortality risk among people with chronic kidney disease. Clin J Am Soc Nephrol. 2005;16(2):520-8.

139 Jorgetti V. Visão geral da doença óssea na doença renal crônica (DRC) e nova classificação. J Bras Nefrol. 2008;30(Supl 1):4-5.

140 McClellan W, Aronoff SL, Bolton WK, Hood S, Lorber DL, Tang $\mathrm{KL}$, et al. The prevalence of anemia in patients with chronic kidney disease. Curr Med Res Opin. 2004;20(9):1501-10. 
141 Canziani MEF, Bastos MG, Bregman R, Pecoits Filho R, Tomiyama C, Draibe SA et al. Deficiência de ferro e anemia na doença renal crônica. J Bras Nefrol. 2006;28(2):86-90.

142 Astor BC, Coresh J, Heiss G, Pettitt D, Sarnak MJ. Kidney function and anemia as risk factors for coronary heart disease and mortality: the Atherosclerosis Risk in Communities (ARIC) Study. Am Heart J. 2006;151(2):492.

143 Kovesdy CP, Trivedi BK, Kalantar-Zadeh K, Anderson JE. Association of anemia with outcomes in men with moderate and severe chronic kidney disease. Kidney Int. 2006;69(3):560-4.

144 Goldwasser P, Feldman J. Association of serum albumin and mortality risk. J Clin Epidemiol. 1997;50(6):693.

145 Djoussé L, Rothman KJ, Cupples LA, Levy D, Ellison RC. Serum albumin and risk of myocardial infarction and all-cause mortality in the Framingham Offspring Study. Circulation. 2002;106(23):2919-24.

146 Gordon DJ, Probstfield JL, Garrison RJ, Neaton JD, Castelli WP, Knoke JD et al. High-density lipoprotein cholesterol and cardiovascular disease. Four prospective American studies. Circulation. 1989;79(1):8-15.

147 Astor BC, Matsushita K, Gansevoort RT, van der Velde M, Woodward M, Levey AS et al. Lower estimated glomerular filtration rate and higher albuminuria are associated with mortality and endstage renal disease. A collaborative meta-analysis of kidney disease population cohorts. Kidney Int. 2011;79(12):1331-40.

148 Brantsma AH, Bakker SJL, Hillege HL, de Zeeuw D, Jong PE, Gansevoort RT. Cardiovascular and renal outcome in subjects with $\mathrm{K} / \mathrm{DOQ}$ I stage 1-3 chronic kidney disease: the importance of urinary albumin excretion. Nephrol Dial Transplant. 2008;23(12):3851-8.

149 Heilberg IP, Schor N. Abordagem diagnóstica e terapêutica na infecção do trato urinário-ITU. Rev Assoc Med Bras. 2003;49(1):10916

150 NANDA International. Diagnósticos de enfermagem da NANDA: definições e classificação: 2009-2011. Porto Alegre: Artmed; 2008.

151 Fontes CMB, Cruz DALM. Diagnósticos de enfermagem documentados para pacientes de clínica médica. Rev Esc Enferm USP. 2007;41(3):395-402. 
152 Capelari C, Almeida MA. Nursing diagnosis Ineffective Protection: content validation in patients under hemodialysis. Rev Gaucha Enferm. 2008; 29(3):415-22.

153 Machado FN. Capacidade e desempenho para a realização das atividades básicas de vida diária: um estudo com idosos dependentes [dissertação]. Belo Horizonte: Universidade Federal de Minas Gerais; 2010.

154 Rubenstein LZ, Josephson KR. The epidemiology of falls and syncope. Clin Geriatr Med. 2002;18(2):141-58.

155 Jamal SA, West SL, Miller PD. Fracture risk assessment in patients with chronic kidney disease. Osteoporos Int. 2012;23(4):1191-8.

156 Mangini S, Silveira FS, Silva CP, Grativvol PS, Seguro L, Ferreira SMA et al. Insuficiência cardíaca descompensada na unidade de emergência de hospital especializado em cardiologia. Arq Bras Cardiol. 2008;90(6):433-40.

157 Roque KE, Melo ECP. Tempo de internação e a ocorrência de eventos adversos a medicamentos: uma questão da enfermagem. Esc Anna Nery. 2011;15(3):595-601.

158 Mansur LL, Scaff M, Conforto AB. Acidente vascular cerebral isquêmico em uma enfermaria de neurologia: complicações e tempo de internação. Rev Assoc Med Bras. 2009;55(3):313-6.

159 Godinho TM, Lyra TG, Braga PS, Queiroz RA, Kraychete AC, Gusmão ENA et al. Perfil do paciente que inicia hemodiálise de manutenção em hospital público em Salvador, Bahia. J Bras Nefrol. 2006;28(2):96-103.

160 Jungers $P$, Joly $D$, Nguyen-Khoa T, Mothu N, Bassilios $N$, Grünfeld JP. Continued late referral of patients with chronic kidney disease. Causes, consequences, and approaches to improvement. Presse Med. 2006;35(1 Pt 1):17.

161 Winkelmayer WC, Glynn RJ, Levin R, Owen W, Avorn J. Late referral and modality choice in end-stage renal disease. Kidney Int. $2001 ; 60(4): 1547-54$.

162 Chan MR, Dall AT, Fletcher KE, Lu N, Trivedi H. Outcomes in patients with chronic kidney disease referred late to nephrologists: a meta-analysis. Am J Med. 2007;120(12):1063-70. 
163 Navaneethan SD, Aloudat S, Singh S. A systematic review of patient and health system characteristics associated with late referral in chronic kidney disease. BMC Nephrol. 2008;9(1):3.

164 Bocchi EA, Marcondes-Braga FG, Bacal F, Ferraz AS, Albuquerque $D$, Rodrigues $D$. Atualização da diretriz brasileira de insuficiência cardíaca crônica-2012. Arq Bras Cardiol. 2012;98(1):133.

165 Goulart FAA, Organização Pan-americana de Saúde. Doenças crônicas não trasnmissíveis: estratégias de controle e desafios para os sistemas de saúde [Internet]. Brasília, 2011 [ciatdo 25 abr 2013]. Disponível em: http://apsredes.org/site2012/wp-content/uploads /2012/06/ Condicoes-Cronicas_flavio1.pdf

166 Fuchs FD, Moreira LB, Moraes RS, Bredemeier M, Cardozo SC. Prevalência de hipertensão arterial sistêmica e fatores associados na região urbana de Porto Alegre: estudo de base populacional. Arq Bras Cardiol. 1995;63(6):473-9.

167 Gus I, Harzheim E, Zaslavsky C, Medina C, Gus M. Prevalência, reconhecimento e controle da hipertensão arterial sistêmica no estado do Rio Grande do Sul. Arq Bras Cardiol. 2004;83:424-8.

168 Jesus ES, Augusto MAO, Gusmão J, Mion Júnior D, Ortega K, Pierin AMG. Profile of hypertensive patients: biosocial characteristics, knowledge, and treatment compliance. Acta Paul Enferm. 2008;21:59-65.

169 Santos MVR, Oliveira DC, Arraes LB, Oliveira DAGC, Medeiros L, Novaes MA. Adesão ao tratamento anti-hipertensivo: conceitos, aferição e estratégias inovadoras de abordagem. Rev Bras Clin Med São Paulo. 2013;11(1):55-61.

170 Coelho EB, Moysés Neto M, Palhares R, Cardoso MCM, Geleilete TJM, Nobre F. Relação entre a assiduidade às consultas ambulatoriais e 0 controle da pressão arterial em pacientes hipertensos. Arq Bras Cardiol. 2005;85:157-61.

171 Silva GCA, Pierin AMG. A monitorização residencial da pressão arterial e o controle de um grupo de hipertensos. Rev Esc Enferm USP. 2012; 46: 922-8.

172 Nobre F, Ribeiro AB, Mion Jr D. Controle da pressão arterial em pacientes sob tratamento anti-hipertensivo no Brasil: Controlar Brasil. Arq Bras Cardiol. 2010; 94: 663-70. 
173 Schmidt MI, Ducan BB, Azevedo e Silva G, Menezes AM, Monteiro CA, Barreto D et al. Doenças crônicas não transmissíveis no Brasil: carga e desafios atuais. Veja. 2011;6736(11):60135-9.

174 Brasil. Ministério da Saúde. Plano de ações estratégicas para o enfrentamento das doenças crônicas não transmissíveis (DCNT) no Brasil 2011-2022. [Internet]. Brasília, 2011 [citado em 25 abr 2013]. Disponível em: http://portal.saude.gov.br/portal/arquivos/pdf/cartilha_dcnt_pequena_ portugues_espanhol.pdf.

175 Arora P, Rajagopalan S, Patel N, Nainani N, Venuto RC, Lohr JW. The MDRD equation underestimates the prevalence of CKD among blacks and overestimates the prevalence of CKD among whites compared to the CKD-EPI equation: a retrospective cohort study. BMC Nephrol. 2012;13(1):4

176 Arbel Y, Halkin A, Finkelstein A, Revivo M, Berliner S, Herz I, et al. Impact of Estimated Glomerular Filtration Rate on Vascular Disease Extent and Adverse Cardiovascular Events in Patients Without Chronic Kidney Disease. Can J Cardiol. 2013; Jan:1-8.

177 Ji B, Zhang S, Gong L, Wang Z, Ren W, Li Q, et al. The risk factors of mild decline in estimated glomerular filtration rate in a community-based population. Clin Biochem. 2013; Jan:1-5.

178 Brasil. Ministério da Saúde. Departamento de Informática do SUS. Pesquisa Nacional por Amostra de Domicílios - pesquisa especial de tabagismo [Internet]. Brasília, 2008. [citado 2013 abr 24]. Disponivel em:

http://tabnet.datasus.gov.br/cgi/tabnet.exe?petab/petab.def. 